Uma arquitetura para sistemas de busca semântica para recuperação de informações em repositórios de biodiversidade

Flor Karina Mamani Amanqui 

SERVIÇO DE PÓS-GRADUAÇÃO DO ICMC-USP

Data de Depósito:

Assinatura:

\title{
Uma arquitetura para sistemas de busca semântica para recuperação de informações em repósitorios de biodiversidade
}

\author{
Flor Karina Mamani Amanqui
}

Orientador: Prof. Dr. Dilvan de Abreu Moreira

Dissertação apresentada ao Instituto de Ciências Matemáticas e de Computação - ICMC-USP, como parte dos requisitos para obtenção do título de Mestre em Ciências - Ciências de Computação e Matemática Computacional. VERSÃO REVISADA 
Ficha catalográfica elaborada pela Biblioteca Prof. Achille Bassi e Seção Técnica de Informática, ICMC/USP, com os dados fornecidos pelo(a) autor(a)

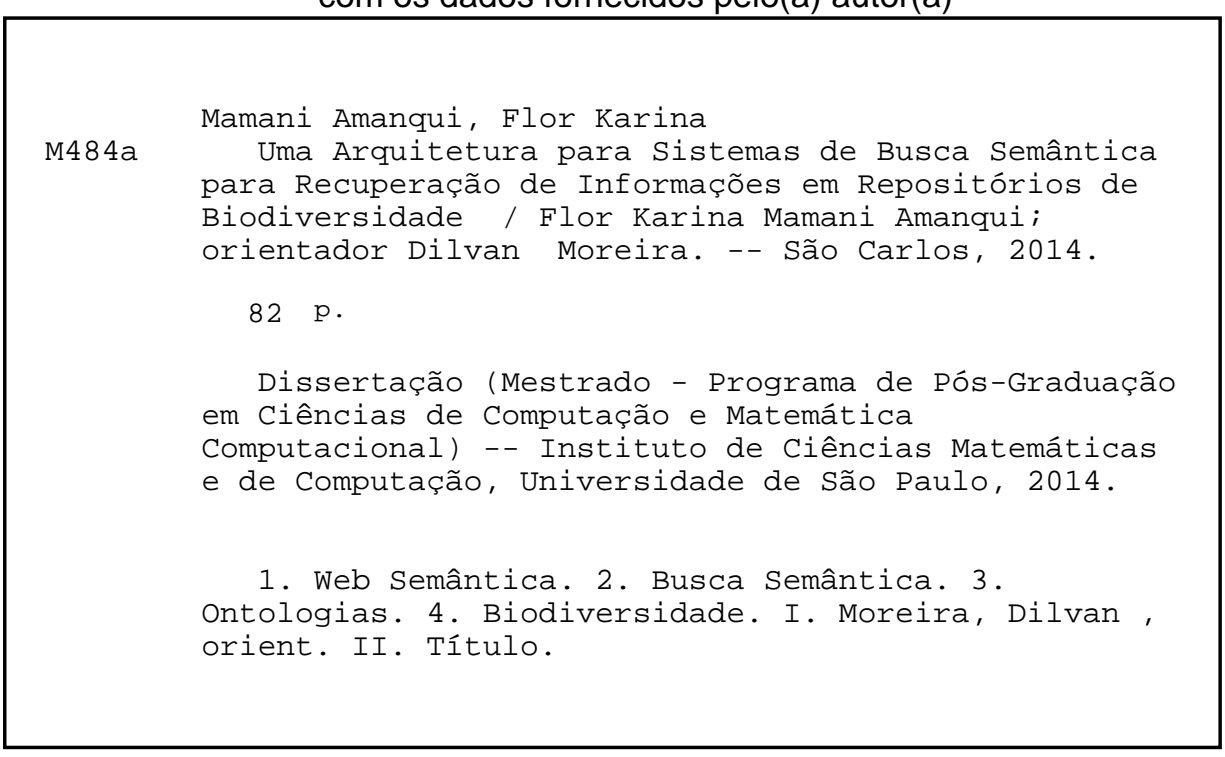


"A Nossa recompensa está no esforço, não no resultado.

Um esforço total é uma vitória completa".

--- Mahatma Gandhi 



\section{Agradecimentos}

Queria deixar um agradecimento muito especial ao meu orientador Prof. Dr. Dilvan de Abreu Moreira, pelo apoio, paciência, sabedoria, confiança e por toda a ajuda dedicada ao meu trabalho. E ainda agradeço a todos demais docentes do ICMC que contribuíram para minha formação.

Agradeço muito a minha familia pelo apoio nesta etapa de minha vida, a minha mãe "Florencia", ao meu irmão Joshimar e minha irma Lesly, pelo carinho e dedicação brindado nesta etapa fora de casa.

Agradeço a meu querido Alexandre pelos gratos momentos que passamos juntos, cada detalhe e amor fizeram que minha vida se torne muito especial.

Agradeço aos meus colegas, do ICMC e do Intermídia, especialmente a João Orlando, Kleberson e Silvio, que me ajudaram várias vezes no desenvolvimento deste mestrado.

E por fim, agradeço ao $\mathrm{CNPq}$ pelo apoio financeiro, ao Instituto de Ciências Matemáticas e de Computação e à Universidade de São Paulo pela estrutura disponibilizada para realização deste projeto. 



\section{Resumo}

A diversidade biológica é essencial para a sustentabilidade da vida na Terra e motiva numerosos esforços para coleta de dados sobre espécies, dando origem a uma grande quantidade de informação. Esses dados são geralmente armazenados em bancos de dados relacionais. Pesquisadores usam esses bancos de dados para extrair conhecimento e compartilhar novas descobertas. No entanto, atualmente a busca tradicional (baseada em palavras-chave) já não é adequada para ser usada em grandes quantidades de dados heterogêneos, como os de biodiversidade. Ela tem baixa precisão e revocação para esse tipo de dado. Este trabalho apresenta uma nova arquitetura para abordar esse problema aplicando técnicas de buscas semânticas em dados sobre biodiversidade e usando formatos e ferramentas da Web Semântica para representar esses dados. A busca semântica tem como objetivo melhorar a acurácia dos resultados de buscas com o uso de ontologias para entender os objetivos dos usuários e o significado contextual dos termos utilizados. Este trabalho também apresenta os resultados de testes usando um conjunto de dados representativos sobre biodiversidade do Instituto Nacional de Pesquisas da Amazônia (INPA) e do Museu Paraense Emílio Goeldi (MPEG). Ontologias permitem que conhecimento seja organizado em espaços conceituais de acordo com seu significado. Para a busca semântica funcionar, um ponto chave é a criação de mapeamentos entre os dados (neste caso, dados sobre biodiversidade do INPA e MPEG) e termos das ontologias que os descrevem, neste caso: a classificação taxonômica de espécies e a OntoBio, a ontologia de biodiversidade do INPA. Esses mapeamentos foram criados depois que extraímos a classificação taxonômica do site Catalog of Life (CoL) e criamos uma nova versão da OntoBio. Um protótipo da arquitetura foi construído e testado usando casos de uso e dados do INPA e MPEG. Os resultados dos testes mostraram que a abordagem da busca semântica tinha uma melhor precisão (28\% melhor) e revocação (25\% melhor) quando comparada com a busca por palavras-chave. Eles também mostraram que é possível conectar facilmente os dados mapeados a outras fontes de dados abertas, como a fonte Amazon Forest Linked Data do Instituto Nacional de Pesquisas Espaciais. (INPE).

Palavras-chaves: Web Semântica; Busca Semântica; Ontologias; Biodiversidade. 



\begin{abstract}
Biological diversity is of essential value to life sustainability on Earth and motivates many efforts to collect data about species. That gives rise to a large amount of information. Biodiversity data, in most cases, is stored in relational databases. Researchers use this data to extract knowledge and share their new discoveries about living things. However, nowadays the traditional search approach (based basically on keywords matching) is not appropriate to be used in large amounts of heterogeneous biodiversity data. Search by keyword has low precision and recall in this kind of data. This work presents a new architecture to tackle this problem using a semantic search system for biodiversity data and semantic web formats and tools to represent this data. Semantic search aims to improve search accuracy by using ontologies to understand user objectives and the contextual meaning of terms used in the search to generate more relevant results. This work also presents test results using a set of representative biodiversity data from the National Research Institute for the Amazon (INPA) and the Emilio Gueldi Museum in Pará (MPEG). Ontologies allow knowledge to be organized into conceptual spaces in accordance to its meaning. For semantic search to work, a key point is to create mappings between the data (in this case, INPA's and MPEG's biodiversity data) and the ontologies describing it, in this case: the species taxonomy (a taxonomy is an ontology where each class can have just one parent) and OntoBio, INPA's biodiversity ontology. These mappings were created after we extracted the taxonomic classification from the Catalogue of Life (CoL) website and created a new version of OntoBio. A prototype of the architecture was built and tested using INPA's and MPEG's use cases and data. The results showed that the semantic search approach had a better precision ( $28 \%$ improvement) and recall (25\% improvement) when compared to keyword based search. They also showed that it was possible to easily connect the mapped data to other Linked Open Data sources, such as the Amazon Forest Linked Data from the National Institute for Space Research (INPE).
\end{abstract}

Keywords: Semantic Web; Semantic Search; Ontology; Biodiversity. 



\section{Sumário}

1 Introdução 1

1.1 Contexto e Motivação . . . . . . . . . . . . . . . . . . . . . . . . 1

1.2 Justificativa . . . . . . . . . . . . . . . . . . . 3

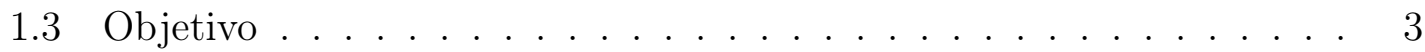

1.4 Organização . . . . . . . . . . . . . . . . . . 4

2 Biodiversidade $\quad 5$

2.1 Introdução . . . . . . . . . . . . . . . . . . . . . . 5

2.2 Disseminação de dados sobre biodiversidade . . . . . . . . . . . . . 5

2.3 Busca por palavra-chave . . . . . . . . . . . . . . 8

2.3.1 speciesLink . . . . . . . . . . . . . . . . . 10

2.3.2 Sistema de Informação Ambiental do Programa Biota/Fapesp 11

2.3.3 Portal de busca do GBIF . . . . . . . . . . . . . 12

2.3.4 Análise das ferramentas de busca por palavra-chave . . . . . . 13

2.4 Considerações Finais . . . . . . . . . . . . . . . . . . . . . . . . . 14

$\begin{array}{lll}3 & \text { Web Semântica } & 17\end{array}$

3.1 Introdução . . . . . . . . . . . . . . . . . . . . 17

3.2 Busca Semântica . . . . . . . . . . . . . . . . . . . 18

3.3 Ontologias . . . . . . . . . . . . . . . . . 20

3.3.1 Componentes . . . . . . . . . . . . . . 21

3.3 .2 XML . . . . . . . . . . . . . . . . . 22

3.3.3 RDF e RDF-Schema . . . . . . . . . . . . . . . 22

3.3.4 Web Ontology Language - OWL . . . . . . . . . . . . . 24

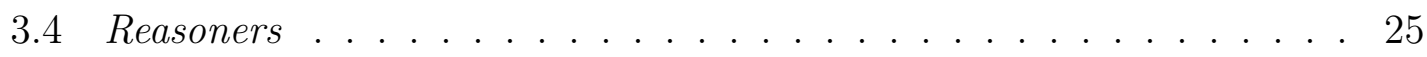

3.5 SPARQL Protocol and RDF Query Language . . . . . . . . . . . 26

3.6 Geo-SPARQL . . . . . . . . . . . . . . . . 27

3.7 Triple Store . . . . . . . . . . . . . . . . . . . . 28

3.8 Ferramentas da Web Semântica . . . . . . . . . . . . . . . . . . . . . 29 
3.8.1 Protégé . . . . . . . . . . . . . . . . . . 29

3.8 .2 Ontop . . . . . . . . . . . . . . . . 30

3.8.3 Virtuoso . . . . . . . . . . . . . . . . . 30

3.8 .4 API Jena . . . . . . . . . . . . . . . . . . 31

3.9 Trabalhos relacionados com Buscas Semânticas . . . . . . . . . . . . . 31

3.10 Considerações Finais . . . . . . . . . . . . . . . . . . . . . 33

4 Arquitetura Proposta 35

4.1 Introdução . . . . . . . . . . . . . . . . . . . . . . . . 35

4.2 Ontologia de Biodiversidade (OntoBio) . . . . . . . . . . . 35

4.3 Arquitetura de Busca Semântica . . . . . . . . . . . . . . . . . . . 41

4.3.1 Camada de Apresentação . . . . . . . . . . . . . . . . . . 42

4.3 .2 Camada de Negócio . . . . . . . . . . . . . . . . . . . . . . . . 43

4.3.2.1 Componente de Reformulação de Consultas . . . . . 44

4.3.3 Camada de Modelo . . . . . . . . . . . . . . . . . . . . . 45

4.3.3.1 Componente de Mapeamento . . . . . . . . . . . . 45

4.3.4 Camada de dados . . . . . . . . . . . . . . . . . . . . . . . . 48

4.4 Considerações Finais . . . . . . . . . . . . . . . . . . . . . . . . . . 49

5 Experimentos $\quad 51$

5.1 Introdução . . . . . . . . . . . . . . . . . . . . . . . 51

5.2 Casos de Uso . . . . . . . . . . . . . . . . . . . . 51

5.2.1 Caso de Uso: Estudo de impacto ambiental . . . . . . . . . . 51

5.2.2 Caso de Uso: Classificação de áreas degradadas . . . . . . . . 53

5.3 Experimento: Criação de triplas de insetos, peixes e mamíferos . . . . 54

5.4 Experimento: Avaliação das Buscas Semântica e por Palavras Chave . 55

5.5 Experimento: Linked Data da floresta Amazônica . . . . . . . . . . . 62

5.6 Considerações Finais . . . . . . . . . . . . . . . . . . . . 66

$\begin{array}{lll}6 & \text { Conclusão } & 67\end{array}$

6.1 Contribuições . . . . . . . . . . . . . . . . . . . . . . 67

6.1.1 Produção Científica . . . . . . . . . . . . . . . 68

6.2 Dificuldades e Limitações . . . . . . . . . . . . . . . . . . . . . . . 69

6.3 Trabalhos Futuros . . . . . . . . . . . . . . . . . . . 70

$\begin{array}{ll}\text { References } & 70\end{array}$

$\begin{array}{ll}\text { A Lista de Axiomas de Mapeamento. } & 77\end{array}$ 
B Coleção de Referência sobre Biodiversidade 



\section{Lista de Figuras}

2.1 Rede para disseminação de informações sobre biodiversidade agrupadas pelo protocolo DIGIR em uma única base virtual (dos Santos,

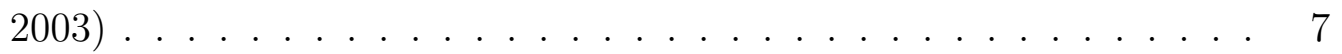

2.2 Exemplo de busca no sistema speciesLink Fonte: (SpeciesLink, 2013). 11

2.3 Exemplo de busca no sistema Sinbiota Fonte: (SinBiota, 2013). . . . 12

2.4 Exemplo de busca no sistema GBIF Fonte: (GBIF, 2001). . . . . . . 13

3.1 Classificação de Componentes para Busca Semântica (Mangold, 2007). 18

3.2 Exemplos de recursos RDF . . . . . . . . . . . . . . . 23

3.3 Mecanismos de um Reasoner . . . . . . . . . . . . . . . . . 25

4.1 Overview da ontologia de biodiversidade. . . . . . . . . . . . . 36

4.2 OntoBio - Ontologia de Biodiversidade: classes e relações. . . . . . . 39

4.3 Grafo da Ontologia OntoBio. . . . . . . . . . . . . . . . . . . 40

4.4 Arquitetura de Busca Semântica. . . . . . . . . . . . . . . . . . . 41

4.5 Interface de Busca Semântica . . . . . . . . . . . . . . . . . . . . . . 42

4.6 EndPoint SPARQL implementado para consultar os dados sobre biodiversidade. . . . . . . . . . . . . . . . 43

4.7 Termos sugeridos pela interface de busca para a consulta Phylum C. . 45

4.8 Mapeamento usando um banco de dados relacional e a ontologia OntoBio. . . . . . . . . . . . . . . . . 46

5.1 Exemplo de triplas do Genus-Creagrutus da ontologia OntoBio. . . . 55

5.2 Comparação das Medidas de Precisão, Revocação e F1 entre busca por palavra-chave e busca semântica. . . . . . . . . . . . . . . . 60

5.3 Média de precisão interpolada em 11 pontos considerando 28 consultas e usando dois sistemas de busca: busca por palavra-chave e busca semântica 
5.4 Áreas de desmatamento de amostras de plantas Tracheophyta coletadas no estado do Amazonas, Brasil. A cor marrom indica áreas com desmatamento maior que 10\%, dados de 2008. A distribuição é bastante concentrada em algumas áreas, a mancha negra representa a área com mais coleções, 835 registros. . . . . . . . . . . . . . . . . 65 


\section{Lista de Tabelas}

2.1 Análise dos sistemas de busca por palavra-chave do speciesLink, Sinbiota e GBIF. . . . . . . . . . . . . . . . . . . . . . . . . . . 14

4.1 Exemplos de campos do padrão Darwin Core usados na OntoBio . . 37

4.2 Exemplos de campos da Ontologia Geonames e do vocabulário WGS84 38

5.1 Exemplos de tarefas e consultas selecionadas de cada caso de uso . . . 57

5.2 Configuração inicial para realizar a avaliação de sistemas de busca . . 58

5.3 Resultado da Precisão e Revocação de Buscas por Palavra-Chave e Buscas Semânticas: "Id" define o código de cada consulta; "ColRef" indica a quantidade de documentos relevantes indicados na coleção de referência; "DR" indica os documentos relevantes recuperados para cada consulta . . . . . . . . . . . . . . . . . 59

5.4 Média da interpolação da precisão de 28 consultas usando Busca por Palavras e Busca Semântica . . . . . . . . . . . . . . . . . . . . . 61 



\section{Lista de Algoritmos}

4.1 Algoritmo de busca semântica desenvolvido para comparar os termos de busca inseridos na interface Web com os grafos da ontologia OntoBio. . . . . . . . . . . . . . . . . . . . 44

4.2 Algoritmo de mapeamento entre a ontologia OntoBio e coletas de dados de em formato CSV. . . . . . . . . . . . . . . . . . . . 47 



\section{Lista de Listagens}

1 Exemplo de Consulta SPARQL para selecionar todos classes e ordens do reino Animal:. . . . . . . . . . . . . . . . . . . . . 27

2 Consulta SPARQL para selecionar todas as ocorrências de plantas do filo Tracheophyta. . . . . . . . . . . . . . . . . . . . . . 64

3 Consulta SPARQL para selecionar as células e polígonos de uma coleta de dados vinculados com informação geográfica da DBpedia . . . 64 



\section{Lista de Siglas e Abreviaturas}

BFO Ontologia Formal Básica

CBA Centro de Biotecnologia da Amazônia

CBOL Consortium for the Barcode of Life

CNPq Conselho Nacional de Desenvolvimento Científico e Tecnológico

CoL Catalogue of Life

CRIA Centro de Referência em Informação Ambiental

DSL Linguagem Especifico de Domínio

ENVO Ontologia de Ambiente

EOL Encyclopedia of Life

Geo-SPARQL A Geographic Query Language for RDF Data

INPA Instituto Nacional de Pesquisas da Amazônia

KB Base de Conhecimento

LBA Programa de Pesquisa em Biodiversidade na Amazônia

MPEG Museu Paraense Emílio Goeldi

NYBG The New York Botanical Garden

OGC Open Geospatial Consortium

OWL Web Ontology Language

PATO Ontologia de Qualidades Fenotípicas

PELD Programa de Pesquisa em Biodiversidade na Amazônia 
PPBio Programa de Pesquisa em Biodiversidade na Amazônia

RDF Resource Description Framework

RDF(S) Resource Description Framework Schema

SQL Structured Query Language

TDWG Biodiversity Information Standards

TEAM Tropical Ecology, Assessement and Monitoring

TREC Text Retrieval Conference

WGS84 Vocabulário básico Geográfico

XML Extensible Markup Language 


\section{Capítulo 1}

\section{Introdução}

\subsection{Contexto e Motivação}

Com os avanços da tecnologia, a Web está se tornando uma das formas mais difundidas de obter dados científicos para a aquisição de novos conhecimentos. Além disso, cada dia mais pessoas têm acesso a esses dados por diferentes equipamentos como smartphones, tablets e computadores. Entretanto, essa ampla disponibilidade de dados gera um grande volume de informações em praticamente todas as mais variadas áreas do conhecimento. Para que esses dados sejam úteis, é necessário que eles sejam analisados e organizados, para que ferramentas de busca de informação recuperem o que os usuários realmente precisam.

Contudo, as ferramentas de busca atuais não apresentam recursos capazes de auxiliar os usuários a descrever, de forma precisa, a informação que desejam. Na maioria delas, usuários especificam um ou mais termos (strings) de busca de seu interesse e, devido ao grande volume de dados disponíveis, possivelmente obtém respostas com muitos resultados (nem todos relevantes). Devido a essa grande quantidade de resultados, usuários têm muita dificuldade para encontrar a informação desejada, pois a resposta apresentada é muito ampla e talvez nem contenha o que o eles realmente estão procurando.

$\mathrm{Na}$ área de biodiversidade isso não é diferente. Existe uma grande quantidade de dados gerados por instituições de pesquisa, que tem levado a discussões sobre qual é a melhor maneira de organizá-los para proporcionar ambientes e ferramentas que estimulem e facilitem a busca por informação (Moritz et al., 2011). Além disso, os dados que eles usam são coletados em vários lugares do mundo e publicados em formatos distintos e especificados em inúmeros padrões. Em função do crescimento da quantidade dos repositórios de informações sobre biodiversidade, a busca por 
fontes de informação e a identificação do seu inter-relacionamento se tornou uma atividade laboriosa para os especialistas.

Essa proliferação de fontes de informação implica que uma busca por informação pode ser atendida por uma variedade de recursos disponíveis, que armazenam dados sobre o mesmo domínio, mas que possuem características de qualidade distintas. Por isso, a necessidade de integração e analise dos dados desses domínios se torna mais evidente (Ziegler and Dittrich, 2007).

Para que esses dados sejam analisados e recuperados de forma eficiente, é necessário que seja utilizado algum tipo de tecnologia, pois, devido a sua grande quantidade, usar apenas o "olhar humano" não vai dar a esses dados nenhum significado. Atualmente, já existe uma tecnologia para associar significado a dados na Web: a Web Semântica.

A Web Semântica é uma progressão evolucionária da World Wide Web (ou simplesmente Web) e baseia-se na ideia que os computadores entendam as informações disponíveis na Web, associando significados a elas (Boley et al., 2001). Dessa forma, computadores poderiam realizar grande parte do trabalho, que os usuários vem fazendo hoje manualmente na Web, através da criação de uma grande quantidade de serviços inteligentes, como agentes de busca, agentes de software, máquinas de busca sofisticadas, filtros de informação, Web Services, entre outros.

Dentre as diversas tecnologias da Web Semântica, a Busca Semântica e as ontologias permitem que o conhecimento seja organizado em espaços conceituais de acordo com seu significado (Coral et al., 2006). Essa organização permite que ferramentas de busca por informação sejam capazes de fazer a seleção e a filtragem dessa informação baseadas na semântica dos termos de busca e dos itens pesquisados.

A Busca Semântica tenta compreender a intenção do usuário e o significado contextual dos termos usados na busca, como eles aparecem no espaço de dados pesquisáveis, seja na Web ou dentro de um sistema fechado, para gerar resultados mais relevantes e precisos.

Uma abordagem baseada em Busca Semântica implica que, para aumentar a eficiência de ferramentas de recuperação de dados, ontologias e mecanismos de inferência sejam utilizados para explorar o conhecimento do domínio e compartilhar a mesma estrutura de informação entre pessoas e agentes de software (programas) no processo de recuperação de documentos (Mangold, 2007).

Nesse contexto, o problema de pesquisa identificado é que a atividade de busca por fontes de dados em um repositório de dados sobre biodiversidade demanda um aperfeiçoamento para se tornar mais eficiente em termos de precisão e revocação dos 
resultados (Magnusson, 2013). Considerando esse problema de pesquisa, a hipótese levantada é que a utilização de tecnologias da Web Semântica irá tornar a atividade de busca mais eficiente em termos de precisão e revocação dos resultados.

\subsection{Justificativa}

Um grande problema, na Web atual, é que grande parte de seus conteúdos não são estruturados nem padronizados e, à medida que eles crescem, surgem problemas na organização, na busca e na recuperação da informação contida neles.

As abordagens de busca existentes na Web se concentram na utilização de mecanismos de busca por palavras-chave e não levam em conta os aspectos semânticos e nem a qualidade da informação recuperada. Efetuar buscas em repositórios com um grande volume de informações utilizando técnicas tradicionais acaba sendo uma tarefa custosa, pois permite a recuperação de informações fora de contexto, ocasionando ambiguidade, ou mesmo a não recuperação de informações inerentemente relacionadas ao contexto de busca. Por isso, existe a necessidade de se categorizar a informação da Web de maneira padronizada, para facilitar seu acesso, e de se desenvolver técnicas de busca utilizando a semântica dos termos da consulta e dos itens pesquisados.

A adição da Web Semântica na busca e na recuperação de informação, juntamente com sua aplicação a partir do uso de ontologias, pode trazer resultados positivos considerando a precisão e revocação dos resultados de buscas (Mangold, 2007). Contudo, a aplicação da Web Semântica na busca e na recuperação de informações é uma área em grande parte não testada dentro da Web atual (Amanqui et al., 2013), daí a importância de projetos que apliquem essa tecnologia ao problema de busca e demonstrem seus resultados através de experimentos.

\subsection{Objetivo}

Este trabalho tem como objetivo geral desenvolver uma arquitetura para buscas semânticas para conjuntos de dados sobre biodiversidade. De maneira sucinta, a arquitetura visa padronizar as informações por meio de uma ontologia, com a finalidade de melhorar o processo de busca e recuperação de informações considerando a precisão e revocação dos resultados. Assim, são objetivos específicos deste trabalho:

- Organizar os dados de maneira padronizada por meio de uma ontologia sobre biodiversidade. 
- Criar um algoritmo de mapeamento entre os dados sobre biodiversidade e ontologias.

- Criar um algoritmo de busca semântica para comparar os termos de busca inseridos na interface Web com os grafos da ontologia sobre biodiversidade.

- Realizar uma análise comparativa considerando à revocação e precisão da busca semântica frente a busca por palavra-chave.

Acreditamos que a aplicação de tecnologias da Web Semântica (como ontologias e as linguagens RDF e OWL, descritas no Capítulo 3) pode ser usada para integrar dados sobre biodiversidade e facilitar a recuperação dos mesmos através do uso da busca semântica. Com esse fim foi iniciada uma parceria entre o grupo do professor Dilvan Moreira do Laboratório Intermídia do ICMC-USP com o Instituto Nacional de Pesquisas da Amazônia (INPA) e o Museu Paraense Emílio Goeldi (MPEG) para o desenvolvimento deste trabalho de mestrado.

\subsection{Organização}

Este trabalho está estruturado da seguinte forma:

Capítulo 2: Explica a área de biodiversidade e os trabalhos relacionados encontrados na literatura, ressaltando as buscas por palavra chave na área de biodiversidade.

Capítulo 3: Apresenta a fundamentação teórica deste trabalho, enfatizando os conceitos de Ontologias, Web Semântica e trabalhos relacionados com Buscas Semânticas.

Capítulo 4: Esse capítulo apresenta a arquitetura de busca semântica, abordando os principais componentes como a ontologia de biodiversidade OntoBio, o componente de mapeamento entre dados e ontologias e o componente de reformulação de consultas.

Capítulo 5: Descreve os principais casos de uso para a avaliação da arquitetura.

Capítulo 6: Apresenta as contribuições do trabalho, bem como as conclusões a que se chegou com este projeto, as recomendações e trabalhos futuros.

Por fim, são listadas as referências bibliográficas utilizadas ao longo deste documento. 


\section{Capítulo 2}

\section{Biodiversidade}

\subsection{Introdução}

A diversidade biológica, ou biodiversidade, é um fator essencial para a sustentabilidade da vida na Terra. O Brasil é considerado como um dos países de maior diversidade biológica por abrigar cerca de $20 \%$ das espécies conhecidas em todo o mundo (Magnusson, 2013). Essa variedade de espécies está sendo diminuída pelas atividades humanas, por isso, pesquisadores em biodiversidade têm a necessidade de coletar e publicar dados para ajudar na conservação, preservação e proteção das espécies. Contudo, com o aumento significativo da quantidade de informação sobre biodiversidade disponível na Web, ferramentas de busca são necessárias para que usuários utilizem essa informação em suas atividades de maneira mais eficiente e eficaz.

\subsection{Disseminação de dados sobre biodiversidade}

No contexto da disseminação de dados sobre biodiversidade, há um grande número de projetos que visam desenvolver meios para integrar, gerenciar e publicar dados disponíveis sobre biodiversidade na Web. Como exemplos, escolhemos cinco projetos representativos (três com foco em dados do Brasil): o Programa de Grande Escala da Biosfera-Atmosfera na Amazônia (LBA), o Programa de Pesquisas em Biodiversidade (PPBio), o Programa de Pesquisas Ecológicas de Longa Duração ( PELD), o Projeto de Ecologia, Avaliação e Monitoramento de Florestas Tropicais (TEAM) e o Projeto de Infra-estrutura Global de Informação sobre Biodiversidade (GBIF). A seguir serão explicados cada um deles:

- O LBA é um programa de pesquisa multidisciplinar, liderado pelo governo 
brasileiro, com participação de outros países, que busca entender o funcionamento dos ecossistemas amazônicos em todas as suas vertentes e estudá-lo como uma entidade regional no planeta Terra (Batistella et al., 2007). Duas instituições proeminentes no LBA são o Instituto Nacional de Pesquisas da Amazônia (INPA) e o Museu Paraense Emílio Goeldi (MPEG). A colaboração interdisciplinar entre essas instituições tem sido a chave para a real efetividade do uso e entendimento dos grandes volumes de dados científicos já produzidos.

- O PPBio foi criado com a missão de desenvolver uma política de Ciência, Tecnologia e Inovação aplicada em diversos campos do conhecimento para a gestão, integração de informações sobre biodiversidade que possam ser utilizadas para diferentes finalidade (Peixoto and Barbosa, 2009). O PPBio tem como principal objetivo o desenvolvimento da capacidade de ampliação da disseminação do conhecimento sobre a biodiversidade brasileira de forma planejada e coordenada, tanto regionalmente como nacionalmente.

- O PELD é uma iniciativa pioneira no sentido de obter informações relevantes para a conservação da biodiversidade e o uso sustentável dos recursos naturais dos ecossistemas brasileiros. O PELD é executado sob a responsabilidade do Conselho Nacional de Desenvolvimento Científico e Tecnológico (CNPq). O PELD consiste de uma rede de sítios de pesquisas, presentes nos diferentes ecossistemas brasileiros, com o objetivo de compreender e prever mudanças ambientais.

- O TEAM objetiva monitorar diversos grupos da fauna, flora e variáveis ambientais ao longo de toda a faixa tropical da Terra. Dessa maneira, o TEAM fornece um sistema de alerta sobre o estado da biodiversidade que pode ser direcionados à ações de conservação. O TEAM conta com cerca de dezesseis sítios de pesquisas espalhados pela África, Ásia e América Latina com apoio de cientistas comprometidos com métodos padronizados de coleta de dados para quantificar como as plantas e os animais respondem a pressões, como as alterações climáticas e a ocupação humana. (Martins et al., 2006).

- O GBIF, oficialmente estabelecido em 2001, é um programa internacional que tem como objetivo consolidar o livre acesso à informação sobre biodiversidade via Internet. A implementação do GBIF é uma iniciativa aberta à participação de países e organizações internacionais interessadas no compartilhamento de dados sobre biodiversidade. O GBIF Trabalha em parceria com outras organizações internacionais, tais como o Catalogue of Life (CoL), a Biodiversity 
Information Standards (TDWG), Consortium for the Barcode of Life (CBOL) e a Encyclopedia of Life (EOL).

Os programas e projetos citados acima, juntos, formam uma vasta rede de conhecimento sobre a biodiversidade do mundo e, em particular, da Amazônia. A Figura 2.1 apresenta a rede para disseminação de informações sobre biodiversidade que integra instituições como: o MPEG, o PPBio, o Centro de Biotecnologia da Amazônia (CBA), o Centro de Referência em Informação Ambiental (CRIA), o The New York Botanical Garden (NYBG), o INPA, entre outros.

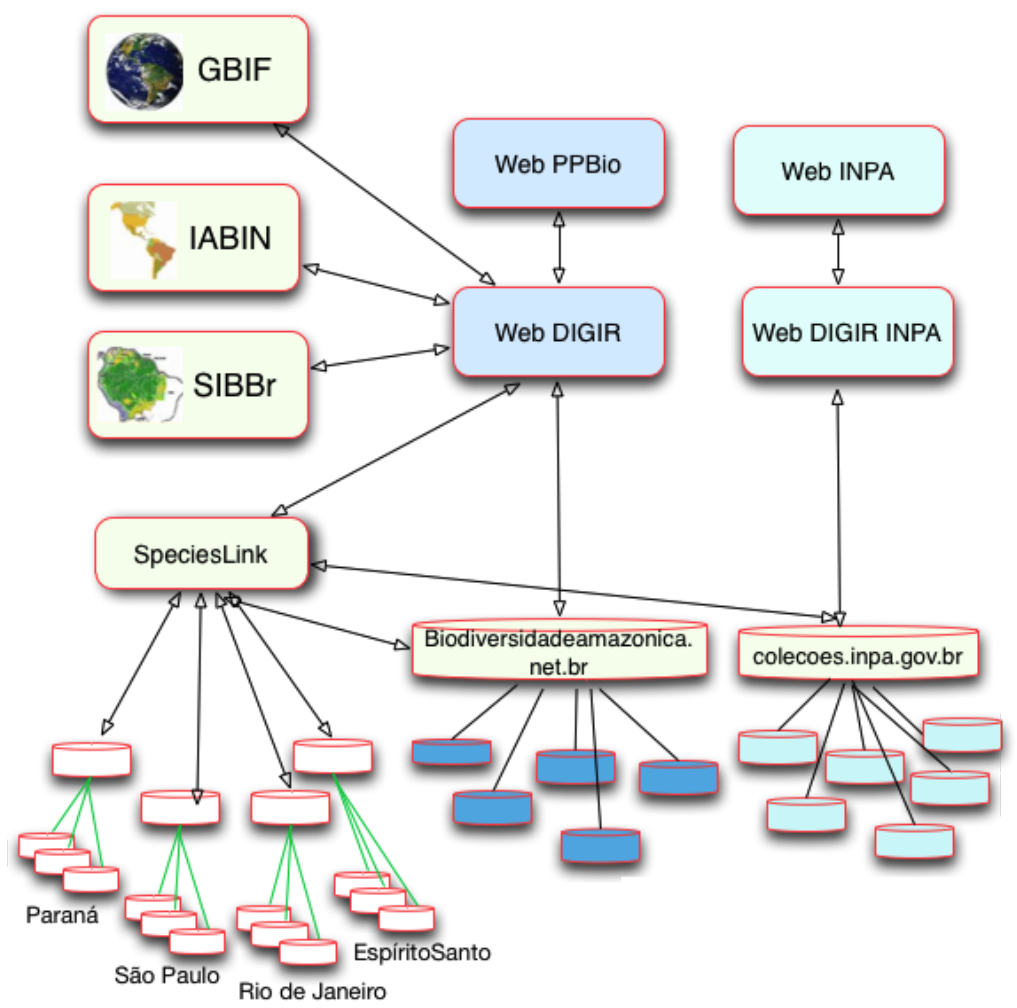

Figura 2.1: Rede para disseminação de informações sobre biodiversidade agrupadas pelo protocolo DIGIR em uma única base virtual(dos Santos, 2003).

Os dados produzidos pelos programas e projetos científicos apresentados na Figura 2.1, juntos, formam a base de conhecimento para diversas medidas de proteção e entendimento de ecossistemas complexos. No entanto, apesar desses programas e projetos terem políticas de dados vigentes que objetivam a integração dos dados gerados e o aprimoramento de ferramentas de busca, sendo que alguns participam de redes internacionais de disseminação de dados, seus dados não são interoperáveis e seus mecanismos de buscas não recuperam dados de diferentes bancos de dados.

A rede para disseminação de informações sobre biodiversidade ainda utiliza modelos tradicionais de busca e recuperação de informação baseados na exatidão do que 
é pesquisado sintaticamente, portanto, algumas vezes é necessário um conjunto de termos para que o sistema retorne aquilo que o usuário almeja realmente pesquisar. Isso demonstra um problema decorrente da falta de semântica nos sistemas de busca por palavra-chave.

\subsection{Busca por palavra-chave}

O processo básico de busca de informação a partir de palavra-chave pode ser resumido nos seguintes passos: (1) o sistema de busca recebe uma consulta $q$ a ser comparada com o conjunto de documentos $d 1, d 2, d 3 \ldots d n$ indexados inicialmente pelo sistema; (2) o sistema de busca identifica a similaridade entre $q$ e os $n$ documentos e (3) o sistema de busca retorna uma listagem de documentos relevantes à consulta $q$ ordenada de acordo com o fator de similaridade, esse fator é calculado a partir de informações estatísticas associadas às propriedades de documentos como: a frequência na qual os termos da consulta ocorrem no documento ou o número de documentos que contêm os termos da consulta.

A principal ferramenta utilizada para estabelecer relações entre os documentos são os motores de busca. Motores de busca baseados em palavras-chave, tais como Yahoo e Google, são, atualmente, as principais ferramentas para encontrar informação na Web. A Web não teria sido bem sucedida sem a criação dos motores de busca. No entanto, podemos citar problemas graves associados à sua utilização (Antoniou and Harmelen, 2008):

- Revocação alta, precisão baixa: Mesmo que os documentos mais relevantes sejam recuperados, eles ficam em meio a diversos documentos pouco relevantes ou irrelevantes;

- Baixo ou nenhuma revocação: Às vezes, não se obtém nenhuma resposta relevante para a busca realizada. Esse é um problema menos frequente nos atuais motores de busca;

- Resultados altamente sensíveis ao vocabulário: Os resultados são muito dependentes de vocabulário, pois mecanismos de busca são fortemente baseados em palavras-chave;

- Os resultados são documentos Web individuais: as informações estão espalhadas por vários documentos. Às vezes, a solução desse problema se dá através de várias consultas para coletar todos os documentos pertinentes e, em seguida, da extração manual da informação necessária, colocando-a em conjunto. 
Existem ferramentas que podem recuperar documentos, dividi-los em partes, verificar a ortografia e contar suas palavras. Entretanto, quando se trata de interpretar frases e extrair informações úteis para os usuários, a capacidade dos programas atuais ainda é muito limitada, pois o significado ainda é muito difícil de ser distinguido (Antoniou and Harmelen, 2008). Uma forma é usar o conteúdo do modo que está e desenvolver técnicas cada vez mais sofisticadas, baseadas em inteligência artificial e processamento de linguagem natural para melhorar os resultados de buscas na Web. Entretanto, apesar dos notados avanços, essa ainda é uma tarefa demasiado ambiciosa. Uma forma alternativa é a representação semântica dos conteúdos Web. Essa representação fornece a formalidade necessária para que máquinas possam processar os significados desses conteúdos.

A busca de informações por palavra-chave é uma operação que pode ser imprecisa, pois nem sempre a consulta indica exatamente as necessidades do usuário. Esse tipo de problema geralmente acontece devido à dificuldade que o usuário tem de utilizar as linguagens ou tipos de consultas empregados pelos sistemas de busca (Baeza-Yates and Ribeiro-Neto, 2011).

De acordo com Souza and Alvarenga (2004), a técnica de busca por palavra-chave concentra-se somente na correspondência da palavra-chave de consulta do usuário com documentos indexados, ignorando-se a semântica da consulta. Palavras usadas por usuários podem ter problemas, tais como sinônimos ou palavras com muitos significados, que são muito difíceis de resolver. Zhao et al. 2010 indicam que os usuários muitas vezes escolhem palavras-chave subjetivamente, arbitrariamente e sem padronização. Em outras palavras, nas buscas por palavras-chave a dificuldade não está em distinguir palavras que são escritas da mesma forma, mas sim os seus devidos significados.

Os projetos e programas de pesquisa em biodiversidade, já discutidos, necessitam disseminar seus dados através da Web. Além disso, eles necessitam também de sistemas de buscas de informações eficientes. A seguir, serão apresentados três sistemas e ferramentas que realizam buscas em dados sobre biodiversidade. Eles são representativos do tipo de ferramenta de busca que sites com dados sobre biodiversidade usam e são utilizados por pesquisadores dos programas e projetos de pesquisa citados na seção anterior. 


\subsection{1 speciesLink}

O speciesLink ${ }^{1}$ é um sistema que funciona em rede para integrar dados de coleções biológicas e possibilitar a realização de buscas e disseminação de dados sobre biodiversidade. O speciesLink foi desenvolvido por diferentes instituições como FAPESP, GBIF, JRS Foundation, CNPq e CRIA (SpeciesLink, 2013).

O speciesLink gerencia dados provenientes de diferentes grupos taxonômicos (plantas, mamíferos, aves, peixes, répteis, anfíbios, vertebrados fósseis, plantas fósseis e insetos). No momento, o speciesLink integra cerca de 313 coleções (Agosto de 2013) e sub-coleções que, juntas, oferecem cerca de 6,274,616 registros on-line, sendo que 2,639,585 desses registros são georreferenciados (SpeciesLink, 2013).

A equipe de desenvolvimento do speciesLink desenvolveu aplicativos específicos para a resolução de problemas em biodiversidade, tais como estudos de espécies invasoras, mudanças climáticas, proteção de espécies ameaçadas, planejamento de áreas de conservação, entre outros. Foram utilizados dados das coleções e modelos de distribuição geográfica de espécies e seus resultados foram disponibilizados na Web, para a comunidade científica. O speciesLink foi desenvolvido utilizando a linguagem de programação PHP, JavaScript e o banco de dados relacional PostgresSQL.

Outro aplicativo que a equipe do speciesLink desenvolveu foi um mecanismo de busca por palavras-chave ${ }^{2}$ (SpeciesLink, 2013). A Figura 2.2 apresenta um exemplo de busca no speciesLink. As buscas são realizadas seguindo três passos, conforme descrito a seguir:

1. No primeiro passo de uma busca, são escolhidas as coleções nas quais a busca deve ser feita. Na Figura 2.2, no campo Cod. Coleção foram escolhidas todas as coleções do INPA;

2. No segundo passo, o usuário especifica os termos de busca. Na Figura 2.2, os termos de busca são phylum magnoliaphyta;

3. Finalmente, o mecanismo de busca apresenta os resultados. No caso do speciesLink, para o termo de busca phylum magnoliaphyta nenhum registro foi encontrado.

\footnotetext{
${ }^{1}$ http://splink.cria.org.br/

${ }^{2}$ http://www.splink.org.br/index?lang $=p t$
} 


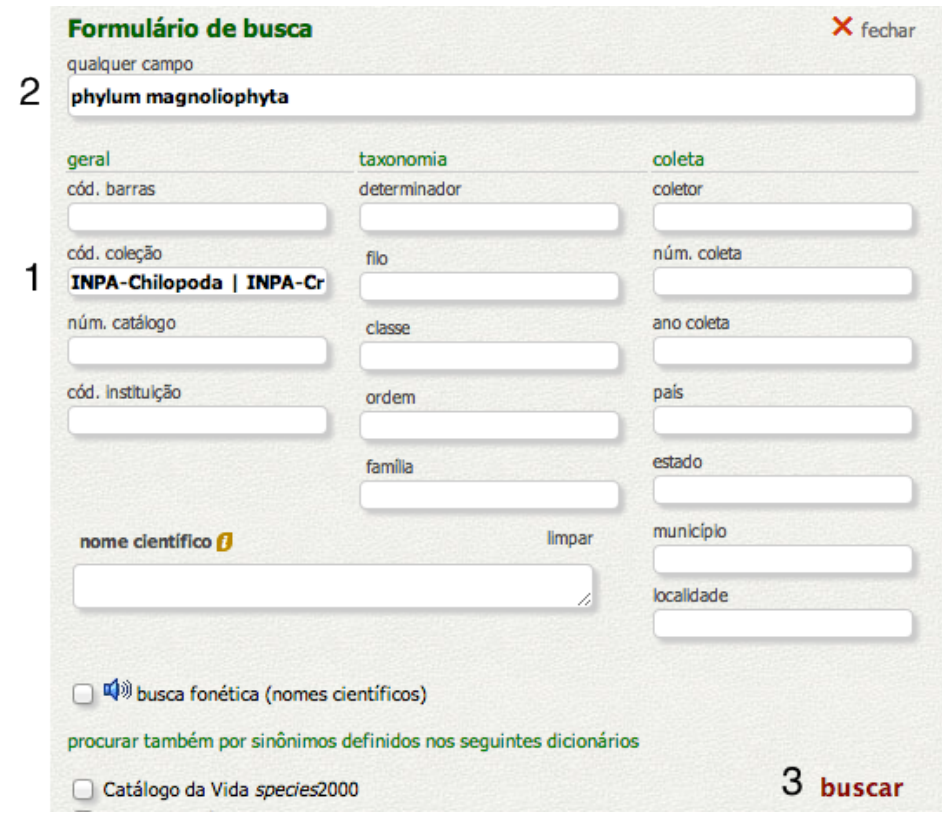

Figura 2.2: Exemplo de busca no sistema speciesLink Fonte: (SpeciesLink, 2013).

\subsubsection{Sistema de Informação Ambiental do Programa Bio- ta/Fapesp}

O Sinbiota é um sistema de busca sobre informações das coletas de espécimens do Estado de São Paulo (Canhos, 2003). O Sinbiota foi desenvolvido pela Universidade de Minnesota e utiliza um banco de dados encapsulado em um serviço web, combinando registros de ocorrências de espécies e registros de catálogos. Os resultados de cada consulta são exibidos em um mapa do estado de São Paulo, sendo possível também visualizar as ocorrências, que incluem referências bibliográficas e uma breve descrição de como foi feita a coleta do espécime.

A Figura 2.3 apresenta um exemplo de busca no Sinbiota. As buscas são realizadas têm os seguintes passos:

1. No primeiro passo, o usuário escolhe o tipo de busca: táxon, autor, ambiente, palavra-chave, entre outros.

2. No segundo passo, o usuário especifica os termos de busca. Na Figura 2.3, os termos de busca são phylum e Magnoliophyta.

3. Finalmente, o mecanismo de busca apresenta os resultados. No caso do Sinbiota, para o termo de busca phylum Magnoliophyta nenhum registro foi encontrado. 


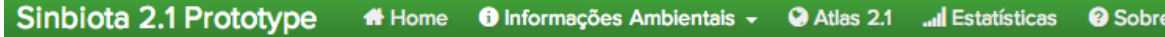

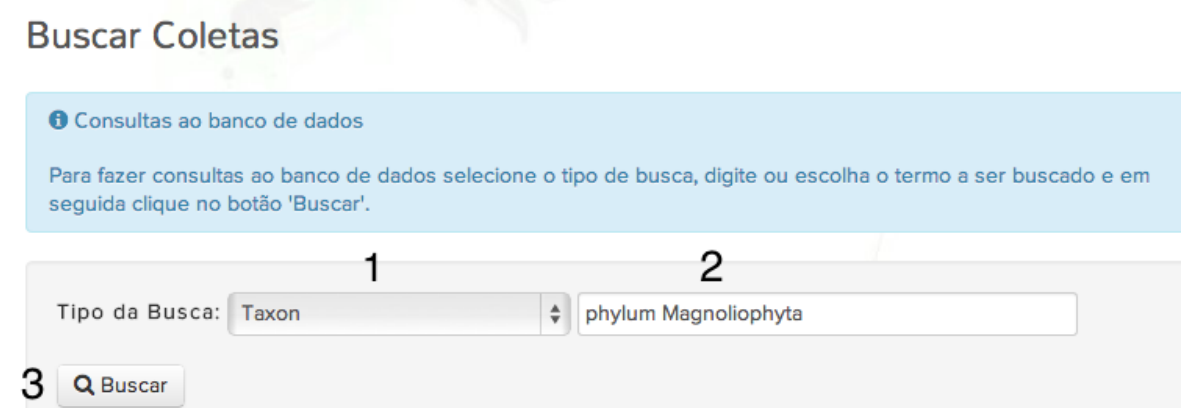

Figura 2.3: Exemplo de busca em sistema Sinbiota Fonte: (SinBiota, 2013).

O mecanismo de busca do sistema SinBiota apresenta os resultados de busca com base na ocorrência da palavra ou frase no banco de dados. Esse tipo de mecanismo permite aos usuários focar suas buscas por tipos específicos de busca tais como, táxon, palavras-chave e nome do determinador da coleta (SinBiota, 2013).

\subsubsection{Portal de busca do GBIF}

O portal de busca do GBIF é um serviço que fornece acesso e consulta a dados científicos sobre biodiversidade, esses dados estão sendo compartilhados atualmente através da rede do GBIF (GBIF, 2001). A rede do GBIF fornece um catálogo de várias espécies, sendo que a navegação é realizada através de uma árvore taxonômica, ou por busca de nomes comuns e científicos das espécies.

A Figura 2.4 apresenta um exemplo de busca no portal do GBIF. As buscas são realizadas seguindo três passos:

1. No primeiro passo, o usuário escolhe o nível taxonômico, como Kingdom, Phylum, entre outros.

2. No segundo passo, o usuário especifica os termos de busca. Na Figura 2.4, os termos de busca são phylum e acanthocephala.

3. Finalmente, o mecanismo de busca apresenta os resultados. No caso do portal do GBIF, para o termo de busca phylum acanthocephala nenhum registro foi encontrado. 


\section{3}

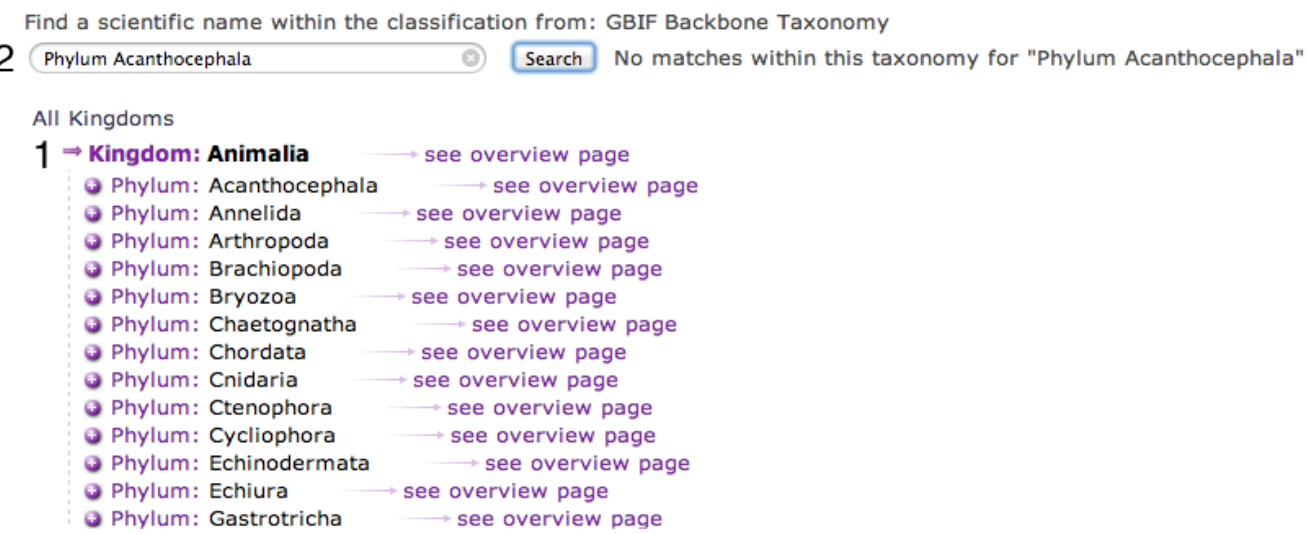

Figura 2.4: Exemplo de busca no sistema GBIF Fonte: (GBIF, 2001).

O mecanismo de busca do portal do GBIF utiliza um indexador, que permite comparar os termos especificados na interface com os termos do banco de dados, dessa forma, ele recupera uma lista de documentos onde os termos de busca foram encontrados.

\subsubsection{Análise das ferramentas de busca por palavra-chave}

Nesta dissertação, foi realizada uma análise das ferramentas de busca em dados sobre biodiversidade do specieslink (Figura 2.2), do Sionbiota (Figura 2.3) e do portal do GBIF (Figura 2.4), no período de agosto a dezembro de 2013. Os critérios de comparação considerados na análise foram: a técnica de busca utilizada e as tecnologias aplicadas. A Tabela 2.1 apresenta um resumo dessa análise.

A Tabela 2.1 mostra as principais características das ferramentas de busca sobre dados de biodiversidade, as três ferramentas utilizam a técnica de busca por palavrachave. As ferramentas speciesLink e Sinbiota utilizam o banco de dados PostgresSQL para armazenar os dados de biodiversidade e a ferramenta do Portal do GBIF utiliza o banco de dados Oracle.

Um problema reportado pelos especialistas em biodiversidade do INPA, é a difícil tarefa de recuperar informações simultaneamente num grande número de fontes de dados disponíveis. Um especialista pode especificar um ou mais termos (strings) num sistema de busca por palavra-chave e, devido a grande quantidade de dados disponíveis nos bancos de dados relacionais, o sistema recupera muitos resultados (não todos relevantes). Essa atividade não é particularmente bem suportada por ferramentas de busca (em dados sobre biodiversidade) baseadas em palavra-chaves, como specieslink, SinBiota e GBIF Species, apresentados nas Figuras 2.2, 2.3 e 2.4.

Novas abordagens no contexto da busca semântica foram propostas para superar 
Tabela 2.1: Análise dos sistemas de busca por palavra-chave do speciesLink, Sinbiota e GBIF.

\begin{tabular}{|c|c|c|c|}
\hline $\begin{array}{c}\text { Ferramentas de } \\
\text { busca }\end{array}$ & $\begin{array}{c}\text { Técnica de } \\
\text { busca }\end{array}$ & Desenvolvido por & Tecnologia \\
\hline \hline speciesLink & $\begin{array}{c}\text { Indexação do } \\
\text { termos de busca }\end{array}$ & $\begin{array}{c}\text { FAPESP, GBIF, JRS } \\
\text { Foundation, CNPq e } \\
\text { CRIA }\end{array}$ & $\begin{array}{c}\text { Linguagem de } \\
\text { programação PHP, } \\
\text { JavaSscript e banco } \\
\text { de dados } \\
\text { PostgresSQL }\end{array}$ \\
\hline \hline Sinbiota & Palavra-chave & $\begin{array}{c}\text { Universidade de } \\
\text { Minnesota }\end{array}$ & $\begin{array}{c}\text { Linguagem de } \\
\text { programação Perl, } \\
\text { Javascript e banco de } \\
\text { dados PostgreSQL e } \\
\text { MapServer }\end{array}$ \\
\hline \hline Portal do GBIF & Palavra-chave & $\begin{array}{c}\text { Global Biodiversity } \\
\text { Information Facility } \\
\text { (GBIF) }\end{array}$ & $\begin{array}{c}\text { Web e banco de } \\
\text { dados Oracle }\end{array}$ \\
\hline
\end{tabular}

as limitações da busca por palavra-chave (Santos et al., 2011). Para aumentar a eficiência de ferramentas de recuperação de documentos, ontologias e mecanismos de inferência são utilizados para explorar o conhecimento do domínio e compartilhar a mesma estrutura de informação entre pessoas e agentes de software no processo de recuperação de documentos. Essa abordagem é chamada de busca semântica (Mangold, 2007). O trabalho realizado nesta dissertação contribui com uma solução para melhorar tarefas de busca em dados sobre biodiversidade ao criar uma arquitetura de busca semântica para esses dados.

\subsection{Considerações Finais}

Os programas e projetos, citados acima, formam uma vasta rede de conhecimento sobre a biodiversidade da Terra. Os dados produzidos por esses programas e projetos científicos formam a base de conhecimento para diversas medidas de proteção e entendimento de ecossistemas complexos. Embora existam muitos dados disponíveis sobre biodiversidade, eles se encontram dispersos e em diversos formatos. Isso torna muito difícil que ferramentas de busca tradicionais os recuperem com eficiência.

Nas ferramentas de busca, citadas acima, diferentes sistemas bancos e esquemas de dados são utilizados. Isso leva a que dados similares não sejam representados uniformemente impedindo assim a integração de dados entre esses sistemas e a busca por conjunto de dados em todos os sistemas usando apenas uma interface/aplica- 
ção. Além dessas ferramentas serem baseadas em busca por palavra-chave, que não captura as necessidades de informação do usuário, e leva, na maioria dos casos, a necessidade do especialista em biodiversidade procurar, nos diversos documentos retornados, pelas informações que está procurando.

Esta pesquisa mostra que a busca semântica usando tecnologias da Web Semântica, além de reduzir problemas de incompatibilidade de representação de dados, melhora a precisão e revocação em buscas por dados sobre biodiversidade. A busca semântica e as tecnologias da Web Semântica serão explicadas no próximo capítulo. 



\section{Capítulo 3}

\section{Web Semântica}

\subsection{Introdução}

Na Web atual, também denominada Web Sintática, existe um crescimento exponencial e de forma desorganizada das informações. Esse crescimento acaba gerando um enorme repositório amorfo de documentos, o que dificulta a recuperação dos dados. Na web sintática, os computadores são usados para apresentar e recuperar informação, mas não para interpretar essa informação. Esse processo é sempre realizado por seres humanos. A Web foi planejada para facilitar o acesso, intercâmbio e a recuperação de informações, porém não é isso o que pode ser sempre observado hoje. Nesse contexto, surge a proposta da Web Semântica como um cenário desejável a Web Sintática (Souza and Alvarenga, 2004).

Berners-Lee et al. (2001) afirmou que a Web Semântica é uma extensão da Web atual que fornece informações com um significado bem definido, permitindo que computadores e pessoas trabalhem em cooperação. Para que os computadores entendam o conteúdo da Web, o primeiro passo será organizar e estruturar a informação e o segundo será adicionar semântica à ela, de tal forma que ferramentas de busca ou agentes de software possam compreendê-la.

A Web Semântica permite melhorar o processo de busca utilizando a semântica das informações. Esse conceito é conhecido na literatura como Busca Semântica. Berkley et al. (2009) define a busca semântica como uma aplicação da Web Semântica para a recuperação de informações. 


\subsection{Busca Semântica}

Uma definição muito usada para Busca Semântica é dada por Mangold (2007), ele a define como um processo de recuperação de documentos que explora o conhecimento de domínio e contexto semântico de termos de consulta para aumentar a precisão e revocação das consultas.

Atualmente, motores de busca como o Google utilizam buscas semânticas. Segundo Amerland (2013), o fato do Google ter a ferramenta de busca mais popular se deve ao fato dele estar promovendo uma grande reforma nos algoritmos dessa ferramenta, introduzindo buscas semânticas para mostrar resultados mais precisos e mais parecidos com a forma como os seres humanos entendem o mundo.

A Figura 3.1 apresenta uma classificação de componentes para busca semântica dada por (Mangold, 2007).

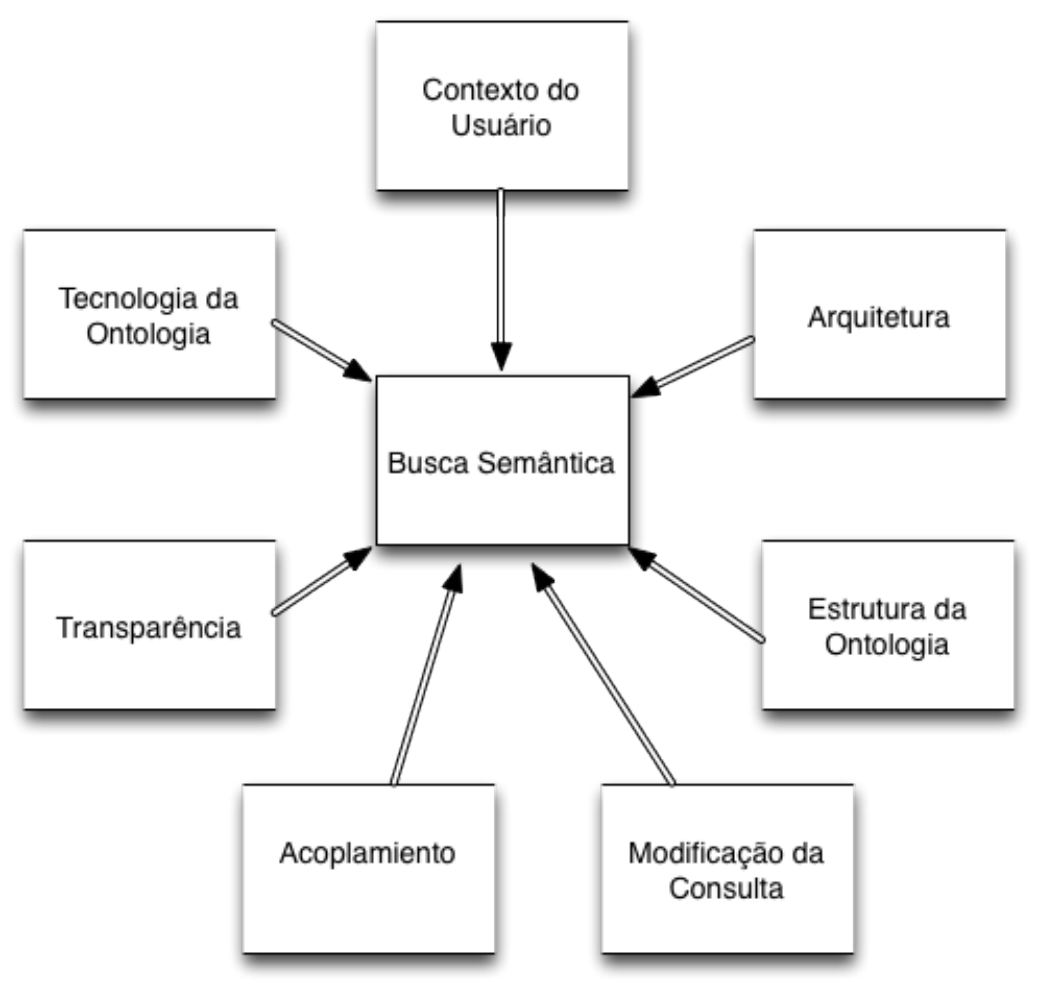

Figura 3.1: Classificação de Componentes para Busca Semântica (Mangold, 2007).

Os componentes para uma busca semântica são:

- O contexto do usuário da Busca Semântica pode ser pré-definido ou dinâmico. O contexto pré-definido pode ser extraído através de uma lista de categorias de perguntas, na qual há menos flexibilidade e por isso é mais indicada para domínios específicos. O contexto do usuário dinâmico pode ser 
extraído do histórico de interações do usuário o que caracteriza um sistema dinâmico.

- A arquitetura da Busca Semântica é categorizada como Stand-alone, quando o sistema armazena os metadados dos documentos em uma estrutura semântica de indexação local, que é usada para atender às solicitações de consulta; e como meta-search, quando as consultas são distribuídas para outras ferramentas de busca subordinadas e o resultado é combinado em seguida antes de ser apresentado ao usuário.

- As propriedades de objetos presentes na estrutura da ontologia utilizada numa Busca Semântica são categorizadas como: anônimas, padronizadas e dependentes de domínio. As propriedades anônimas indicam que os conceitos compartilham o mesmo contexto, as propriedades padronizadas fornecem uma sintaxe uniforme para a descrição dos conceitos e as propriedades dependentes de domínio explicitam mais o tipo de relação que existe entre os conceitos e são as mais indicadas para Buscas Semânticas.

- Quanto à modificação da consulta, Mangold (2007) considera três categorizações:

- De forma Manual, quando a consulta retorna documentos depois da busca e o usuário refina a consulta através da própria navegação pela ontologia;

- Baseada em grafo (de documentos), quando existe acoplamento forte entre a ontologia e os documentos. Nesse caso, o algoritmo percorre o grafo para recuperar documentos que são instâncias de conceitos semanticamente relacionados;

- Reescrita, quando ocorre a reformulação da lista de palavras-chave através de três formas:

* Por Argumentação, onde novos termos, relacionados com os conceitos na ontologia, são derivados para aumentar a abrangência da consulta;

* Por Substituição dos termos da consulta por termos que identificam os conceitos da ontologia que são sinônimos deles;

* Por Remoção de termos que possuam baixa seletividade na coleção.

- O acoplamento existente entre a ontologia e os documentos pode ser empregado de duas formas: 
- Acoplamento forte quando os metadados de um documento se relacionam explicitamente a uma ontologia, ou seja, o documento é representado como instância da ontologia, requerendo, por isso, a anotação semântica dos documentos. Entretanto, as anotações semânticas são informações adicionais anexadas aos documentos que identificam ou definem conceitos em um modelo semântico que descrevem parte do documento.

- Acoplamento fraco permite medir o quanto dois documentos são semanticamente similares através da distância conceitual, considerando o menor caminho entre os conceitos a que esses documentos estão associados como instâncias. O acoplamento fraco também é utilizado através da adição de anotações semânticas aos recursos publicados na Web Semântica.

- A transparência de Buscas Semânticas acontece quando não existem solicitações de informação adicionais, requeridas pelo sistema ao usuário.

- A tecnologia da ontologia é definida pelas linguagens que são usados na Web Semântica como RDF, OWL e DAML-OIL.

De acordo com Mangold (2007), a abordagem de busca semântica utiliza ontologias e mecanismos de inferência para explorar o conhecimento do domínio e compartilhar a mesma estrutura de informação entre pessoas e agentes de software no processo de recuperação de documentos.

\subsection{Ontologias}

O W3C afirma que as ontologias são a tecnologia de consolidação para a construção da Web Semântica. O termo é emprestado da Filosofia, em que uma ontologia é um relato sistemático da existência.

Gruber (1993) define ontologia como uma especificação formal e explícita de uma conceituação compartilhada. Conceituação se refere a um modelo abstrato de algum fenômeno do mundo, identificando os conceitos relevantes desse fenômeno. Explícito significa que os conceitos utilizados e as restrições sobre seu uso são explicitamente definidos. Formal refere-se ao fato de que a ontologia deve ser legível por máquinas. Compartilhado refere-se à noção de que uma ontologia captura o conhecimento consensual, isto é, não é privado de algum indivíduo, mas aceito por um grupo.

Ontologias são utilizadas para promover a interoperabilidade entre sistemas, ao representarem os dados compartilhados por diversas aplicações (Uschold and Gru- 
ninger, 2004). Ontologias são amplamente utilizadas para fins diferentes e em diferentes comunidades .

De acordo com (Devedzic, 2004), a ontologia deve ser um modelo de conhecimento compartilhado e consensual, acordado por uma comunidade. Dessa forma, espera-se que objetivos sejam alcançados, que o conhecimento extraído seja coerente com o domínio e que a formalização esteja de acordo com o nível exigido da aplicação.

Os componentes básicos de uma ontologia são classes (organizadas em uma taxonomia), relações, axiomas e instâncias. Esses componentes são explicados a seguir.

\subsubsection{Componentes}

Existe um conjunto mínimo de componentes para à representação de uma ontologia. Eles são Taxonomia, Classe, Relação, Axioma Formal e Instância (Coral et al., 2006). A seguir, uma breve explicação de cada um:

- Taxonomia: serve para classificar informação em uma hierarquia (árvore), utilizando o relacionamento pai-filho;

- Classes: representam conceitos que são retirados de um domínio amplo e são organizados em taxonomias por meio de herança;

- Relações: representam os tipos de interações entre os conceitos de um domínio.

- Axiomas formais: servem para modelar sentenças que são sempre verdadeiras. De acordo com Gruber (1995), os axiomas formais são usados para representar o conhecimento que não pode ser definido formalmente por outros componentes. Axiomas formais também são usados para verificar a consistência da própria ontologia ou a consistência do conhecimento armazenado, além de serem muito usados para inferir novos conhecimentos;

- Instâncias: são usadas para representar elementos ou indivíduos em uma ontologia.

Esses componentes são importantes porque representam um modelo compartilhado de um domínio. Tal modelo compartilhado é necessário para superar diferenças entre terminologias. Essas diferenças podem ser superadas através do mapeamento de cada terminologia específica para uma ontologia compartilhada, ou para ontologias diferentes que têm mapeamentos entre si. 
Para que recursos possam ser expressivos para máquinas são necessárias linguagens de representação. Para Berners-Lee et al. (2001), só uma ontologia não seria suficiente para imprimir semântica à Web, requerendo a adoção de tecnologias, como por exemplo, XML (Extensible Markup Language) e RDF (Resource Description Framework). Além delas é possível citar a OWL (Web Ontology Language) que é uma recomendação do W3C para definir e instanciar ontologias na Web.

\subsubsection{XML}

XML é uma meta-linguagem universal para a definição de marcação. Ela fornece uma estrutura uniforme e um conjunto de ferramentas, como analisadores para intercâmbio de dados e metadados entre aplicações. No entanto, a XML não fornece qualquer meio para falar sobre a semântica, o significado, dos dados. Nesse ponto entra o RDF (Resource Description Framework), uma linguagem baseada em XML, para a definição de informações na Web.

\subsubsection{RDF e RDF-Schema}

O RDF prove a tecnologia para expressar o significado de termos e conceitos de modo que computadores possam facilmente processá-los (Berners-Lee et al., 2001). Ele foi desenvolvido pelo W3C com o objetivo de especificar semântica para dados baseados em XML de forma padronizada e interoperável. O RDF amplia a estrutura de links da Web para usar URIs para nomear a relação entre dois recursos (isso é normalmente referido como "tripla"). Com esse modelo simples, ele permite que os dados estruturados e semi-estruturados possam ser misturados, expostos e compartilhados entre aplicações diferentes (KLYNE, G.and CARROL, J., 2004).

A descrição de um recurso em RDF é uma lista de declarações (triplas), cada uma expressa em termos de um recurso Web (sujeito), uma de suas propriedades e o valor da propriedade (objeto). Cada descrição RDF também pode ser representada como um grafo rotulado (Devedzic, 2004). De acordo com (Mizoguchi, 2003), o sujeito $(\mathrm{S})$ e o objeto $(\mathrm{O})$ são considerados nós e a propriedade $(\mathrm{P})$ é um link entre os nós. A Figura 3.2 apresenta um exemplo de tripla RDF, o ciclo de vida (P) de uma borboleta $(\mathrm{S})$ é lagarta $(\mathrm{O})$. 
(S)

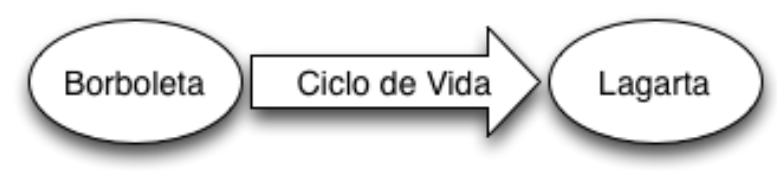

Figura 3.2: Exemplo de recursos $R D F$.

O RDF define um modelo para descrição de relações entre objetos em termos de propriedades e valores, porém não define mecanismos para descrever tais propriedades e relações entre essas propriedades e outros recursos. Para isso o RDF-Schema $(\mathrm{RDF}(\mathrm{S}))$ foi criado, ele é responsável por definir o relacionamento entre propriedades e recursos, em RDF, e sua respectiva semântica.

O RDF $(\mathrm{S})$ descreve regras para o uso das propriedades do RDF, definindo um vocabulário de domínio e representando esse vocabulário em hierarquias entre classes e relacionamentos. Ou seja, o RDF é usado para descrever instâncias de ontologias, enquanto o $\mathrm{RDF}(\mathrm{S})$ codifica ontologias.

Uma importante característica do $\operatorname{RDF}(\mathrm{S})$ é que as propriedades são definidas separadamente das classes. Com isso, qualquer um, em qualquer momento, pode criar uma propriedade e declarar que será usada com determinada classe ou múltiplas classes. Cada propriedade é tipicamente descrita com rdfs:domain e rdfs:range, que restringem as possíveis combinações de propriedades e classes.

$\mathrm{RDF}(\mathrm{S})$ podem ser visto como uma linguagem para descrever conhecimento de maneira bem simples, mas existem muitos tipos de conhecimento que não podem ser expressos nessa linguagem. Por exemplo: afirmar que cada livro tem um único título e pelo menos um autor, afirmar que um livro tem que ter capa dura ou capa "normal". Assim, para expressar o conhecimento necessário ao desenvolvimento de uma Web Semântica se faz necessário desenvolver uma linguagem mais poderosa.

Feigenbaum et al. (2007) indica que o RDF é o mais fundamental bloco de construção para a Web Semântica pois, além de poder ser utilizado para criar dados semânticos, é também utilizado como base para as linguagens de ontologia da Web Semântica. Entretanto para Staab et al. (2001), os dados em RDF são fracamente interligados, de modo que a Web Semântica necessita de técnicas ainda mais sofisticadas.

Nesse contexto, o W3C desenvolveu a linguagem OWL para estender o vocabulário do $\mathrm{RDF} / \mathrm{RDF}(\mathrm{S})$ sendo, desse modo, mais rica para descrever classes, relacionamentos, igualdades ou desigualdades entre classes, restrições de cardinalidade e características das propriedades. Além disso, ela permite uma representação explícita de um vocabulário de conceitos e relacionamentos de um domínio de conhecimento. 


\subsubsection{Web Ontology Language - OWL}

A OWL foi recomendada pelo W3C em 10 de fevereiro de 2004 para representar e compartilhar ontologias na Web. A linguagem OWL foi projetada para aplicações que necessitam processar o conteúdo da informação em vez de apenas apresentar informações em nós (Smith et al., 2004).

A OWL é uma linguagem que permite que a semântica seja explicitamente associada ao conteúdo dos dados na web e formalmente especificada através de ontologias, compartilhadas na Internet. OWL é baseada em XML e RDF, oferecendo mecanismos para uma semântica formal. Para representar conceitos, como classes em OWL, definem-se um nome, uma descrição resumida e expressões que podem definir subclasses, disjunções, classes equivalentes, uniões, interseções e complementos de classe. Podem ser definidas taxonomias de conceitos, relações binárias e instâncias para essas classes (Schreiber and Dean, 2004).

Ontologias em OWL foram desenvolvidas em várias áreas, como e-Science, medicina, biologia, geografia, astronomia e nas indústrias automobilística e aeronáutica (Grau et al., 2008). Contudo, foram encontradas algumas deficiências na linguagem OWL 1.0 e, para resolver e responder aos comentários e requisições de seus usuários, surgiu a OWL versão 1.1 (2006) como uma revisão incremental da linguagem e, depois de extensivas discussões, veio a OWL versão 2 (abril de 2008).

A OWL 2 foi considerada um passo substancial para a evolução da linguagem (Grau et al., 2008). De acordo com as especificações do W3C, a OWL 2 criou três novos perfis (sub-linguagens): OWL EL, OWL QL e OWL RL. Cada um desses perfis oferece um poder de expressividade diferente para diversos cenários de aplicação:

- OWL 2 EL é particularmente útil em aplicações que empregam ontologias que contêm um grande número de propriedades e / ou classes (Motik et al., 2009). Este perfil capta o poder expressivo usado por muitas ontologias e é um subconjunto do OWL 2 onde os problemas de raciocínio básico podem ser processados em tempo polinomial em relação ao tamanho da ontologia (Motik et al., 2009). Algoritmos de raciocínio dedicados a esse perfil estão disponíveis e têm-se demonstrado implementáveis de uma forma altamente escalável (Motik et al., 2009).

\section{- OWL 2 QL}

O perfil OWL 2 QL foi baseado na família DL-Lite de lógica de descrição. Esse perfil foi criado para permitir o raciocínio (reasoning) eficiente com grandes quantidades de dados estruturados. Ele fornece a maioria dos recursos neces- 
sários para capturar modelos conceituais, tais como diagramas de classe UML, diagramas de Entidade de Relacionamento, e esquemas de banco de dados.

\section{- OWL 2 RL}

O perfil OWL 2 RL é voltado para aplicações que exigem raciocínio escalável em troca de alguma restrição de poder expressivo. Ele define um subconjunto sintático de OWL 2 que favorece a implementação utilizando tecnologias baseadas em regras. Esse perfil pode ser utilizado na maioria das construções OWL 2, porém, para permitir implementações baseadas em regras de raciocínio, a forma como essas construções podem ser usadas em axiomas foi restringida.

As linguagens da Web Semântica possuem uma semântica formal que possibilita a realização de inferências usando raciocinadores (reasoners) automatizados. Os Reasoners são uma das mais importantes ferramentas utilizadas em nossa arquitetura de busca semântica.

\subsection{Reasoners}

Os Reasoners possuem a finalidade de realizar inferência usando os conceitos codificados nas ontologias com o objetivo de obter novos conhecimentos.

Eles utilizam um motor de inferência e um conjunto de regras expressas em linguagens semânticas como OWL, RDF, RDf(S). Portanto, um Reasoner está associado a uma base de conhecimento (KB) e possui dois mecanismos internos para a compreensão desse conhecimento, as Tbox e Abox (Baader et al., 2003). A Figura 3.3 apresenta os mecanismos de um Reasoner:

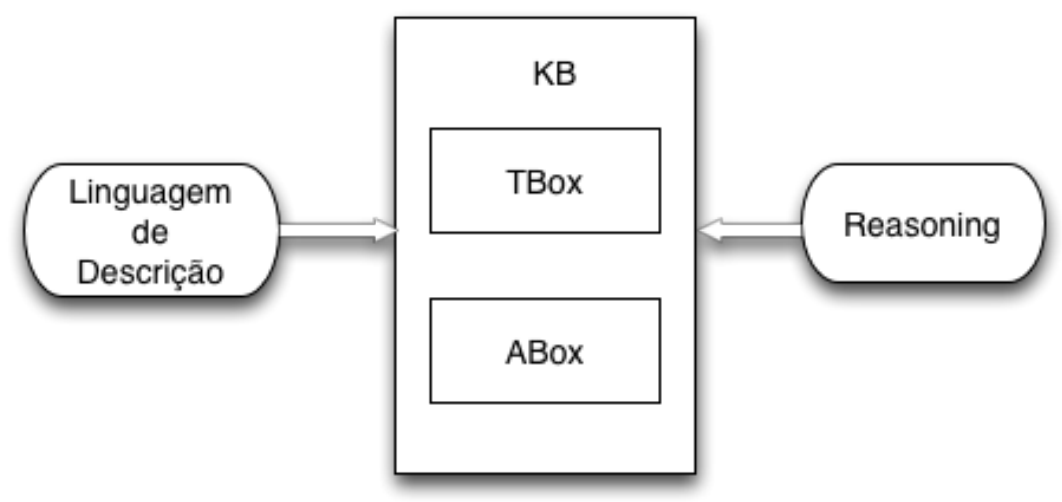

Figura 3.3: Mecanismos de um Reasoner.

Os mecanismos de um Reasoner são: 
- Tbox ou Parte Terminológica: Parte da KB que possui um conjunto de declarações e axiomas que descrevem a estrutura de um domínio. Contém frases que descrevem conceitos hierárquicos (relações entre conceitos). Um exemplo de um Tbox é mostrado a seguir:

$$
\text { Mulher } \equiv \text { Pessoa } \sqcap \text { Fêmea }
$$

Nesse exemplo, o conceito (classe) Mulher é declarado como o conceito resultante da interseção entre as interpretações dos conceitos Pessoa e Fêmea, ou seja, o conceito Mulher é formado pelos indivíduos que pertencem aos conceitos (classes) Pessoa e Fêmea simultaneamente.

- Abox ou Parte Declarativa: Parte da KB que possui sentenças assertivas sobre os indivíduos que indicam a hierarquia a qual os indivíduos pertencem (relações entre indivíduos e conceitos). Um exemplo de um Abox é mostrado a seguir:

$$
\text { Mulher } \equiv \text { Valeria }
$$

Esse exemplo mostra a declaração que o conceito Valeria é um indivíduo do conceito (classe) Mulher.

Os principais Reasoners, ou sistemas de inferência com base em lógica descritiva, disponíveis atualmente são o Racer, Pellet, Flora-2 e KAON-2 (Eiter et al., 2008). Esses Reasoners também podem ser integrados a ferramentas da Web Semântica como os editores de ontologia Protégé, TopBraid Composer, Virtuoso, Ontop, Ontotext, OntoEdit, entre outros.

Vale destacar que uma função dos Reasoners é executar as consultas na Web Semântica. As linguagens de consultas da Web Semântica são SPARQL (SPARQL Protocol And RDF Query Language) e Geo-SPARQL (A Geographic Query Language for RDF Data). Considerando que as consultas SPARQL e Geo-SPARQL não possuem a capacidade de efetuar qualquer tipo de inferência, estas devem ser efetuadas mediantes os Reasoners.

\subsection{SPARQL Protocol and RDF Query Language}

SPARQL é uma importante tecnologia para o desenvolvimento da Web Semântica, basicamente é uma linguagem de consulta de dados na Web que foi desenvolvida pelo W3C em 2005. 
Conceitualmente, as consultas realizadas em SPARQL fazem a correspondência de padrões em grafos. Os padrões são como declarações RDF, mas podem conter nomes de variáveis no lugar de alguns nós (recursos) ou links (propriedades) (Devedzic, 2004). O mais simples padrão em grafo é uma única tripla RDF (sujeitopropriedade-objeto).

$\mathrm{Na}$ Listagem 1 é apresentada uma consulta SPARQL que permite selecionar todas as classes e ordens do reino Animal:

Listagem 1 Exemplo de Consulta SPARQL para selecionar todos classes e ordens do reino Animal:

PREFIX : <http://purl.org/biodiv/ontobio\#>

PREFIX owl: <http://www.w3. org/2002/07/owl\#>

PREFIX rdf: <http://www.w3.org/1999/02/22-rdf-syntax-ns\#>

PREFIX rdfs: <http://www.w3.org/2000/01/rdf-schema\#>

select ? CollectLocal ?GeographicSpace where

\{ ? CollectLocal : localizationEspaGeoCoordGeo ?GeographicSpace . \}

A sintaxe das consultas SPARQL se assemelha à sintaxe de linguagens de consulta em banco de dados, como a Structured Query Language (SQL). Além disso, os prefixos (Prefix) são usados como mecanismos de abreviação para URIs/namespaces e são aplicados para a consulta toda.

Consultas SPARQL são realizadas em um banco de dados RDF por meio de um SPARQL EndPoint. Um SPARQL EndPoint é uma interface que usuários (humanos ou aplicações) podem acessar para realizar consultas SPARQL. Para humanos, este endpoint pode ser uma aplicação stand-alone ou Web. Para aplicações, o endpoint é um conjunto de APIs usadas para acessar os dados. Um SPARQL EndPoint pode ser configurado para retornar os resultados em vários formatos (RDF/XML, Turtle, HTML para humanos, etc).

Uma outra funcionalidade notável da SPARQL diz respeito às operações de consulta em dados geográficos, ou seja, consultas sobre a localização espacial de determinado objeto. Existe extensão do SPARQL para esse tipo de consultas, a linguagem GeoSPARQL, explicada na seção seguinte.

\subsection{Geo-SPARQL}

Geo-SPARQL é uma linguagem de consulta geográfica para dados RDF, publicada em junho de 2012, como um padrão de implementação do Open Geospatial Consortium (OGC) (Consortium, 2012). 
A linguagem de consulta Geo-SPARQL suporta a representação de dados geoespaciais na Web Semântica. Além disso, a linguagem Geo-SPARQL fornece um padrão para expressar elementos espaciais em RDF para que os usuários possam trocar dados geográficos facilmente e também para que as implementações de triplas possam ter um formato único de indexação para esses dados (Consortium, 2012).

A linguagem GeoSPARQL define uma pequena ontologia para representar geometrias a uma série de predicados e funções de consulta SPARQL. Segundo Popescu et al. (2008), a linguagem GeoSPARQL é especificada em três componentes principais:

1. Definição de um vocabulário para representar relacionamentos, geometrias e características;

2. Um conjunto de funções específicas de domínio, espaciais para uso em consultas SPARQL;

3. Um conjunto de regras de transformação de consulta.

Devido ao fato de que as coletas sobre biodiversidade especificas no Capitulo 2 conterem informações georeferenciadas e do computador entender a semântica dessas informações em relação aos dados (localidades, habitat, APA, etc.) e aos operadores geo-topológicos (como conter ou fazer fronteira) é possível fazer buscas com semântica sofisticada que não seriam possíveis usando-se puramente com busca por strings. Por exemplo, a busca "procurar por anfíbios coletados usando redes de coleta a até $10 \mathrm{Km}$ do centro do lago do Tapari (Santarém)" seria impossível de ser feita num sistema que apenas busca por strings.

Para que as linguagens de consulta como SPARQL e GeoSPARQL recuperem as informações da Web Semântica é necessário que essa informação seja armazenada em um banco de dado de triplas, comumente conhecido como triple store.

\subsection{Triple Store}

Um triple store é um framework usado para armazenar e consultar dados em RDF. Além disso, um triple store fornece um mecanismo de armazenamento persistente e acesso a grafos RDF. As triplas armazenadas em triple stores permitem adicionar novos predicados e a responder complicadas consultas para melhorar o processo de inferência e processamento de regras. 
Os triple stores não-comerciais mais importantes são: Virtuoso-open source, Jena, SWIFT-OWLIM e 4Store. Em (Mironov et al., 2010), os autores examinaram e compararam o desempenho desses triple stores utilizando dados biológicos e considerando o tempo de execução das consultas. O resultado foi que o triple store Virtuoso teve um melhor tempo de resposta para todas as consultas e mostrou uma excelente escalabilidade. Nesse contexto, na seção a seguir serão discutidas as ferramentas da Web Semântica utilizadas neste trabalho.

\subsection{Ferramentas da Web Semântica}

Nesta seção, apresentaremos o conjunto de ferramentas que permitiram o desenvolvimento da arquitetura de busca semântica apresentada neste trabalho:

\subsubsection{Protégé}

O Protégé ${ }^{1}$ é um ambiente para criação e edição de ontologias desenvolvido pela Stanford University. A arquitetura do Protégé permite que os usuários desenvolvam novos plugins capazes de aumentar significativamente o conjunto de funcionalidades da ferramenta (Gennari et al., 2002). Suas características mais importantes são:

- O Protégé utiliza um mecanismo de inferência para a verificação de ontologias e sua classificação automática. Esse mecanismo é chamado de Reasoner e é implementado pelos programas $\mathrm{FaCT}++$ e Hermi (mas outros podem ser acoplados).

- O Protégé tem suporte para a OWL (1 e 2), o que permite que ontologias para a Web Semântica possam ser desenvolvidas nessa ferramenta.

- A versão 4.X do Protégé (versão atual) é baseada na biblioteca OWL-API (OWL 2). Essa biblioteca fornece uma plataforma mais sólida para o desenvolvimento de ontologias em OWL 2.

O Protégé também possui uma versão Web denominada Web-Protégé. Essa versão facilita a colaboração entre desenvolvedores, já que não é necessário instalar programas locais e as ontologias estão disponíveis de forma centralizada e compartilhada na Web.

\footnotetext{
${ }^{1}$ http://protege.stanford.edu/
} 


\subsubsection{Ontop}

O Ontop ${ }^{2}$ é um framework Java que permite a integração e interpretação de grandes conjuntos de dados. O Ontop foi desenvolvido pelo Grupo de Pesquisa de Bases de Dados (KRDB) da Universidade Livre de Bolzano Bozen (FUB) (Mariano R and Calvanese, 2012). O Ontop permite realizar o mapeamento de dados através de consultas em ontologias e banco de dados relacionais. O resultado desse mapeamento é executado mediante o reasoner Quest para gerar um conjunto de triplas RDF ou OWL.

\subsubsection{Virtuoso}

A plataforma Virtuoso ${ }^{3}$ foi desenvolvida pela empresa OpenLinks Software com a finalidade de realizar a integração de dados de uma empresa e proporcionar uma solução para a gestão de processos de negócios que envolvam SQL, RDF, XML, OWL e Web Service (Hassanzadeh et al., 2009).

A arquitetura da plataforma Virtuoso permite integrar e comunicar diferentes funcionalidades dentro de um único produto através das seguintes características:

- Gestão e integração de dados SQL, XML, RDF e OWL;

- Integração de aplicações (Web Services e SOA);

- Gestão e integração de processos (BPEL);

- Aplicações distribuídas colaborativas.

- Virtuoso permite utilizar SPARQL 1.1, mediante a inferência de sentenças (eg. rdfs:subClassOf, rdfs:subPropertyOf) e suporte limitado para o predicado owl:sameAs

A plataforma Virtuoso tem uma licença Open Source que permite a realização de modificações e adaptações para as necessidades deste trabalho.

Outra característica importante da arquitetura da plataforma Virtuoso é a possibilidade de realizar o enlace com repositórios de Linked Open Data (por exemplo, DBpedia, Freebase, BBC, New York Times, Geonames, Bio2RDF, NeuroCommons, entre outros) (Lewis and Software, 2008).

\footnotetext{
${ }^{2}$ http://ontop.inf.unibz.it/

${ }^{3} \mathrm{http}: / /$ virtuoso.openlinksw.com/
} 


\subsubsection{API Jena}

Jena $^{4}$ é uma API Java desenvolvida com o objetivo de construir aplicações da Web Semântica baseadas nas recomendações do W3C. Jena foi originalmente desenvolvida pela companhia Hewlett-Packard e possui uma licença Open Source para o desenvolvimento de aplicações (Carroll et al., 2003). A API Jena suporta as linguagens RDF e OWL, inclui também um motor de inferência e transforma uma determinada ontologia em um modelo abstrato de dados orientado a objetos.

Diversos trabalhos encontrados na literatura utilizam as ferramentas da Web Semântica. Nesse contexto, na Seção a seguir serão discutidos os trabalhos relacionados com buscas e recuperação de informações.

\subsection{Trabalhos relacionados com Buscas Semânticas}

Realizou-se uma revisão sistemática da literatura que compreendeu uma análise aprofundada de 12 estudos primários dentre os 296 artigos inicialmente recuperados, publicados no período de janeiro de 2002 a dezembro de 2013. Os principais objetivos motivadores dessa revisão foram:

1. Identificar as técnicas de busca semântica para recuperação de fontes de informação.

2. Identificar os principais componentes para uma arquitetura de busca semântica.

3. Identificar as técnicas de validação de busca semântica.

Com base nos objetivos descritos acima, nós elaboramos a questão de pesquisa, "quais são as técnicas de busca semântica em repositórios de informação sobre Biodiversidade?" para construir os strings de busca. Esses strings foram executados nas seguintes bases de busca eletrônica: IEEExplore, ACM, ScienceDirect, PubMed e SpringerLink para descobrir, na literatura, os principais trabalhos relacionados com este projeto de mestrado.

No contexto da Web Semântica, os seguintes trabalhos foram selecionados por estarem associados ao mesmo tema de pesquisa e com o uso de tecnologias da Web Semântica para a busca e recuperação de informações:

- A arquitetura de compartilhamento de dados sobre biodiversidade proposta por Jr. and Medeiros (2007) possibilita a consulta e gerenciamento de dados

\footnotetext{
${ }^{4}$ https://jena.apache.org/
} 
através de ontologias e anotações de dados sobre biodiversidade. Todavia, o sistema ainda utiliza um mecanismo híbrido, combinando SQL e SPARQL, para consultar grandes conjuntos de dados, o que dificulta a extração de informação. Como tecnologias da Web Semântica, como SPARQL, permitem que as informações sejam extraídas de forma padronizada, utilizando linguagens como OWL e RDF, um mecanismo híbrido não usa essa padronização em todas as suas respostas.

- Na área de Geociências, Xiong et al. (2009) propõem uma abordagem de busca semântica para interagir com extensos bancos de dados sobre geociências. Eles concentram seus estudos no desenvolvimento de um agente de consulta de vocabulários léxicos para extrair informação sobre ontologias geológicas. No entanto, os autores não especificam como os dados da área de geociências são tratados, nem que associações seriam necessárias para adaptar as informações semânticas com o processo de busca.

- A ferramenta Metacat, desenvolvida por Berkley et al. (2009), permite realizar consultas semânticas em repositórios de dados sobre ecologia. Todavia, o sistema não explora outras relações semânticas apresentadas em ontologias externas. Apenas faz uso de buscas estruturadas de palavra-chave e metadados.

- De S. Fedel et al. (2012) apresentam um framework para processar consultas multimodais na área de biodiversidade. Esse sistema permite realizar consultas utilizando textos e imagens como parâmetros de busca. Todavia, ele não disponibiliza nenhum mecanismo que adicione significado a essas consultas. Apenas serve para realizar consultas por conteúdo da imagem.

Nos trabalhos e estudos citados acima, é possível perceber que eles ainda utilizam bancos de dados relacionais para armazenar os dados e ontologias. No entanto, nenhum desses estudos inclui detalhes mais específicos no que diz respeito as suas implementações, ou como os significados são relacionados com os termos de busca. Tal cenário dificulta a consulta de dados em outros sistemas dentro da Web, visto que os dados consultados por uma ferramenta apenas são úteis para essa ferramenta. Seria necessária alguma arquitetura adicional que integre todas as informações dos bancos de dados para que esses dados pudessem ser utilizados em outros domínios e para outros fins.

Ao se fazer uso de padrões abertos como OWL, RDF, SPARQL, Geo-SPARQL (do W3C e OGC), criados e testados pela comunidade Web, aumenta-se a chance 
de que outros desenvolvedores compreendam o que foi feito e possam estender uma arquitetura, criando novos componentes e adicionando novas funcionalidade. Uma arquitetura aberta também possibilita o compartilhamento de informações entre os diversos domínios de aplicação. Já arquiteturas de dados fechadas dificultam esse compartilhamento (Jones, 2000).

Trabalhos sobre técnicas de busca semântica, não diretamente relacionados com biodiversidade, também foram estudados.

- Li and Yang (2008) propõem um método de construção de buscas semânticas espaciais em portais Web. As buscas estão baseadas na expansão de termos em outras ontologias como agricultura, saúde publica, desastres, entre outros.

- No trabalho de Zhao et al. (2010) é proposto o modelo SDDP (semântica, densidade, distancia e propriedade) que utiliza um calculo melhorado de similaridade semântica em uma ontologia, de acordo com os fatores de densidade semântica, profundidade, distância semântica e propriedades de uma ontologia.

- Dos Santos et al. (2011) propõem uma arquitetura suportada por busca semântica para recuperar dados em repositórios de metadados, eles utilizam uma abordagem de expansão de consulta semântica assistida pelo usuário.

- Latiri et al. (2012) propõem um método automático de expansão de consulta. Esse método realiza a expansão dos termos de busca numa ontologia e num banco de dados relacional.

Mais recentemente, grandes empresas, como Google e Microsoft, vêm desenvolvendo algoritmos de buscas semânticas para melhorar os motores de busca (Amerland, 2013)(Suter and Huser, 2013). Ainda que diversos detalhes relativos à implementação desses algoritmos não sejam publicados (por razões comerciais), existem iniciativas para tornar parte desses serviços acessíveis a desenvolvedores. Nesse sentido, por exemplo, a Microsoft lançou sua própria API de desenvolvimento para buscas semânticas utilizando um banco de dados e ontologias (Suter and Huser, 2013). No entanto, nenhuma dessas iniciativas inclui detalhes específicos sobre as implementações, deixando um espaço aberto para novas pesquisas.

\subsection{Considerações Finais}

Este capítulo apresentou os conceitos necessários para o entendimento deste trabalho, cujas contribuições principais encontram-se relatadas no Capítulo 4. Inicial- 
mente, foi apresentada a definição formal e os conceitos relacionados com a Busca Semântica. Em seguida, foi apresentado um resumo das principais ferramentas da Web Semântica que permitiram a edição da ontologia de biodiversidade e a implementação do protótipo de busca semântica. Por fim, este capítulo apresentou uma revisão crítica da literatura sobre o tema do presente trabalho

De forma geral, as vantagens na aplicação de técnicas da Web Semântica são diversas. Uma delas é a busca semântica, que possui uma melhoria na precisão e na revocação em relação aos métodos tradicionais de busca. Outra vantagem é poder combinar os conjuntos de dados com outras fontes de dados e poder descobrir novas informações relevantes. Os conceitos discutidos neste capitulo são fundamentais para o desenvolvimento deste trabalho, uma vez que iremos aplicar as tecnologias da Web Semântica para criar uma arquitetura de busca semântica utilizando dados sobre biodiversidade disponibilizados pelo INPA e MPEG. 


\section{Capítulo 4}

\section{Arquitetura Proposta}

\subsection{Introdução}

Nos três capítulos anteriores foram apresentados os conceitos referentes à fundamentação teórica do trabalho. Neste capítulo será descrita a arquitetura de busca semântica que permite realizar buscas em um repositório de dados sobre biodiversidade. A arquitetura de busca semântica proposta utiliza uma ontologia sobre biodiversidade, denominada OntoBio, como base para ligar os dados dos registros de coletas de espécimens, disponibilizados pelo INPA e MPEG, a termos bem definidos. Essas ligações são então armazenadas em uma triple store na forma de triplas RDF.

\subsection{Ontologia de Biodiversidade (OntoBio)}

A ontologia de biodiversidade, Ontobio, foi desenvolvida inicialmente pelo INPA e conjuntamente estendida neste trabalho. O principal objetivo da OntoBio é fornecer uma conceitualização clara e precisa das informações sobre coletas biológicas.

A versão original da OntoBio foi apresentada e disponibilizada em Albuquerque (2011). A Figura 4.1(a) apresenta as cinco sub-ontologias iniciais: coleta, entidade material, localização espacial, ecossistema e ambiente. A partir da versão original da OntoBio, identificou-se a necessidade de expandi-la mediante a reutilização de termos de outras ontologias já existentes. Ao se reutilizar termos de outras ontologias, fica mais fácil usar dados anotados, com termos da OntoBio, em conjunto com dados anotados com termos dessas outras ontologias. Isso leva ao compartilhamento de termos e definições dentro da Web Semântica. A reutilização de ontologias é muito importante para integração de informações e desenvolvimento de novas ontologias 
para a Web Semântica (Gomez-Perez and Corcho, 2002).

Nesse contexto, estendeu-se a ontologia OntoBio através da reutilização de elementos de outras ontologias públicas disponíveis na Web. Isso foi feito inserindo-se ou modificando-se termos que essas ontologias compartilhavam com a OntoBio, com o objetivo de melhorar a interoperabilidade com as mesmas. Por exemplo, a classe Cidade da OntoBio original foi substituído por dbpedia:City. A Figura 4.1(b) mostra um overview das ontologias adicionadas na ontologia OntoBio.

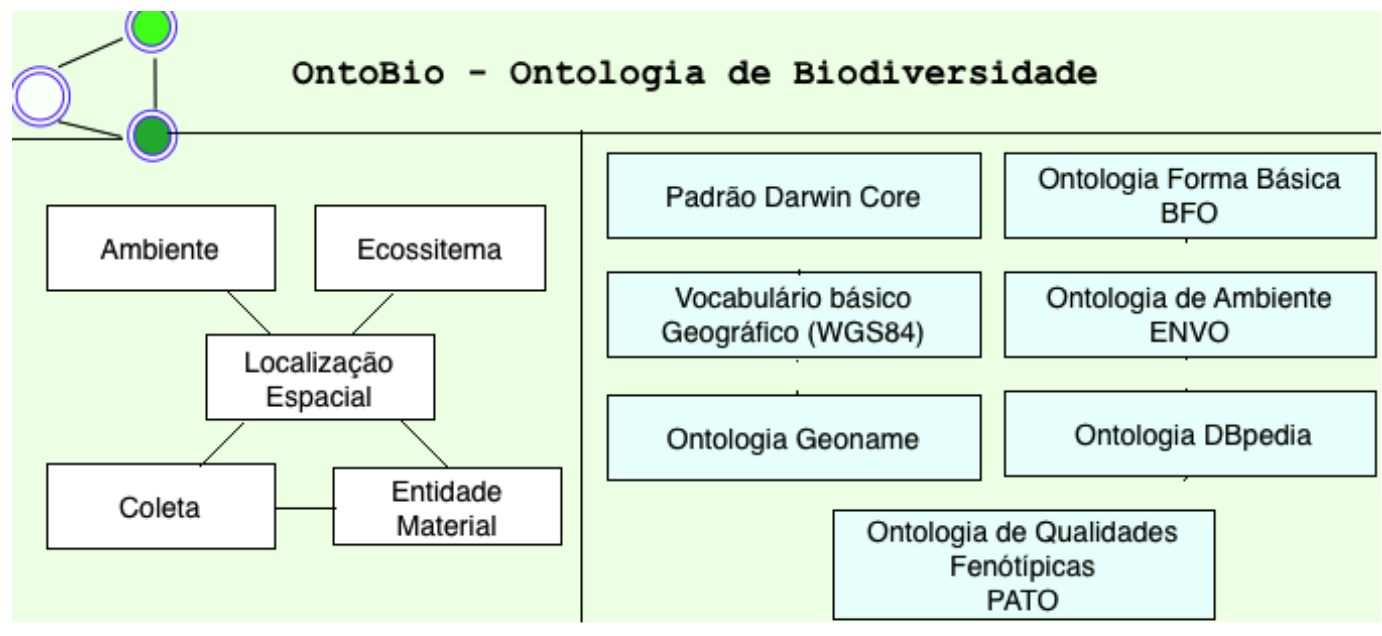

(a) Sub-ontologias iniciais da OntoBio

(b) Ontologias adicionadas na OntoBio

Figura 4.1: Overview da ontologia de biodiversidade.

As ontologias e vocabulários que tiveram termos adicionados na OntoBio foram:

- O Padrão Darwin Core é um padrão de glossários de termos sobre biodiversidade como propriedades, elementos, áreas, colunas, atributos e conceitos. O objetivo desse padrão é facilitar o intercâmbio de informação semântica sobre a ocorrência geográfica das espécies disponibilizadas na Web. A ontologia OntoBio foi estendida utilizando o padrão Darwin Core para a descrição de recursos, de modo a viabilizar a arquitetura de busca semântica na recuperação de informações. A Tabela 4.1 apresenta alguns elementos contidos na especificação do padrão Darwin Core utilizados na OntoBio. 
Tabela 4.1: Exemplos de campos do padrão Darwin Core usados na OntoBio

\begin{tabular}{|c|c|c|}
\hline Campo & Descrição & Exemplos \\
\hline \hline Scientific Name & Nome científico de uma espécie & $\begin{array}{c}\text { Semaprochilodus Taenlurus } \\
\text { (Genus + Espécie) }\end{array}$ \\
\hline Collecting Method & $\begin{array}{c}\text { Nome ou breve descrição do } \\
\text { método ou protocolo usado na } \\
\text { coleta }\end{array}$ & $\begin{array}{c}\text { Armadilla de raios UV, rede } \\
\text { de arrastão }\end{array}$ \\
\hline Collector & Nome(s) do(s) coletor(es) & Erica P. Anseloni \\
\hline Spatial Location & $\begin{array}{c}\text { Latitude ou Longitude do local } \\
\text { no qual o organismo foi coletado, } \\
\text { em graus decimais }\end{array}$ & 23,41 \\
\hline
\end{tabular}

- A Basic Formal Ontology (BFO) é uma ontologia de nível superior, pequena contendo apenas 39 classes e nenhuma propriedade. Uma ontologia de nível superior descreve conceitos muito gerais que são iguais em todos os domínios do conhecimento. A BFO foi a única ontologia a ser integralmente importada para a OntoBio. Isso quer dizer que todas as suas classes e estruturas são usadas na OntoBio. Na verdade, todos os conceitos mais gerais da OntoBio vem da BFO. A BFO foi projetada para apoiar a recuperação de informação, análise e integração em domínios científicos. Sua principal função é apoiar a interoperabilidade semântica entre a OntoBio e outras ontologias que também têm a BFO como ontologia de nível superior. Algumas classes da BFO são: Entidade, Entidade Material, Organismo, entre outras.

- A Environment Ontology (ENVO) é uma ontologia que fornece um vocabulário estruturado para dar suporte à anotação de qualquer amostra de organismo biológico. A ontologia ENVO contém termos de biomas como, por exemplo, floresta boreal, floresta tropical e savana; características e materiais ambientais tais como sedimento, solo, água e ar. A ontologia OntoBio usa as classes ambientais da ontologia ENVO, assumindo assim uma descrição padronizada dos dados do ambiente de uma coleta.

- A Ontology of Phenotypic Qualities (PATO) é uma ontologia para definição de fenótipos compostos. A ontologia PATO é usada para descrever as qualidades biológicas que residem em indivíduos definidos na ontologia OntoBio, por exemplo: sexo biológico (PATO:0000047), maturidade (PATO:0000261), etc.

- O Basic Geo Vocabulary (WGS84 lat/long) é um vocabulário básico RDF que fornece um campo para representar a latitude, longitude e outras 
informações espaciais. O vocabulário WGS84 é usado para descrever os dados geográficos da ontologia OntoBio. A Tabela 4.2 apresenta exemplos de dados da ontologia OntoBio utilizando definições do vocabulário geográfico WGS84.

- A Ontologia Geonames é uma ontologia para definições de dados geoespaciais na Web. A ontologia Geonames tem mais de 8,3 milhões de nomes próprios de localidades como, por exemplo, cidades, vilas, municípios, províncias, países, etc. Assim, vinculou-se os dados geoespaciais da ontologia OntoBio (dados com latitude, longitude ou local da coleta) com as definições de dados geoespaciais da ontologia Geonames. Isso foi feito usando-se um serviço Web proporcionado pelo Geonames que permite descarregar esses dados no formato RDF. A Tabela 4.2, apresenta exemplos de dados da ontologia OntoBio utilizando definições da ontologia Geonames.

Tabela 4.2: Exemplos de campos da Ontologia Geonames e do vocabulário WGS84

\begin{tabular}{|c|c||c|}
\hline Campo & Descrição & Exemplo \\
\hline \hline countryCode & Código do Pais & $<$ gn:countryCode $>$ \\
& & BR \\
& & $</$ gn:countryCode $>$ \\
\hline Spatial Location & latitude e longitude da & $<$ wgs84_pos:lat $>-$ \\
& localização espacial do local da & 3.04361 \\
& coleta & $</$ wgs8 $84 \_$pos:lat $>$ \\
& $<$wgs84_pos:long $>$- \\
& & 60.01282 \\
& & $</$ wgss8_pos:long $>$ \\
\hline
\end{tabular}

- Ontologia da DBpedia é uma ontologia composta de 320 classes e 1.650 propriedades diferentes. A DBpedia é um esforço colaborativo para extrair informações estruturadas da Wikipedia, tornando estas informações disponíveis na Web Semântica. Ela permite consultas sofisticadas, usando SPARQL, sobre informações da Wikipedia, opcionalmente incluindo ligações com outras fontes de dados ligados na Web. A DBpedia oferece um grande banco de informações sobre diferentes áreas de conhecimento em várias línguas, compartilhadas sob uma licença de domínio público, podendo ser diretamente reutilizada em outros projetos. No contexto da OntoBio, a ontologia DBpedia foi utilizada para mapear instâncias de dados em inglês (da dbpedia.org) e português (da pt.dbpedia.org) que descrevem nomes e características de cidades, estados e países, tais como http://pt.dbpedia.org/resource/Manaus. 
Integrar as ontologias e vocabulários descritos anteriormente com a ontologia OntoBio oferece vantagens para nossa arquitetura de busca semântica, tal como a padronização e organização de termos, pois facilita o reúso de ontologias. O resultado dessa integração foi a criação de 6311 recursos dentro da ontologia OntoBio divididos em: 200 classes, 6021 indivíduos e 90 propriedades.

Uma forma de apresentar as propriedades da OntoBio é utilizando o ambiente da ferramenta Protégé. Na Figura 4.2(a) são mostradas todas as classes da ontologia OntoBio, na Figura 4.2(b) são ilustradas as propriedades que relacionam duas classes (Propriedades de Objetos) e na Figura 4.2(c) são mostradas as propriedades que relacionam uma classe a um valor (indivíduo).

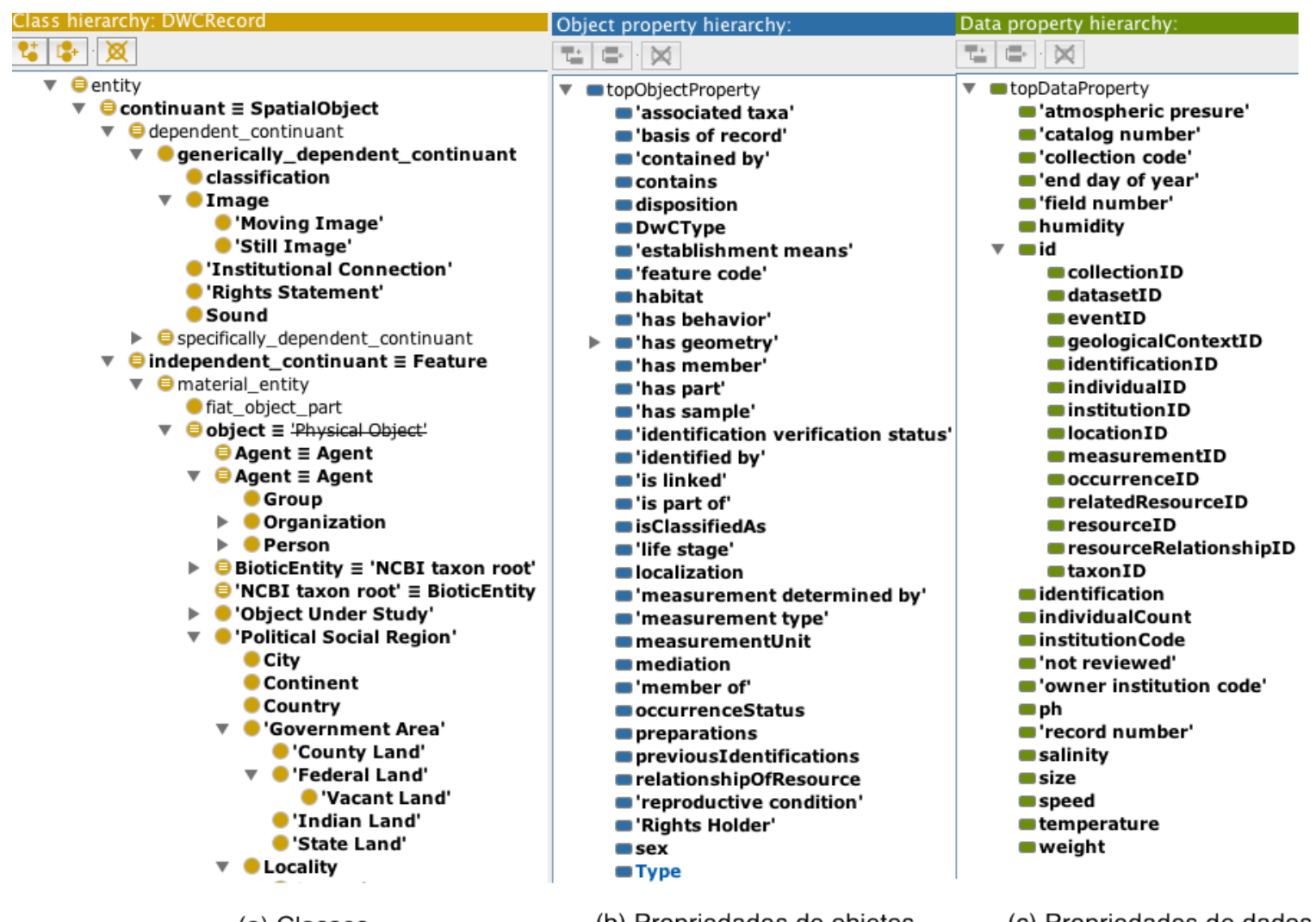

Figura 4.2: OntoBio - Ontologia de Biodiversidade: classes e relações.

Na Figura 4.3 é mostrado um grafo com classes e relações da ontologia OntoBio. As linhas entre as classes representam as propriedades específicas entre elas.

A OntoBio foi escrita na linguagem OWL 2 (Web Ontology Language), por essa se tratar de uma recomendação da W3C, essa linguagem permite a representação de classes (conceitos), propriedades de objetos e de dados (relacionamentos e atributos). A OntoBio foi desenvolvida usando o editor de ontologias Protégé 4. A nova versão 


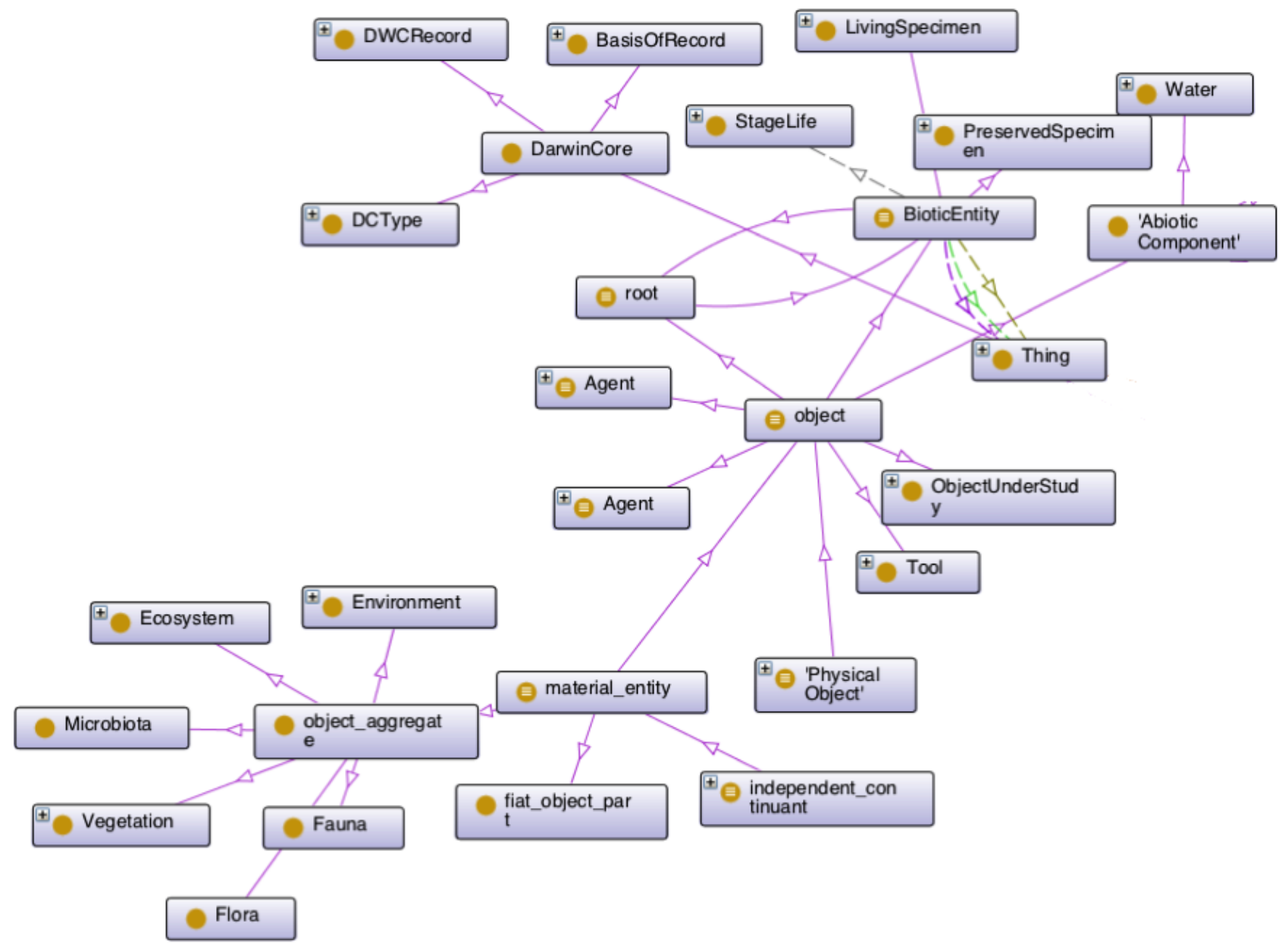

Figura 4.3: Grafo da Ontologia OntoBio.

da OntoBio está disponível por meio do NCBO Bioportal ${ }^{1}$ e pela URI da OntoBio 2. O NCBO BioPortal é um aplicativo Web para acessar e compartilhar ontologias biomédicas. Assim, por meio do NCBO Bioportal, os usuários podem transferir, procurar e sugerir termos para a ontologia OntoBio.

A ontologia OntoBio fornece um vocabulário para representação do conhecimento sobre biodiversidade. Esse vocabulário pode ser compartilhado e integrado a outros domínios específico. A arquitetura de busca semântica utiliza a ontologia OntoBio para organizar o conhecimento sobre biodiversidade em espaços conceituais. Essa organização permite a seleção e a filtragem das informações.

\footnotetext{
${ }^{1}$ http://bioportal.bioontology.org/projects/OntoBio

${ }^{2}$ http://purl.org/biodiv/ontobio
} 


\subsection{Arquitetura de Busca Semântica}

Uma arquitetura determina a maneira como componentes se organizam e se integram para facilitar a compreensão do seu funcionamento (Gacek et al., 1995). A arquitetura de busca semântica, apresentada na Figura 4.4, foi desenvolvida em quatro camadas: apresentação, camada de negócios, camada de modelo e camada de dados, onde cada uma delas possui uma determinada função.

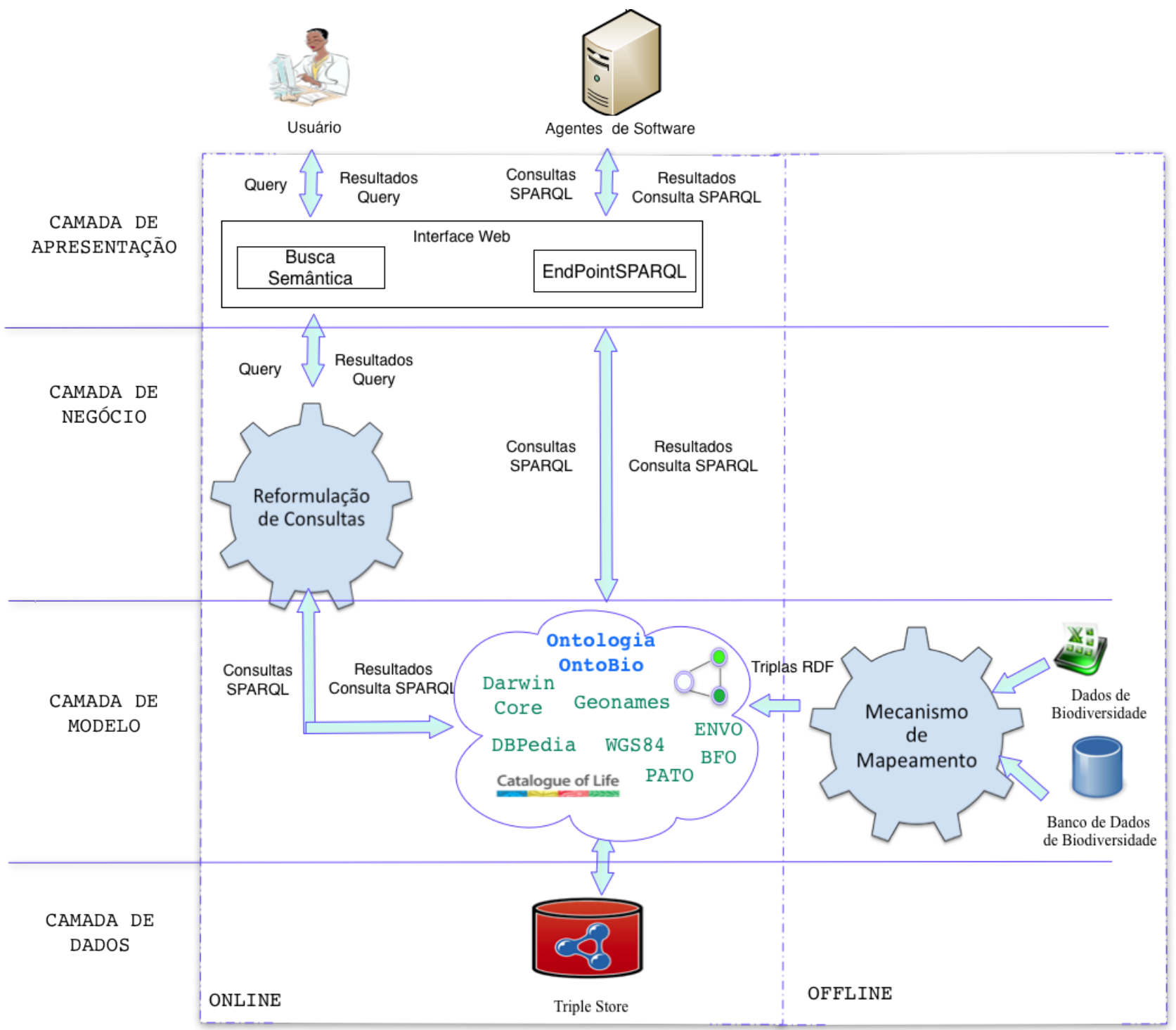

Figura 4.4: Camadas da Arquitetura de Busca Semântica.

As camadas da arquitetura de busca semântica estão integradas por um conjunto de componentes que serão descritos a seguir: 


\subsubsection{Camada de Apresentação}

A camada de apresentação contém uma interface Web que é responsável pela interação entre usuários ou agentes de software com a arquitetura de busca semântica.

O processo de busca é iniciado com uma lista de palavras-chave, inseridas por um especialista em biodiversidade, que representam suas intenções de busca. Os termos de busca são processados pelos componentes da camada de negócio. A exibição dos resultados de pesquisa consiste em uma lista vertical de títulos de documentos e várias linhas de registros que atendem os critérios de busca como família, gênero, espécie, latitude e longitude. A Figura 4.5 ilustra a interface de busca.

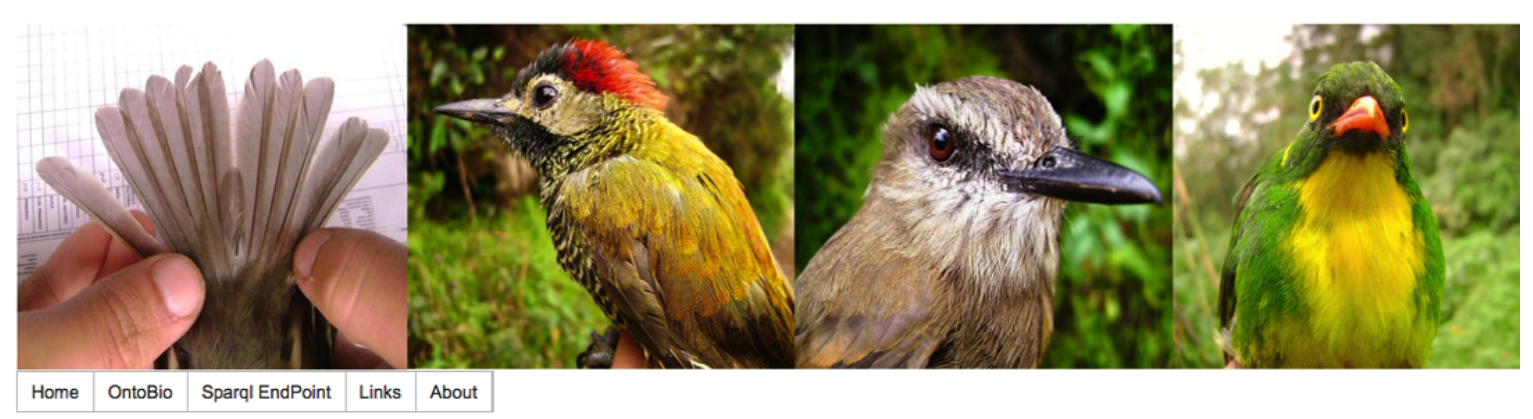

\section{Semantic Search for Biodiversity}

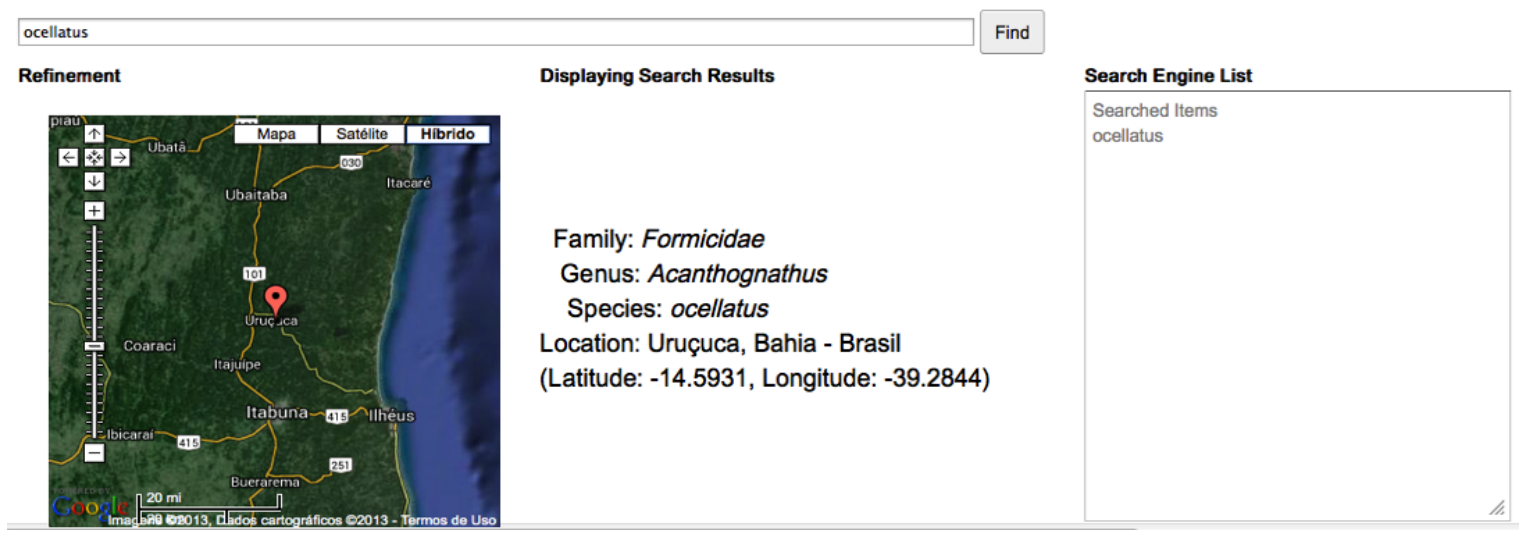

Figura 4.5: Interface de Busca Semântica.

A camada de apresentação também conta com um EndPoint SPARQL SPue $^{3}$ permite aos usuários ou agentes de software consultarem as informações por meio de consultas SPARQL. A Figura 4.6 apresenta uma consulta SPARQL que recupera os dados do INPA usando o EndPoint SPARQL da arquitetura.

Os agentes de software na Web Semântica reúnem, organizam, selecionam e apresentam as informações ao usuário final, que tomará as decisões com base nas

\footnotetext{
${ }^{3}$ http://biobak.icmc.usp.br:8890/sparql
} 
informações relatadas pelo agente de software. Eles podem extrair informações das coletas do INPA mediante o EndPoint SPARQL. Aqui, o termo agentes de software pode representar tanto programas sofisticados baseados em inteligência artificial como scripts escritos pelos próprios usuários com a ajuda de alguma DSL (por exemplo, o software R é uma linguagem DSL popular entre especialistas em biodiversidade) para realizar uma tarefa especifica, como o experimento realizado na Seção 5.5.

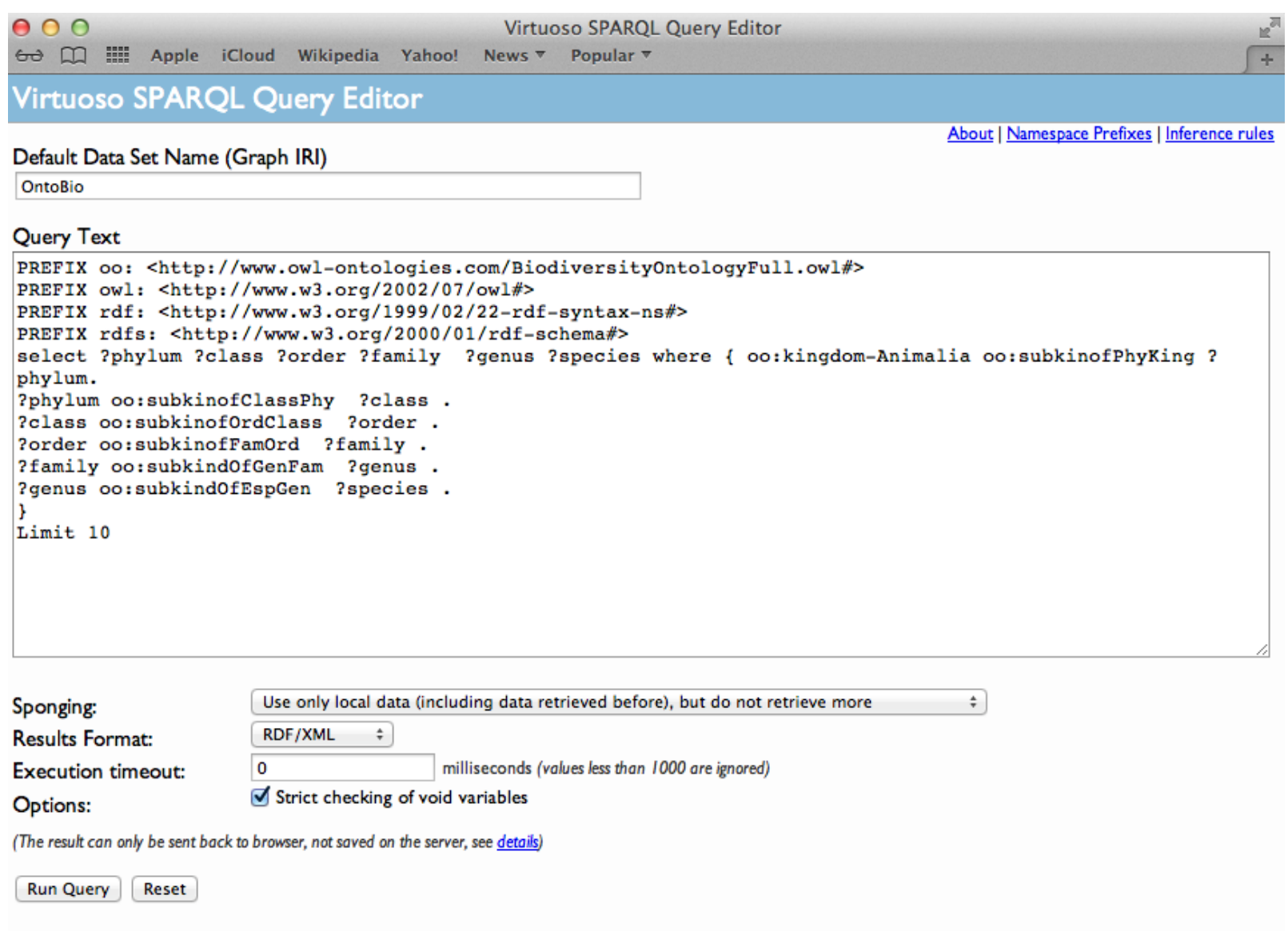

Figura 4.6: EndPoint SPARQL implementado para consultar os dados sobre biodiversidade.

A camada de apresentação é responsável por enviar os termos de busca para a camada de negócio, com o objetivo de processar os termos mediante o componente de reformulação de consultas.

\subsubsection{Camada de Negócio}

A camada de negócio é responsável por processar os termos inseridos na interface

Web mediante o componente de reformulação de consultas apresentado a seguir. 


\subsubsection{Componente de Reformulação de Consultas}

O componente de reformulação de consultas recebe como entrada os termos procurados pelo usuário na interface de busca. Esses termos são transformados em consultas SPARQL para recuperar as fontes de informação no triple store.

O componente de reformulação de consultas interage com a ontologia OntoBio para obter os recursos (labels) das triplas RDF a partir dos termos de busca. O Algoritmo 4.1 de busca semântica compara se há termos de busca na ontologia OntoBio que atendam às necessidades de informação solicitadas.

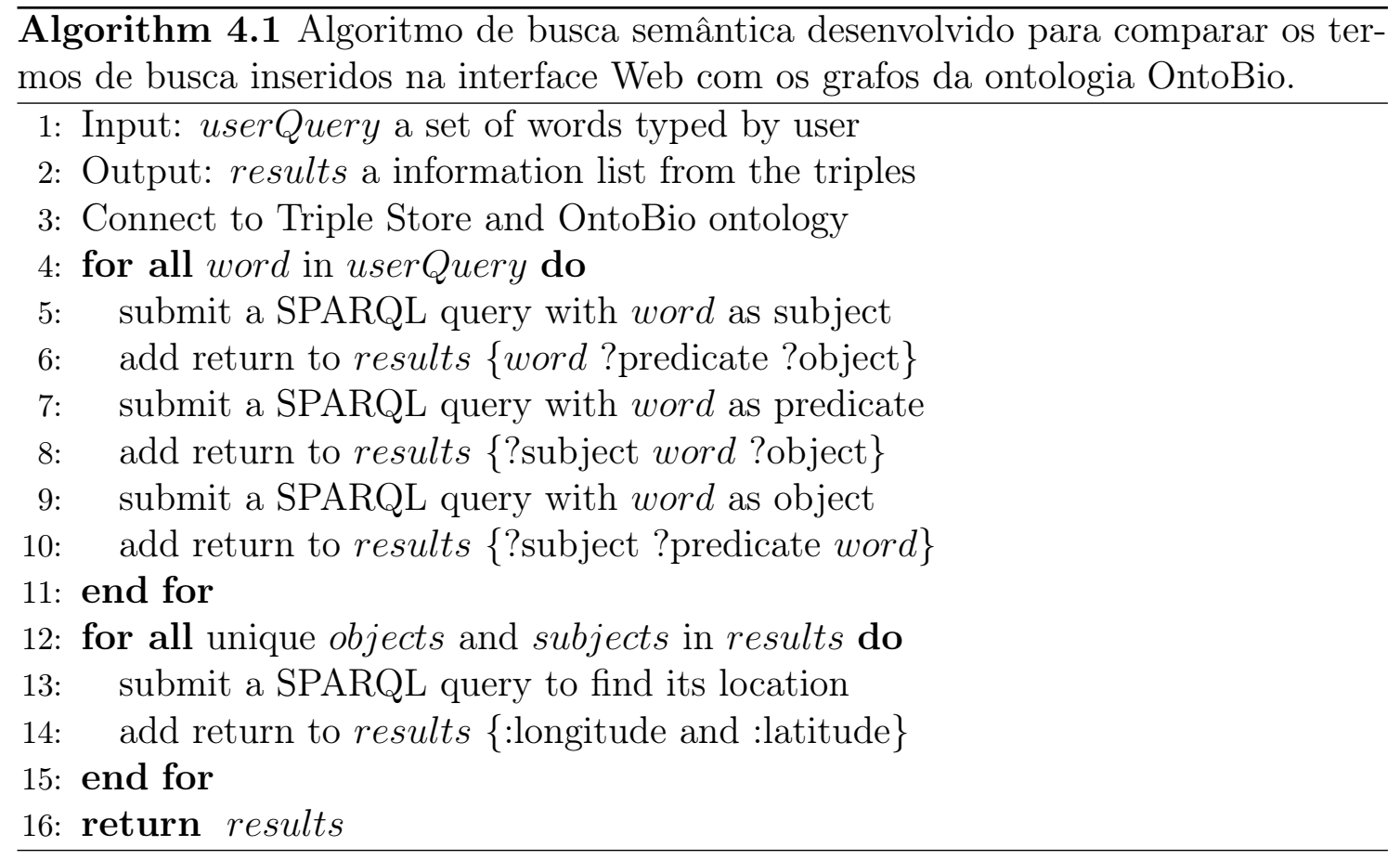

O algoritmo 4.1 de busca semântica trata a ontologia OntoBio como um grafo onde cada recurso é um nó e a ligação entre esses nós representa a existência de uma associação entre os recursos da mesma ontologia.

O objetivo do algoritmo 4.1 de busca semântica é comparar termos inseridos ou sugeridos aos usuários pela interface de busca com o grafo da ontologia OntoBio. Ao digitar termos na interface de busca, um widget do BioPortal (campo de termoseleção) sugere novos termos, com base no dicionário de termos da ontologia OntoBio hospedada no BioPortal. A Figura 4.7 apresenta os termos sugeridos para a consulta Phylum C.

Cada termo da consulta é comparado com os labels das triplas RDF no triple store (na nossa implementação o Virtuoso) mediante consultas SPARQL. Todas as triplas relevantes são recuperadas. Se uma tripla também tem dados de latitude e longitude anexados a ela, esses dados também são recuperadas. Os resultados do 
algoritmo são apresentados ao usuário na interface Web.

Semantic Search for Biodiversity

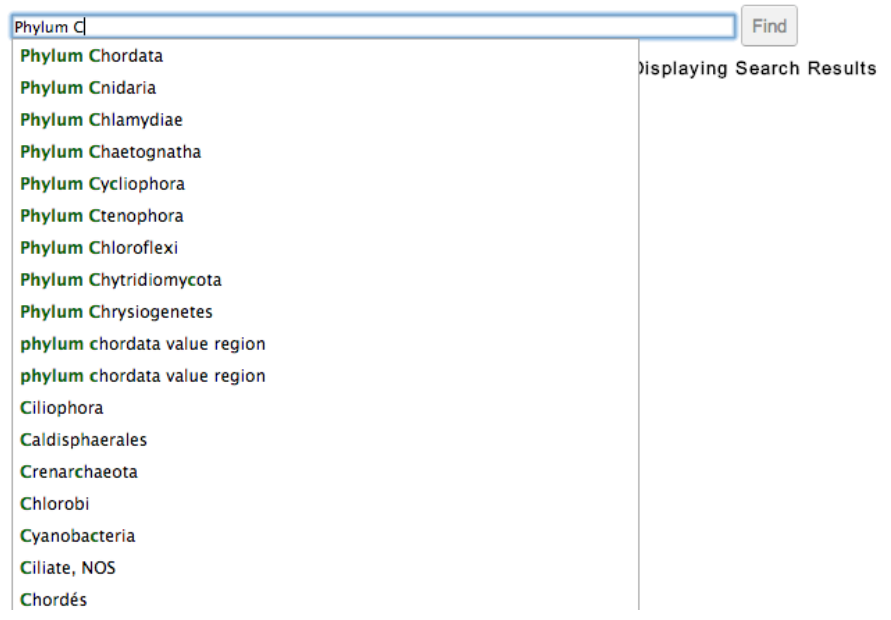

Figura 4.7: Termos sugeridos pela interface de busca para a consulta Phylum C.

As triplas RDF, recuperadas pelo componente de reformulação de consultas, foram geradas na camada de modelo, especificamente pelo mecanismo de mapeamento entre a ontologia OntoBio e as planilhas de dados sobre biodiversidade disponibilizadas pelo INPA e MPEG.

\subsubsection{Camada de Modelo}

A camada de modelo realiza a modelagem da base de conhecimento, ela é responsável por converter os dados do INPA e do MPEG em triplas RDF. Essa conversão é realizada de maneira offline mediante o componente de mapeamento.

\subsubsection{Componente de Mapeamento}

O componente de mapeamento carrega as informações sobre biodiversidade do INPA e do MPEG na camada de dados utilizando duas abordagens:

- Usando um banco de dados relacional e uma ferramenta gráfica para a geração de triplas;

- Usando uma Linguagem de Domínio Específico (DSL) para representar o mapeamento entre objetos RDF e linhas de tabelas de dados contidas em arquivos csv. 
Usando um banco de dados relacional e uma ferramenta gráfica para a geração de triplas $\mathrm{O}$ mecanismo de mapeamento entre um banco de dados e a ontologia OntoBio foi realizado usando o framework Ontop que permite a integração e interpretação de grandes conjuntos de dados através de bancos de dados relacionais e ontologias RDF ou OWL.

O framework Ontop permite a criação de axiomas de mapeamento. Um axioma de mapeamento é definido mediante uma consulta num banco de dados relacional e uma consulta em uma ontologia. A execução dessas consultas é realizada mediante o reasoner Quest e tem como resultado um conjunto de triplas no formato RDF.

Um resumo deste método de mapeamento é ilustrado na Figura 4.8. O Source é definido como uma consulta SQL num banco de dados e já o Target é definido como uma consulta na ontologia. O reasoner Quest executa as consultas e gera um conjunto de triplas no formato RDF.

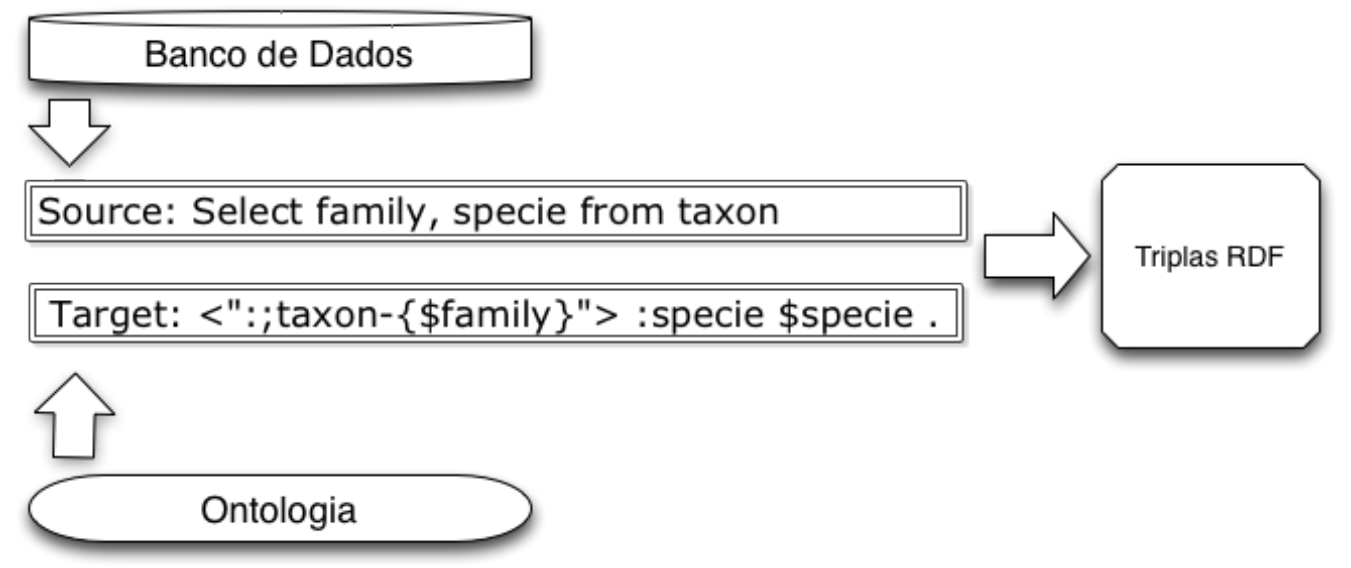

Figura 4.8: Mapeamento usando um banco de dados relacional e a ontologia OntoBio.

Esse método de mapeamento tem a vantagem de ter uma interface gráfica, mas não é adequado quando os dados usados como entrada estão incompletos, tais como os dados incompletos nas coletas sobre biodiversidade. Devido a falta de registros em alguns campos dos dados do INPA, um segundo método, que considera a verificação da consistência dos dados, foi elaborado utilizando uma linguagem de domínio específico (DSL).

Mapeamento usando uma Linguagem de Domínio Específico (DSL) O mapeamento entre grafos RDF e registros de dados contidos em arquivos CSV foi realizado usando-se uma DSL (Domain Specific Language). O algoritmo de mapeamento 4.2 vincula cada registro de arquivos CSV com recursos da ontologia OntoBio e das outras ontologias na Web (usadas no OntoBio), tais como a Geonames, WSG84 
e DBpedia.

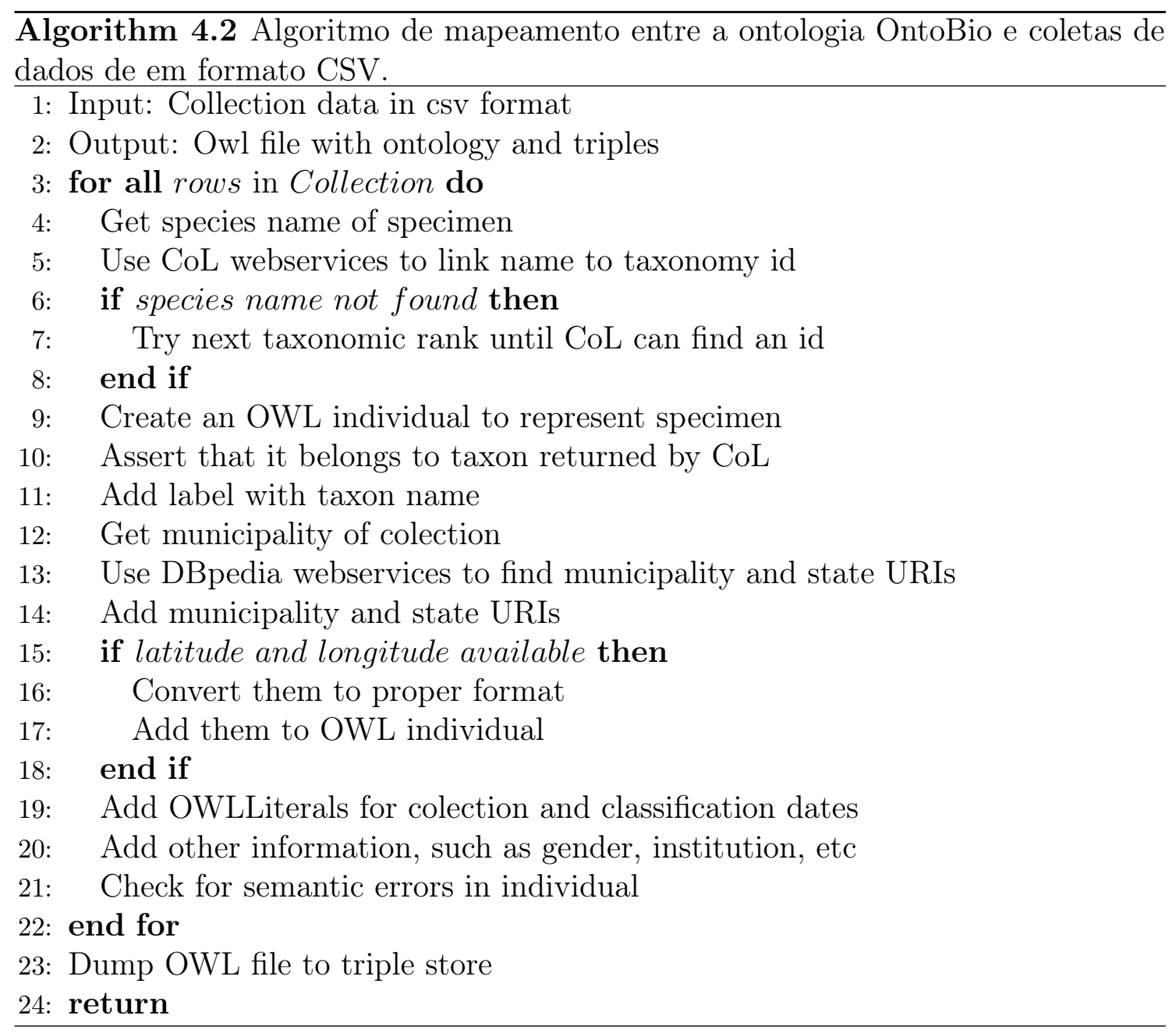

O mecanismo de mapeamento usando uma DSL permite a geração de triplas RDF de maneira muito mais flexível que o framework Ontop. Cada registro de amostra da coleta biológica (linha no arquivo csv) é associada a várias termos da OntoBio e gera várias triplas RDF. Essa associação permite verificar possíveis erros semânticos em cada registro, como, por exemplo, uma espécie de animal declarada como pertencente ao reino vegetal, um sexo inexistente, entre outros. Alguns registros tiveram que ser descartados por terem erros semânticos sérios, outros apenas perderam alguma informação entrada incorretamente. Especialistas do INPA ajudaram a definir que tipos de erros eram inaceitáveis.

O algoritmo de mapeamento é capaz de:

1. Criar uma classe (entidade) representando cada espécie.

2. Automaticamente conectar cada registro de coleta a um nomes de espécie (táxon) na classificação taxonômica do Catalogue of Life $(\mathrm{CoL})^{4}$. Isso é feito

\footnotetext{
${ }^{4}$ http://www.catalogueoflife.org/
} 
utilizando-se os Web Services do site do $\mathrm{CoL}^{5}$. Cada registro da coleção recebe uma URI vinculada a um id de um táxon do site CoL. Se a espécie não for encontrada, um táxon de nivel superior é usado (por exemplo gênero ou família);

3. Criar um link automático para as informações geográficas da DBpedia Linked Data $^{6}$. Por exemplo, o URI na DBpedia do município onde a coleta foi feita é adicionado as informações da coleta;

4. Converter e validar dados das coletas. Por exemplo, o campo data foi inserido utilizando diversos formatos, o algoritmo padroniza os dados para o tipo XSD date (usado por RDF) adequado e verifica erros de semântica, como uma espécie animal, sendo declarado como pertencente ao reino vegetal.

Depois de mapear os dados sobre biodiversidade em triplas RDF, essas triplas são armazenadas no triple store Virtuoso. A camada de modelo interage com a camada de dados para consultar as triplas RDF, a partir das queries inseridas pelo usuário e também mediante consultas SPARQL.

\subsubsection{Camada de dados}

A camada de dados armazena as triplas RDF sobre biodiversidade num repositório de informações, uma triple store (definida na Seção 3.7). As triplas RDF são criadas por meio do componente de mapeamento entre a ontologia de biodiversidade OntoBio e as planilhas disponibilizadas pelo INPA e MPEG. O triple store pode ser consultado por meio do EndPoint SPARQL $L^{7}$.

A arquitetura de busca semântica foi implementada usando a linguagem Java e o Google Web Toolkit ${ }^{8}$ (GWT 2.5.1) no lado do cliente. No lado do servidor, a arquitetura de busca semântica utilizou a linguagem Java e a ferramenta Jena para processar as consultas SPARQL.

Para realizar o mecanismo de mapeamento, o protótipo da arquitetura de busca semântica utilizou a ferramenta Protégé para editar as ontologias, o framework Ontop para criar as triplas RDF e a linguagem Clojure $^{9}$ para a verificação de dados.

Como repositório de triplas RDF a arquitetura de busca semântica utilizou o Virtuoso triple store.

\footnotetext{
${ }^{5}$ http://webservice.catalogueoflife.org/col/webservice

${ }^{6}$ http://wiki.dbpedia.org/OnlineAccess

${ }^{7}$ http://biobak.icmc.usp.br:8890/sparql

${ }^{8}$ http://www.gwtproject.org/download.html

${ }^{9}$ http://clojure.org/
} 
De acordo com o esquema de categorização proposto por Mangold (2007) (explicado no Capítulo 3.2), nossa arquitetura pode ser classificada como Stand-alone, em razão do processo de busca semântica utilizar recursos de classes, propriedades, mapeamentos e instâncias de ontologias de domínio representadas na linguagem OWL 2. A arquitetura proposta neste trabalho armazena os dados num formato estruturado, separado dos mecanismos de busca para que os dados possam ser integrados com outros domínios.

\subsection{Considerações Finais}

A arquitetura para buscas semânticas, apresentada neste capítulo, permite que os dados do INPA e do MPEG sejam organizados e padronizados em um formato único (triplas RDF) por meio de uma ontologia sobre biodiversidade, dessa maneira, ferramentas de busca ou agentes de software podem recuperar automaticamente essas informações.

O papel da ontologia OntoBio dentro da arquitetura proposta é explicitar um vocabulário sobre biodiversidade e fornecer um padrão para o compartilhamento dessas informações. A reutilização de termos de outras ontologias e vocabulários (como o Darwin Core, BFO, ENVO, PATO, WGS84, Geonames e DBpedia) na ontologia OntoBio permite integrar, de forma automática, os dados das coleções do INPA e MPEG com outros grandes conjuntos de dados biológicos, tais como Linked Brazilian Amazon Rainforest (como será mostrado no próximo capítulo).

As ferramentas de mapeamento de dados e ontologias constituem um desafio. Muitas não oferecem os recursos necessários às demandas do domínio, especialmente domínios complexos como biodiversidade. Isso acontece com o Ontop/Protégé, que usa ferramentas gráficas para visualizar as ontologias/mapeamentos, mas que, devido à inexistência de ferramentas de validação, cria a possibilidade da propagação de erros semânticos. O uso de DSLs para mapeamento se torna uma opção atraente, pois permite a validação dos dados de forma transparente ao usuário. Por esse motivo, o algoritmo de mapeamento adotado (apresentado na Seção 4.3.3.1) usa uma DSL. Contudo, tem-se que criar uma DSL nova para cada domínio de aplicação.

No próximo capítulo, alguns cenários especificados por especialistas do INPA serão descritos a fim de exemplificar o uso da arquitetura proposto neste capítulo. Também serão descritos experimentos realizados para demonstrar as vantagens do uso dessa arquitetura. 



\section{Capítulo 5}

\section{Experimentos}

\subsection{Introdução}

A fim de validar a arquitetura de busca semântica apresentada no Capítulo 4, experimentos práticos foram realizados. Em primeiro lugar, cientistas da área de biodiversidade do INPA foram entrevistados para categorizar informações e definir casos de uso, com características e cenários, para identificar as várias tarefas que eles realizam. Esses casos de uso são explicados na Seção 5.2. A partir desses casos de uso, três tipos de experimentos foram criados. A Seção 5.3 descreve experimentos realizados para a criação de um conjunto de triplas RDF sobre biodiversidade. Esse conjunto de triplas foi usado em experimentos sobre buscas semânticas por fontes de informação, os resultados encontrados são apresentados na Seção 5.4. Finalmente, a Seção 5.5 apresenta um experimento sobre interligação de triplas RDF sobre espécimens de plantas do INPA com dados do Linked Data da Floresta Amazônica de Brasil do INPE.

\subsection{Casos de Uso}

Esses casos de uso foram criados com a ajuda de pesquisadores do INPA e da Escola de Engenharia de Piracicaba.

\subsubsection{Caso de Uso: Estudo de impacto ambiental}

PERSONAGEM: João Batista, Engenheiro Ambiental, 37 anos, trabalha para uma empresa de consultoria ambiental. Ele está fazendo um estudo de impacto ambiental para a construção de uma estrada vicinal que passa num charco. 
META: Determinar se as espécies catalogadas no charco são endêmicos ou cosmopolitas.

MOTIVAÇÃO: Se um habitat contém espécies endêmicas é necessária maior proteção contra sua deterioração devido a construção da estrada. O engenheiro João, trabalhando de seu escritório, precisa determinar se as espécies catalogadas em um habitat, do tipo charco, são de espécies endêmicas ou cosmopolitas. Para isso ele tem que realizar as seguintes tarefas:

TAREFAS :

1. Descobrir em todas as coleções disponíveis os registros referentes a esse espécime;

2. Descobrir a localização geográfica de cada coleta;

3. Descobrir o habitat onde foi feita a coleta;

4. Determinar se a distribuição geográfica do habitat caracteriza uma espécie endêmica ou não, segundo critérios técnicos estabelecidos.

CARACTERÍSTICAS NECESSÁRIAS DA FERRAMENTA :

- Como o habitat charco fica na região amazônica, João usa a ferramenta de busca semântica do INPA-USP para buscar essas informações. A razão do uso dessa ferramenta é que a partir dela João conseguirá especificar o nome da espécie de forma flexível, usando o nome da espécie ou qualquer nível taxonômico mais geral (filo, gênero, etc.) sem ter que se preocupar se a coleção original usou esse nível em particular.

- João pode obter a localização geográfica no formato mais conveniente para ele, por exemplo, as coordenadas de latitude e longitude (com informação de precisão) ou município, independentemente do modo que a coleção tem essa informação registrada.

- João também pode descobrir que outros espécimens do mesmo gênero ou outro nível taxonômico foram encontrados na mesma região do estudo, num determinado raio em volta dela, no mesmo habitat ou uma combinação dos dois modos.

João ficou satisfeito pois seu trabalho pôde ser feito de forma muito mais rápida e simples. Ele não precisa mais procurar por dezenas de descrições de habitat para 
classificá-los de acordo com o tipo que ele procura. Além disso, João não precisa mais se preocupar se não souber exatamente a espécie de alguns dos espécimens catalogados

\subsubsection{Caso de Uso: Classificação de áreas degradadas}

PERSONAGEM: Ana Silva, Bióloga, 32 anos, trabalha para uma ONG ambiental na Amazônia. Ela está mapeando áreas dos municípios do Pará a partir do grau de degradação ambiental dessas áreas.

META: Determinar se uma área é degradada a partir da proporção de desmatamento dessa área e dos espécimes coletados na mesma.

MOTIVAÇÃO: A incidência ou não de algumas espécies de plantas ou animais em uma área pode servir de marcador biológico ou bioindicador que indica o grau de degradação ou conservação de um habitat.

TAREFAS :

A bióloga Ana, trabalhando de seu escritório em Belém, tem que determinar o grau de desmatamento de uma área e cruzar essa informação com os espécimes catalogados em coleções que vieram dessa área (e que podem ser usados como bioindicadores).

CARACTERÍSTICAS NECESSÁRIAS DA FERRAMENTA:

- Ana recorre à ferramenta de busca semântica do INPA-USP para buscar informações ambientais como, por exemplo, índice de desmatamento de um local. A ferramenta de busca semântica cruza as informações de diferentes fontes (ou seja Linked Open Data sources) disponíveis na Web semântica, recupera e exibe as informações para Ana. O uso dessa ferramenta se faz necessário devido ao fato de coleções de espécimens não disponibilizarem informações ambientais, como o índice de desmatamento

- Usando o dataset Endpoint SPARQL "Linked Brazilian Amazon Rain Forest Data", que fornece informações sobre desmatamento em quadrados de 25 quilômetros, a ferramenta de busca semântica do INPA-USP consegue associar índices de desmatamento às áreas que a Ana está interessada. Além disso, ao mesmo tempo é possível retornar os registros dos espécimens das espécies encontrados na mesma área.

- Ana também pode especificar o nome das espécies bioindicadoras de forma flexível, usando o nome da espécie ou qualquer nível taxonômico mais geral 
(filo, gênero, etc) sem ter que se preocupar se a coleção original usou esse nível em particular (alguns bioindicadores podem usar indivíduos da mesma espécie, família ou ordem). Também é possível limitar os habitats de interesse (uma espécie pode ser bioindicadora se aparece num habitat mas não em outro) de maneira flexível, por exemplo, ela pode especificar ambiente aquático sem especificar se o local é um rio, igarapé, lago, etc.

- Ana não precisou fazer manualmente o mapeamento dos espécimens para as áreas desmatadas, nem procurar por descrições de habitats para classificá-los.

Ana fica satisfeita pois seu trabalho pode ser feito a partir do seu escritório, seus recursos orçamentários são limitados e ela não dispõe de uma equipe para percorrer o estado para coletar as informações.

\subsection{Experimento: Criação de triplas de insetos, pei- xes e mamíferos}

O primeiro experimento tem por meta executar e testar o mecanismo de mapeamento entre a ontologia de biodiversidade OntoBio e as coleções de insetos, peixes e mamíferos do INPA. O objetivo é criar um conjunto de triplas (no formato RDF) úteis para realizar as buscas semânticas.

Inicialmente os dados sobre insetos, peixes e mamíferos, num total de 21,107 (Agosto, 2013) registros, disponibilizados pelo INPA e MPEG no site speciesLink, foram analisados e armazenados no banco de dados PostgresSQL. Em seguida, o framework Ontop, explicado na Seção 4.3.1, foi utilizado para vincular os termos da ontologia OntoBio ao conteúdo desse banco de dados, por meio de axiomas de mapeamento. Esses axiomas contém consultas SQL e consultas SPARQL que filtram os dados no banco de dados PostgresSQL e na ontologia OntoBio.

O Apêndice A apresenta os axiomas de mapeamento utilizados neste trabalho, um total 19 axiomas. A partir das execuções desses axiomas, criaram-se triplas sobre biodiversidade no formato RDF num total de 401,000 triplas. Essas triplas foram armazenadas no triple store Virtuoso para que o sistema de busca semântica recupere informações sobre biodiversidade.

A Figura 5.1 ilustra um exemplo das triplas RDF para o Genus Creagrutus. O Genus-Creagrutus (sujeito) tem a propriedade subkindOfEspGen que relaciona quatro espécies (objetos) Specie-cochui, Specie-beni, Specie-phasma e Specie anary. Além disso, é possível observar que a família Characidae (sujeito) tem a propriedade 


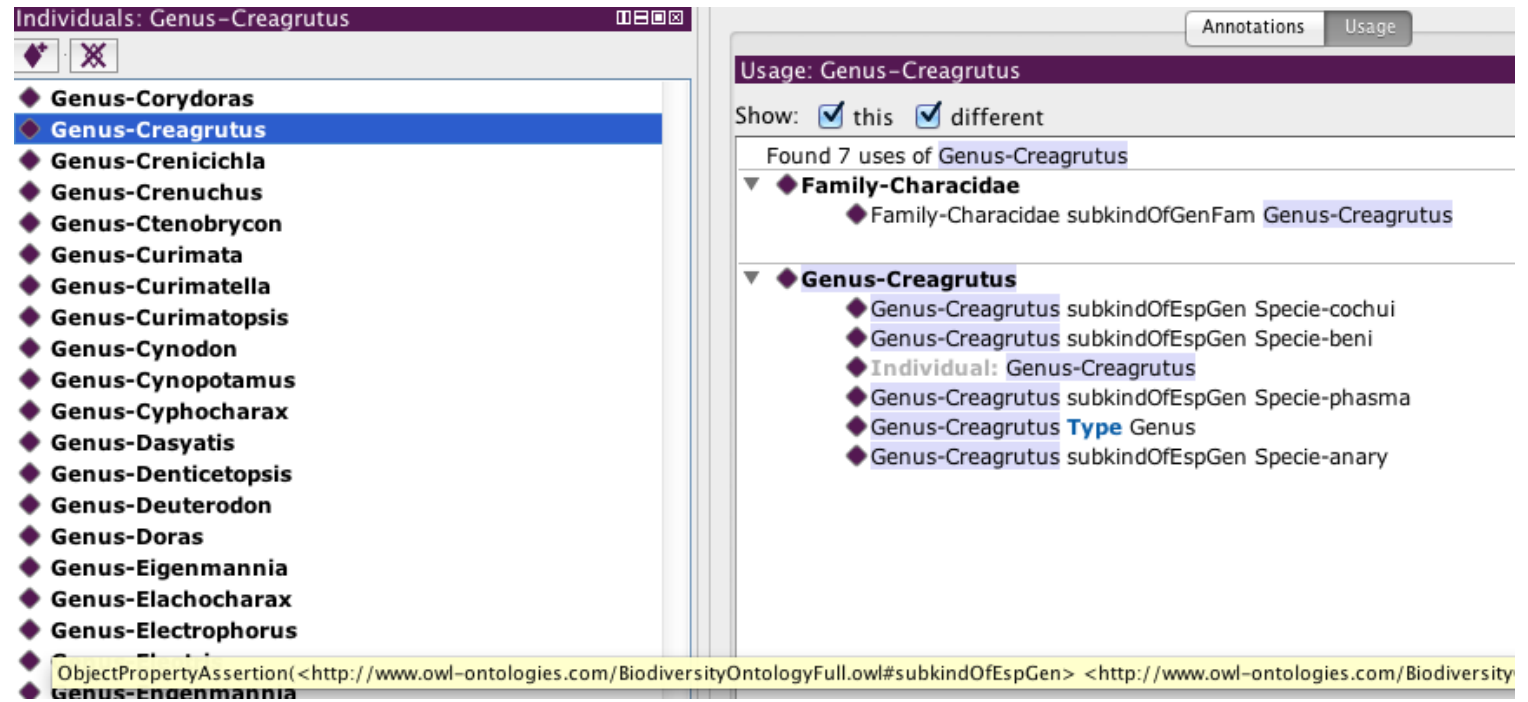

Figura 5.1: Exemplo de triplas do Genus-Creagrutus da ontologia OntoBio

subkindofGenFam que relaciona o Genus-Creagrutus (objeto). Essas relações entre Família e Gênero são conhecidas pelo reasoner devido a forma que foram modeladas na ontologia OntoBio.

Por fim, vale destacar que todas as triplas RDF criadas neste experimento serão utilizadas pelo sistema de Busca Semântica (que será analisado na próxima seção).

\subsection{Experimento: Avaliação das Buscas Semântica e por Palavras Chave}

Diversas avaliações de recuperação de informação encontradas na literatura utilizam com frequência as métricas (precisão, revocação e F1) provenientes da área de bibliometria, que é encarregada de estudar e aplicar métodos matemáticos e estatísticos em documentos (Bailey et al., 2005).

A revocação mede a habilidade do sistema em recuperar os documentos mais relevantes para o usuário, ou seja, mede a quantidade de itens relevantes que foram recuperados dentre os existentes na base de dados. Já a precisão mede a habilidade do sistema em manter os documentos irrelevantes fora do resultado de uma consulta.

A precisão é capaz de indicar o trabalho que o usuário teria para analisar cada documento em uma determinada busca.

A medida F1 pode ser interpretada como uma media ponderada da precisão e revocação, onde uma pontuação F1 atinge o seu melhor valor em 1 e pior resultado em 0. Essas métricas podem ser calculadas pelas seguintes equações: 


$$
\begin{gathered}
\text { Precisão }=\frac{\text { DocumentosRelevantesRetornados }}{\text { DocumentosRetornados }} \\
\text { Revocação }=\frac{\text { DocumentosRelevantesRetornados }}{\text { DocumentosRelevantes }} \\
F 1=\frac{2 .(\text { Precisão } * \text { Revocação) }}{(\text { Precisão }+ \text { Revocação }}
\end{gathered}
$$

O cálculo dessas métricas requer que um especialista identifique, dentro da coleção de documentos, quais são relevantes e atendem uma determinada necessidade de informação. Uma coleção de referência, muito utilizada em experimentos para avaliação e comparação de abordagens de recuperação de informação, é o Text Retrieval Conference (TREC) ${ }^{1}$. Essa coleção contém as descrições das necessidades de informação associadas a um tópico e o julgamento de relevância em cada uma delas (Baeza-Yates and Ribeiro-Neto, 2011).

Uma busca bibliográfica sobre coleções de referência não encontrou na literatura uma coleção de referência, como o TREC, aplicada a abordagem de busca semântica ou ontologias relacionadas com a área de biodiversidade. Assim, para avaliar a nossa arquitetura de busca semântica (em comparação ao sistema de busca por palavra-chave) é necessário que especialistas em biodiversidade do INPA ou de outras instituições indiquem uma coleção de referência, que contenha uma listagem de consultas para testes, e uma listagem de documentos relevantes para cada consulta.

Para cada caso de uso, explicado na Seção 5.2, especialistas em biodiversidade identificaram um conjunto de consultas e uma lista de resultados relevantes. Esse processo de feedback de informações é comumente conhecido na literatura como feedback de relevância (Salton, 1971), isso acontece quando especialistas numa determinada área fornecem informações sobre os documentos relevantes para uma consulta (Baeza-Yates and Ribeiro-Neto, 2011).

Vale ressaltar que o feedback de relevância permitiu que especialistas em biodiversidade criassem uma coleção de referência com consultas relacionadas a cada caso de uso e documentos relevantes para cada consulta. Tal coleção comporta uma listagem de mais de 200 documentos, uma listagem de consultas para testes e uma listagem de documentos relevantes a cada consulta. Essa coleção é uma das contribuições

\footnotetext{
${ }^{1}$ http://trec.nist.gov/
} 
deste trabalho (o Apêndice B apresenta a coleção de referência completa).

A Tabela 5.1 mostra alguns exemplos de tarefas selecionadas de cada caso de uso.

Tabela 5.1: Exemplos de tarefas e consultas selecionadas de cada caso de uso .

\begin{tabular}{|l||l|}
\hline Tarefas de Usuário & Consultas \\
\hline \hline - Descobrir o habitat onde foi feita a coleta. & $\begin{array}{l}\text { • Potamorrhapis } \\
\text { guianensis }\end{array}$ \\
- Descobrir a localização geográfica de cada coleta. & $\bullet$ fish brasiliensis \\
- Determinar se a distribuição geográfica e por \\
$\begin{array}{l}\text { habitat caracteriza uma espécie endêmica ou não, } \\
\text { segundo critérios técnicos estabelecidos pelos } \\
\text { especialistas. }\end{array}$ & $\begin{array}{l}\text { - fish corydoras } \\
\text { splendes }\end{array}$ \\
$\begin{array}{l}\text { - Diferenciar nome cientifico de espécies. Por } \\
\text { exemplo, existem insetos que tem o mesmo nome } \\
\text { científico (gênero) que peixes. }\end{array}$ & $\begin{array}{l}\text { gracilis } \\
\text { gemigrammus } \\
\text { guyanensis }\end{array}$ \\
& $\bullet$ gnathocharax \\
& steindachneri \\
\hline
\end{tabular}

É importante destacar que, como agora possuímos uma coleção de referência fornecida por especialistas em biodiversidade, podemos adotar a estratégia de avaliar de forma quantitativa o resultado de cada consulta em dois sistemas: no protótipo da nossa arquitetura para busca semântica e no sistema de busca por palavra-chave do SpeciesLink. O SpeciesLink tem um sistema de busca padrão (baseado em palavras chaves) para dados sobre biodiversidade, explicado na Seção 2.3.1. Ambos sistemas utilizam os mesmos dados das coletas de insetos, peixes e mamíferos disponibilizados pelo INPA (lembrando que o conjunto de dados csv usado para gerar as triplas RDF da seção anterior veio justamente do SpeciesLink).

A avaliação quantitativa requer a definição de variáveis numéricas que tem por objetivo verificar o quanto uma abordagem proposta é melhor que outra (Wainer, 2007). Assim, a Tabela 5.2 mostra a configuração inicial do experimento. 
Tabela 5.2: Configuração inicial para realizar a avaliação de sistemas de busca .

\begin{tabular}{|l||l||l|}
\hline Variáveis de Controle & $\begin{array}{l}\text { Variável } \\
\text { Independentes }\end{array}$ & $\begin{array}{l}\text { Variáveis } \\
\text { Dependentes }\end{array}$ \\
\hline \hline Número de Entidades da & Consultas: 28 & Precisão \\
ontologia: 6311 & & Revocação \\
Número de Classes: 200 & F1 \\
Número de Indivíduos: 6021 & & \\
Número de Propriedades: 90 & & \\
Sistemas de busca: 2 & & \\
\hline
\end{tabular}

O desempenho de um sistema de buscas é então avaliado de acordo com a sua capacidade em recuperar o maior número de itens relevantes, ao mesmo tempo em que filtra ao máximo os itens irrelevantes. Em cima dessa estratégia é que as métricas e variáveis são aplicadas. Como variáveis de controle estão definidas a quantidade de entidades da ontologia OntoBio em total 6311 entidades divididas em 200 classes, 6021 indivíduos e 90 propriedades. Como variável independente temos, a quantidades de consultas realizadas nos dois sistemas, que foram em total 28, e como variáveis dependentes estão definidas as medidas de precisão, revocação e F1.

A Tabela 5.3 mostra o resultado do cálculo da precisão e revocação para as 28 consultas, considerando a quantidade de itens retornados (conhecida como top $\mathrm{k}$ ), no caso $\mathrm{k}=10$. Na Tabela 5.3, a coluna "Id" define o código de cada consulta, a coluna "ColRef" indica a quantidade de documentos relevantes indicados na coleção de referência e a coluna "DR" indica os documentos relevantes recuperados para cada consulta. 
Tabela 5.3: Resultado da Precisão e Revocação de Buscas por Palavra-Chave e Buscas Semânticas: "Id" define o código de cada consulta; "ColRef" indica a quantidade de documentos relevantes indicados na coleção de referência; "DR" indica os documentos relevantes recuperados para cada consulta

\begin{tabular}{|c|c|c|c|c|c|c|c|}
\hline \multirow{2}{*}{ Id } & \multirow{2}{*}{ ColRef } & \multicolumn{3}{|c|}{ Busca por Palavra-Chave } & \multicolumn{3}{|c|}{ Busca Semântica } \\
\hline & & DR & Precisão & Revocação & DR & Precisão & Revocação \\
\hline $\mathrm{q} 1$ & 11 & 6 & 0.66 & 0.54 & 7 & 0.70 & 0.63 \\
\hline q2 & 11 & 6 & 0.66 & 0.54 & 8 & 0.80 & 0.72 \\
\hline q3 & 11 & 5 & 0.55 & 0.45 & 7 & 0.70 & 0.63 \\
\hline $\mathrm{q} 4$ & 11 & 4 & 0.44 & 0.36 & 7 & 0.70 & 0.63 \\
\hline q5 & 11 & 4 & 0.44 & 0.36 & 6 & 0.60 & 0.54 \\
\hline q6 & 12 & 8 & 0.79 & 0.66 & 9 & 0.90 & 0.75 \\
\hline q7 & 11 & 3 & 0.33 & 0.27 & 7 & 0.70 & 0.63 \\
\hline q8 & 11 & 4 & 0.33 & 0.36 & 8 & 0.80 & 0.72 \\
\hline q9 & 11 & 3 & 0.33 & 0.27 & 8 & 0.80 & 0.72 \\
\hline q10 & 11 & 3 & 0.33 & 0.27 & 7 & 0.70 & 0.63 \\
\hline q11 & 10 & 4 & 0.44 & 0.4 & 6 & 0.60 & 0.6 \\
\hline q12 & 11 & 3 & 0.33 & 0.27 & 6 & 0.60 & 0.54 \\
\hline q13 & 11 & 4 & 0.44 & 0.36 & 5 & 0.50 & 0.45 \\
\hline q14 & 10 & 6 & 0.66 & 0.6 & 6 & 0.60 & 0.6 \\
\hline q15 & 11 & 6 & 0.66 & 0.54 & 7 & 0.70 & 0.63 \\
\hline q16 & 11 & 5 & 0.55 & 0.45 & 7 & 0.70 & 0.63 \\
\hline q17 & 12 & 8 & 0.88 & 0.66 & 7 & 0.70 & 0.58 \\
\hline q18 & 11 & 7 & 0.77 & 0.63 & 10 & 1.00 & 0.90 \\
\hline q19 & 11 & 3 & 0.33 & 0.27 & 9 & 0.90 & 0.81 \\
\hline q20 & 11 & 6 & 0.66 & 0.54 & 8 & 0.80 & 0.72 \\
\hline $\mathrm{q} 21$ & 11 & 4 & 0.44 & 0.36 & 8 & 0.80 & 0.72 \\
\hline $\mathrm{q} 22$ & 11 & 4 & 0.44 & 0.36 & 8 & 0.80 & 0.72 \\
\hline q23 & 10 & 3 & 0.33 & 0.3 & 7 & 0.70 & 0.7 \\
\hline q24 & 11 & 4 & 0.44 & 0.36 & 8 & 0.80 & 0.72 \\
\hline $\mathrm{q} 25$ & 12 & 3 & 0.33 & 0.25 & 7 & 0.70 & 0.58 \\
\hline $\mathrm{q} 26$ & 11 & 6 & 0.66 & 0.54 & 8 & 0.80 & 0.72 \\
\hline $\mathrm{q} 27$ & 13 & 3 & 0.33 & 0.23 & 8 & 0.80 & 0.61 \\
\hline \multirow[t]{2}{*}{$\mathrm{q} 28$} & 12 & 4 & 0.44 & 0.33 & 8 & 0.80 & 0.66 \\
\hline & 311 & 129 & 0.46 & 0.41 & 207 & 0.73 & 0.66 \\
\hline
\end{tabular}

Ao analisar as 28 consultas referentes aos casos de uso, é possível observar que a busca semântica tem maior número de documentos relevantes recuperados, no total 207, do que a busca por palavra-chave, no total 129. A busca semântica tem a precisão mais alta, em média 27,8\% melhor do que a precisão da busca por palavrachave. Já a revocação da busca semântica foi 25,1\% melhor (em média) que a da busca por palavra-chave.

Uma forma de definir uma media harmônica entre a precisão e a revocacão da 
Tabela 5.3 é através da medida F1. A medida F1 pode variar entre o pior resultado (0) e o melhor resultado (1), ou seja, quanto mais próximo de 1, maior é a precisão e a revocação da busca pois significa que houve maior eficácia e exatidão em retornar os itens considerados relevantes. A sua importância é que a F1 pode medir a qualidade geral de um resultado de busca em uma medida.

Assim, utilizou-se a medida F1 para obter uma melhor comparação dos resultados de precisão e revocação das consultas em ambos sistemas, conforme apresentado no gráfico da Figura 5.2.

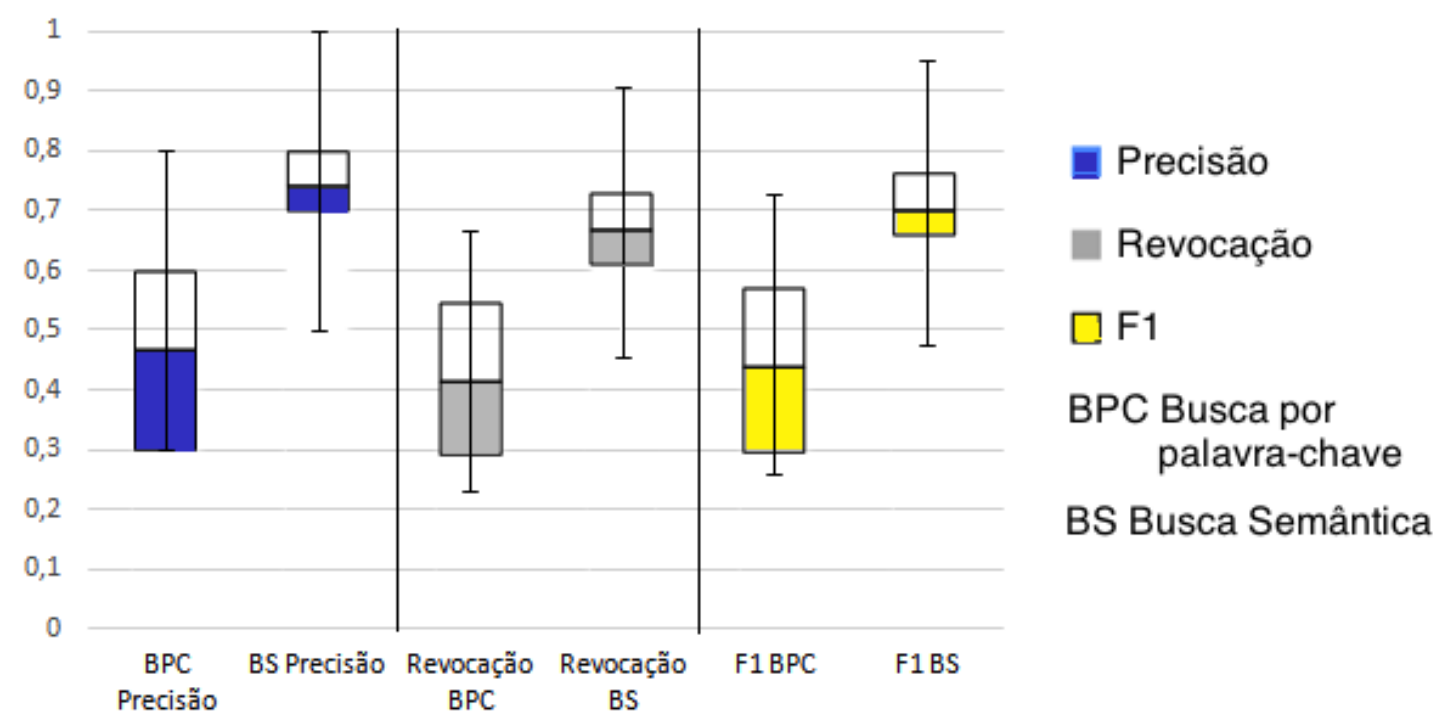

Figura 5.2: Comparação das Medidas de Precisão, Revocação e F1 entre busca por palavrachave e busca semântica.

Pode-se observar que a abordagem de busca semântica obteve melhores resultados na medida F1, no total $26.4 \%$ melhor do que a busca por palavra-chave. A comparação indica que houve maior eficácia e exatidão no sistema de busca semântica pois ele tem uma maior quantidade de itens considerados relevantes.

Além da medida F1 apresentada na Figura 5.2, foi usado o teste T-Student para avaliar estatisticamente os resultados da precisão e revocação e verificado se os valores evidenciados nos resultados informavam qual dos dois sistemas era estatisticamente melhor. Esse teste gera uma probabilidade $(p)$ que indica o valor da significância estatística entre os dois conjuntos, se $p$ é menor que 0,05 indica que existe uma significância estatística melhor nesse conjunto de dados, se $p$ é igual ou superior a 0,05 indica que não existe nenhuma significância estatística entre os conjuntos de dados. Nós aplicamos o teste T-Student aos conjuntos de precisão e revocação de buscas semânticas e buscas por palavra-chave. O teste T-Student mostrou que a busca semântica tem uma melhor significância estatística na preci- 
são com $\mathrm{p}=0.0001$ e na revocação com $\mathrm{p}=0.0002$ em comparação com o sistema de busca por palavra-chave. Os resultados do teste T-Student indicam que a utilização de busca semântica torna a atividade de busca por fontes de informação mais eficiente ao utilizar ontologias e vocabulários da Web Semântica do que a busca por palavra-chave.

Outra medida muito utilizada para mostrar os resultados de desempenho de um sistema é a média pde recisão interpolada em 11 pontos. Ela consiste num conjunto de 11 pontos de desempenho de um sistema variando de 0 a 1 por décimos de documentos. A Tabela 5.4 mostra a média da interpolação da precisão das 28 consultas em ambos os sistemas.

Tabela 5.4: Média da interpolação da precisão de 28 consultas usando Busca por Palavras e Busca Semântica

\begin{tabular}{|c||c||c|}
\hline \multirow{2}{*}{ Revocação } & \multicolumn{2}{c|}{$\begin{array}{c}\text { Média da interpolação da } \\
\text { precisão de 28 consultas }\end{array}$} \\
\cline { 2 - 3 } & $\begin{array}{c}\text { Busca por } \\
\text { Palavra } \\
\text { Chave }\end{array}$ & $\begin{array}{c}\text { Busca } \\
\text { Semântica }\end{array}$ \\
\hline \hline 0 & 0.98 & 1 \\
\hline \hline 0.1 & 0.97 & 1 \\
\hline \hline 0.2 & 0.83 & 0.91 \\
\hline \hline 0.3 & 0.77 & 0.85 \\
\hline \hline 0.4 & 0.49 & 0.81 \\
\hline \hline 0.5 & 0.32 & 0.79 \\
\hline \hline 0.6 & 0.26 & 0.77 \\
\hline \hline 0.7 & 0.13 & 0.67 \\
\hline \hline 0.8 & 0.09 & 0.40 \\
\hline \hline 0.9 & 0 & 0.10 \\
\hline 1 & 0 & 0.03 \\
\hline
\end{tabular}

A interpolação em 11 pontos ajuda na comparação entre os resultados conseguidos pelos sistema de busca semântica e de busca por palavras-chave. Ela tem como principal objetivo comparar a forma como o sistema está mudando a medida em que consultas são submetidas a ele. A Figura 5.3 ilustra a interpolação de 11 pontos para a avaliação realizada nos dois sistemas de busca. 


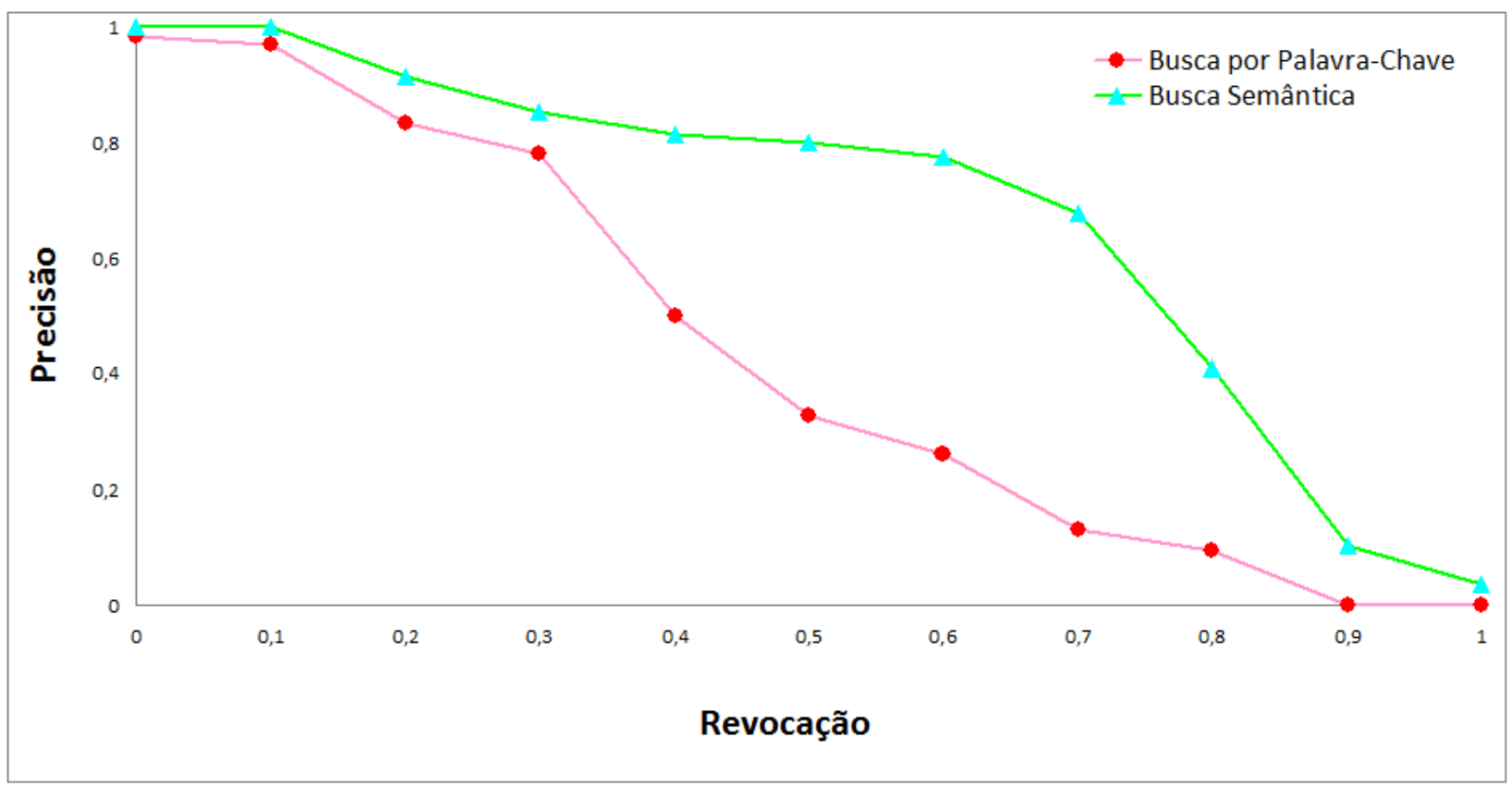

Figura 5.3: Média de precisão interpolada em 11 pontos considerando 28 consultas e usando dois sistemas de busca: busca por palavra-chave e busca semântica

Ao analisar a média de precisão interpolada em 11 pontos, pode-se observar que a busca semântica alcançou a mais alta precisão nos cenários descritos pelos especialistas em biodiversidade, isso porque conseguiu mais informações relevantes.

O sistema de busca semântica reconhece a palavra filo (phylum), pois a OntoBio contém elementos de uma taxonomia sobre biodiversidade, isso permite que a busca semântica percorra toda a ontologia e retorne os espécimes com base em qualquer nível taxonômico (reino, filo, classe, ordem, família, gênero e espécie). Na próxima seção, essa característica é explorada quando a busca semântica retorna 19.887 registros de plantas como resultado da consulta sobre o filo Tracheophyta (mesmo que na verdade os registros usados não tivessem a classificação por filo).

\subsection{Experimento: Linked Data da floresta Amazô- nica}

Uma das vantagens da Web Semântica é a possibilidade de interligar recursos por meio de links semânticos, permitindo aos usuários uma navegação intuitiva, seguindo links para cada recurso (Berners-Lee et al., 2001). Para isso, é preciso que os dados estejam disponíveis na Web em formatos padrões como RDF, OWL e XML, acessíveis e gerenciáveis por meio de EndPoints SPARQL.

Devido a necessidade da criação de padrões para a publicação de dados na Web e 
do modo como eles devem se interligar, surgiu dentro da Web Semântica o conceito de Linked Open Data (LOD) ou dados abertos ligados. LOD refere-se ao conjunto de melhores práticas para a publicação de dados estruturados na Web (Bizer and et al., 2010).

Com o objetivo de utilizar a tecnologia de $L O D$, as triplas RDF referentes as plantas do INPA foram interligadas com o Linked Data sobre a Floresta Amazônica do Brasil disponível em (Kauppinen and de Espindola, 2011).

Inicialmente, os registros de coletas de plantas do estado do Amazonas (108.220 registros) disponibilizados pelo INPA no site SpeciesLink foram coletados. Em seguida, usando o algoritmo de mapeamento usando uma DSL (explicado na Seção 4.3.3.1) mapeamos todos os registros de plantas para a ontologia OntoBio no formato de triplas RDF. Essas triplas sobre plantas do INPA foram armazenadas e colocadas à disposição da comunidade no triple store Virtuoso ${ }^{2}$.

O Linked Data sobre a Floresta Amazônica do Brasil contem informações sobre o desmatamento no estado de Amazonas no formato RDF (provenientes do INPE), especificamente 8250 triplas (células), cada uma do tamanho de $25 \mathrm{~km}$ por $25 \mathrm{~km}$. Com a ajuda do software R (uma linguagem DSL popular entre especialistas em biodiversidade) e consultas SPARQL criamos um script para realizar as seguintes tarefas:

1. Ler todas as ocorrências de plantas do filo Tracheophyta que tenham informações de latitude e longitude (19.887 registros) do conjunto de dados do INPA (estado do Amazonas) e vincular com a ontologia DBpedia, obtendo os nomes e a localização geográfica das municipalidades do estado do Amazonas. A Listagem 2 ilustra uma consulta SPARQL para selecionar todas as ocorrências da planta filo Tracheophyta.

\footnotetext{
${ }^{2}$ http://143.107.231.220:8890/sparql
} 
$\overline{\text { Listagem } 2 \text { Consulta SPARQL para selecionar todas as ocorrências de plantas do }}$ filo Tracheophyta.

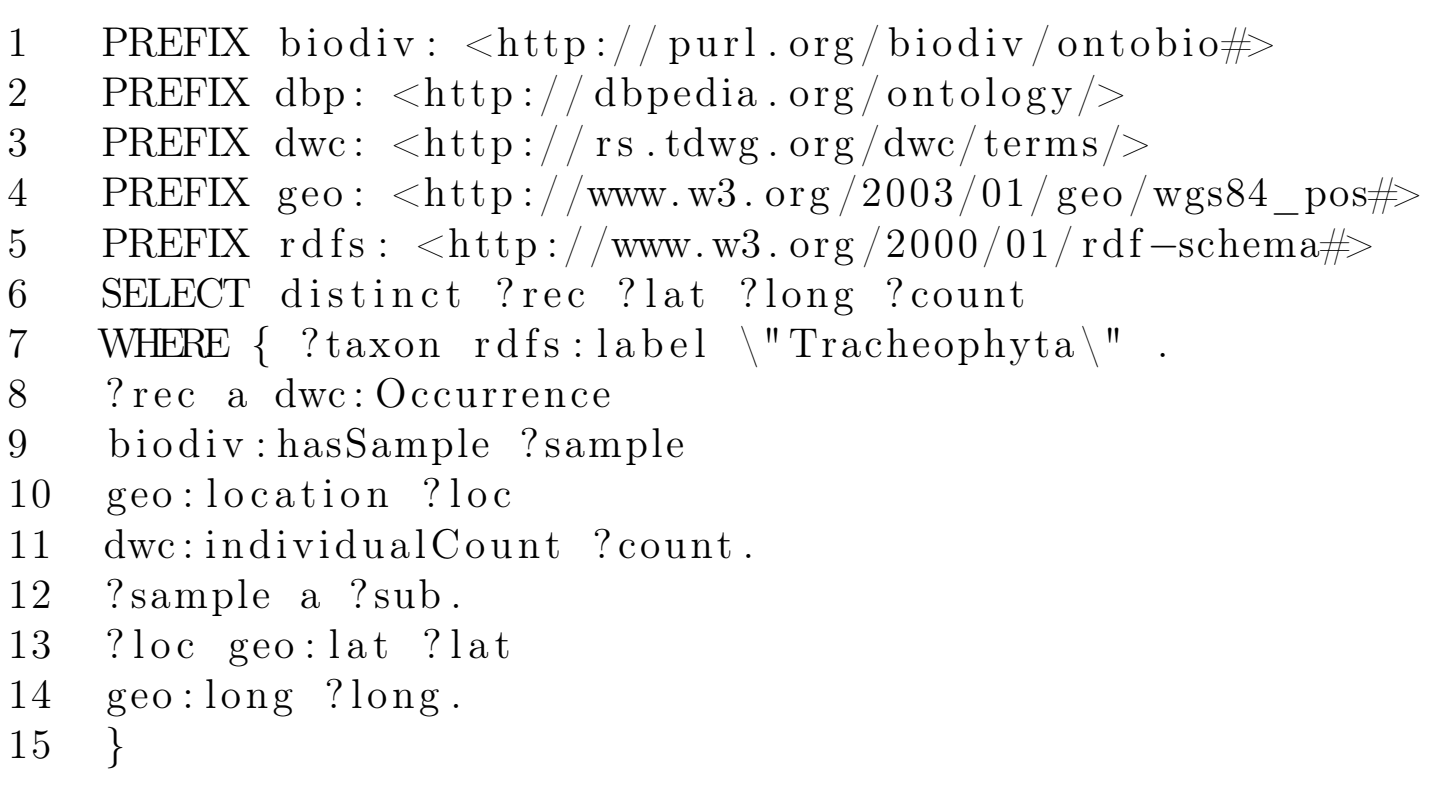

2. Ler todas as células do estado de Amazonas com a porcentagem de desmatamento de cada uma (do Linked Data sobre a Floresta Amazônica). A Listagem 3 ilustra a consulta SPARQL para selecionar as células de uma coleta de dados vinculadas com informação geográfica da DBpedia.

$\overline{\text { Listagem } 3 \text { Consulta SPARQL para selecionar as células e polígonos de uma coleta }}$ de dados vinculados com informação geográfica da DBpedia

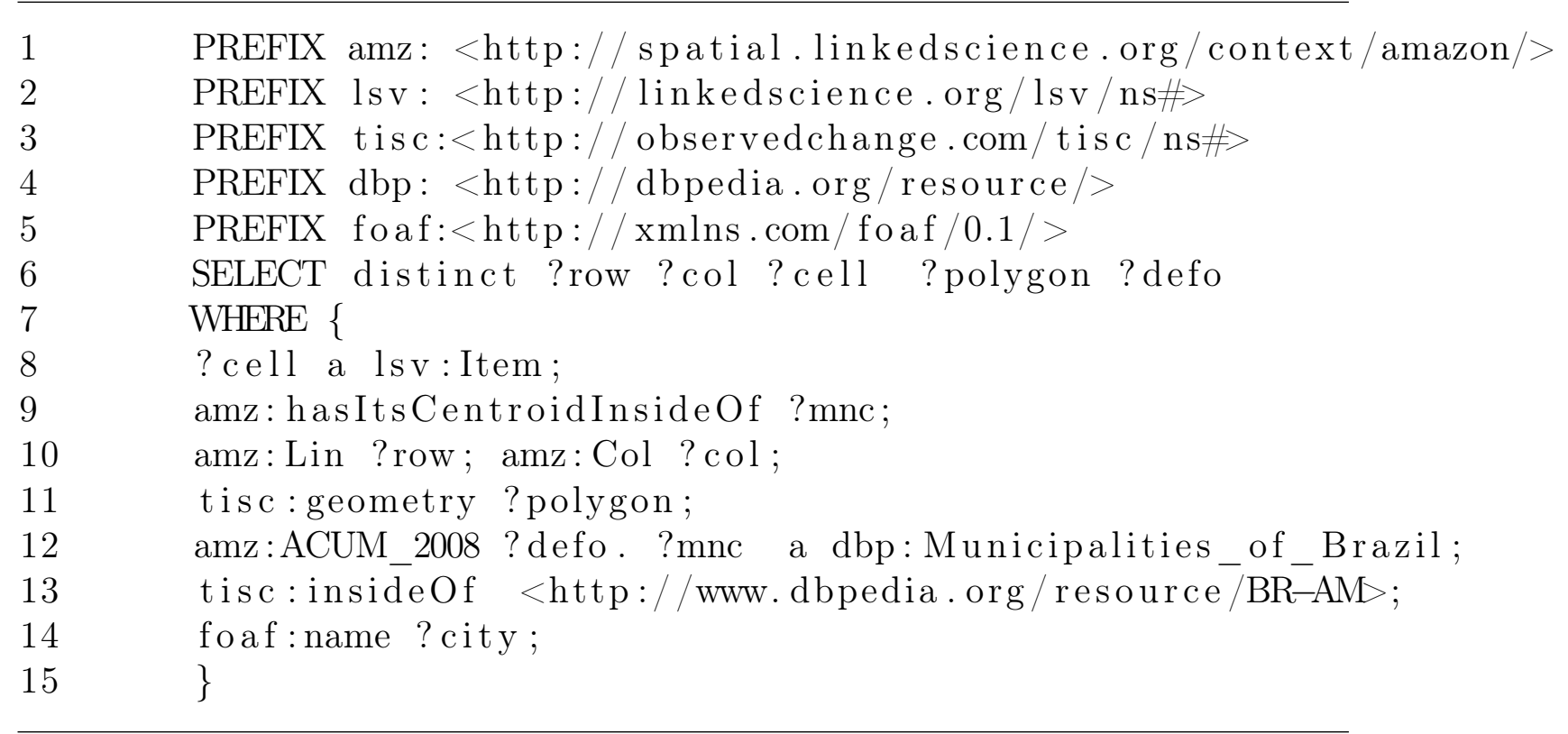

A consulta SPARQL mostrada, na Listagem 3, seleciona as células e polígonos de uma coleta de dados. As cinco primeiras linhas são utilizadas para definir 
prefixos, de forma a tornar a consulta mais compacta. O prefixo amz e lsv contém informações sobre as células vinculadas ao desmatamento no estado de Amazonas. O prefixo $d p b$ da DBpedia contém informações geográficas de municipalidades.

Na sexta linha é definido o resultado da consulta das variáveis que contém informações relacionadas a cada célula de desmatamento: linha ?row, coluna ?col, célula ?cell, polígono ?polygon, taxa de desmatamentos ?defo, o ponto de interrogação antes de cada palavra indica que se trata de uma variável. Dentro do bloco WHERE, na sétima linha, estão as restrições. As restrições selecionam uma célula do Linked Data da Floresta Amazônica que contenha informações sobre desmatamento de áreas de interesse.

3. Para cada célula da etapa anterior, que tenha uma taxa de desmatamento menor de $10 \%$, capturar o número de coletas feitas dentro dela e mostrá-la no mapa com uma cor que representa o número de coletas nela. A Figura 5.4 mostra o mapa gerado, as células de cor marrom mostram áreas com desmatamento maior que 10\% (nenhuma coleta foi computada nessas áreas).

Number of collections in areas with $10 \%$ deforestation or less.

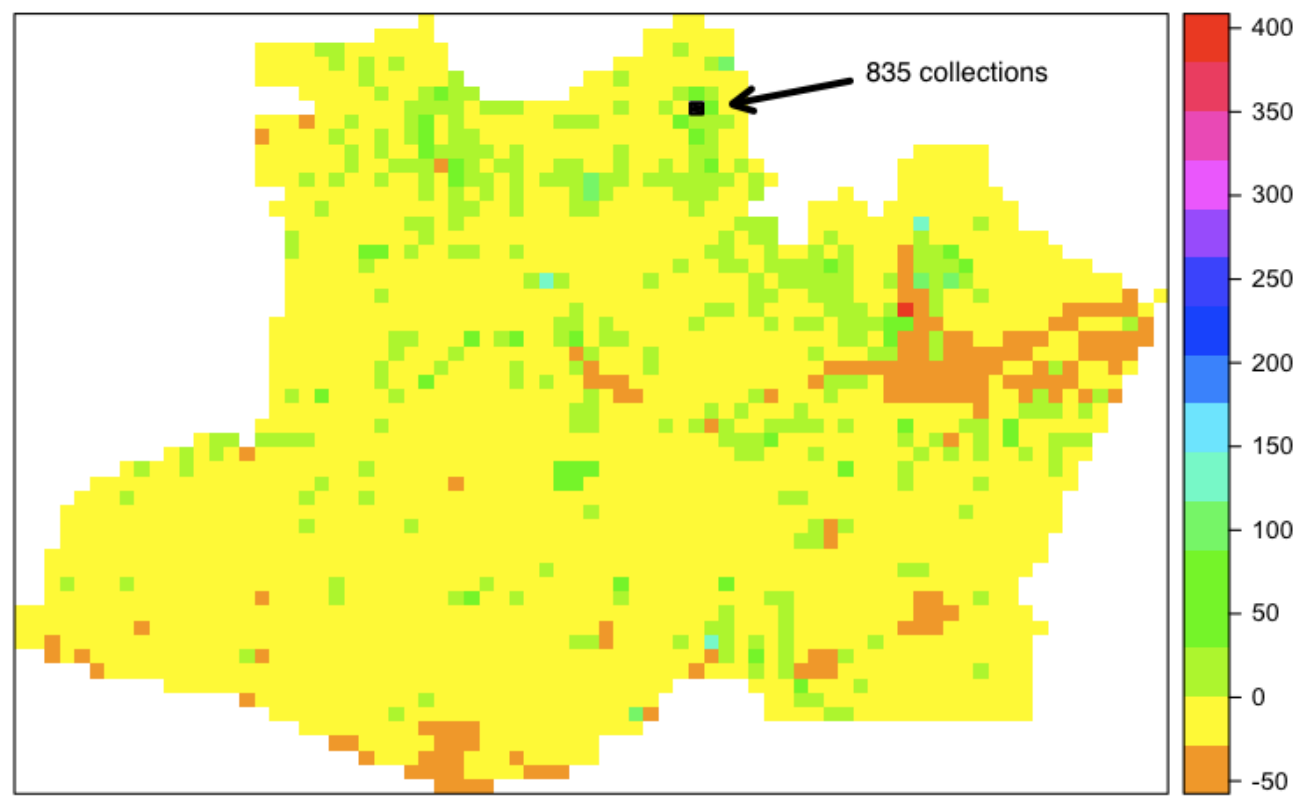

Figura 5.4: Áreas de desmatamento de amostras de plantas Tracheophyta coletadas no estado do Amazonas, Brasil. A cor marrom indica áreas com desmatamento maior que 10\%, dados de 2008. A distribuição é bastante concentrada em algumas áreas, a mancha negra representa a área com mais coleções, 835 registros.

Percebe-se que o mapa mostra uma quantidade grande de espécimes de plantas do filo Tracheophyta em algumas áreas. O quadrado preto possui o maior número 
de coletas, 835 registros. Esse mapa mostra que é possível vincular e compartilhar os dados do INPA sobre coletas (através da Web Semântica) com fontes de dados de outras áreas do conhecimento (desmatamento do INPE), aumentando seu valor informativo. Usando os resultados evidenciados na Figura 5.4, usuários podem saber quais coletas vêm de áreas mais preservadas e visualizar sua distribuição no mapa.

\subsection{Considerações Finais}

Neste Capítulo foram usados casos de uso para avaliar a arquitetura de busca semântica. Esses casos de uso demonstraram os benefícios da utilização da busca semântica em um cenário real. O feedback de relevância das fontes de informação recuperadas foi essencial para avaliar o desempenho da arquitetura. Os experimentos evidenciaram que a abordagem da busca semântica obteve um aumento de $27.8 \%$ no que diz respeito à precisão e de $25.1 \%$ na revocação em comparação com a busca por palavra-chave.

O experimento de Linked Data da Floresta Amazônica, apresentado neste capitulo, demostrou que os dados sobre biodiversidade do INPA e MPEG armazenados no triple store podem ser integrados, compartilhados e reutilizados com outras ontologias, para que os especialistas de biodiversidade possam responder a questões científicas de cada coleta por meio da integração com a Web Semântica. A integração de dados é muito importantes porque, em muitos casos, depois de encontrar os dados relevantes em uma busca, é quase impossível manipulá-los a mão, dado o seu volume. Então, os usuários têm que escrever scripts para integrar e analisar dados para obter as respostas às suas perguntas científicas.

O próximo capítulo conclui a dissertação consolidando os resultados obtidos na avaliação, e ressalta as principais contribuições e limitações da pesquisa, além de sugerir trabalhos futuros. 


\section{Capítulo 6}

\section{Conclusão}

Nesta dissertação de mestrado foi desenvolvida uma arquitetura de busca semântica para recuperação de informações em repositórios sobre biodiversidade. Um protótipo, implementando essa arquitetura, foi desenvolvido. Ele foi testado e comparado, com a ajuda de casos de uso e uma coleção de referência, criados com a ajuda de especialistas do INPA, com a ferramenta de busca por palavras-chave do SpeciesLink (uma implementação representativa desse tipo de ferramenta de busca). Os resultados mostraram que o protótipo da arquitetura proposta tem melhor precisão e revocação que a ferramenta baseada em palavras-chave do SpeciesLink e que essa melhor performance é, em grande parte, devido ao fato de sistemas baseados em palavras-chave não usarem informações semânticas em suas buscas (por exemplo, não poderem saber a que filo uma determinada planta pertence).

\subsection{Contribuições}

As principais contribuições deste trabalho são detalhadas a seguir:

- Uma nova arquitetura de busca que fornece um novo processo de recuperação de documentos, explorando o conhecimento de domínio (OntoBio) para apoiar pesquisadores na descoberta e integração de dados sobre biodiversidade.

- Evidencias, através da análise quantitativa dos resultados das avaliações e seus resultados, que a arquitetura proposta produz resultados mais relevantes, (27,8\% melhor em precisão e 25,1\% melhor em revocação) do que uma ferramenta de busca por palavras-chave (SpeciesLink) usando dados reais sobre biodiversidade.

- Evidencias que a arquitetura proposta oferece suporte à reutilização de on- 
tologias existentes e a capacidade de integrar dados das coleções do INPA e MPEG com outros grandes conjuntos de dados biológicos como o experimento realizado na Seção 5.5, que integra 19.887 registros de plantas com dados de desmatamento do INPE.

- Estendeu-se a ontologia OntoBio com o objetivo de compartilhar a informação sobre biodiversidade do INPA e MPEG com outras fontes e dados na Web Semântica.

- Para interligar os dados da ontologia OntoBio foram inseridos termos de outras ontologias e vocabulários como o padrão de Darwin Core, BFO, ENVO, PATO, WGS84, Geoname, DBpedia e CoL.

- Com a extensão da OntoBio, novos trabalhos já se encontram em andamento como: (i) A construção de um Gazetteer Colaborativo para auxiliar a recuperação de informações geográficas sobre biodiversidade e (ii) Uma Infraestrutura Semântica para integração de dados científicos sobre biodiversidade.

- Uma coleção de referencia de dados de biodiversidade foi desenvolvida e disponibilizada neste trabalho. Essa coleção foi desenvolvida (mediante feedback de relevância) com ajuda de especialistas em biodiversidade para avaliar a busca semântica frente à busca por palavra-chave.

- Os dados das coletas de insetos, peixes, mamíferos e plantas disponibilizados pelo INPA e MPEG foram convertidas em triplas RDF. Essas triplas se encontram disponíveis em um EndPoint SPARQL ${ }^{1}$ aberto a comunidade da Web.

Em conclusão, a arquitetura apresentada fornece um novo processo de recuperação de documentos, explorando os termos da consulta para apoiar aos cientistas no processo de descoberta e integração de dados sobre biodiversidade. Assim, a arquitetura de busca semântica permite alcançar o objetivo desta dissertação melhorando os resultados das consultas e recuperação de dados sobre biodiversidade utilizando as tecnologias da Web Semântica.

\subsubsection{Produção Científica}

Este projeto de mestrado resultou na publicação de alguns artigos em eventos científicos que são listadas a seguir:

\footnotetext{
${ }^{1}$ http://bio.icmc.usp.br:8890/sparql
} 
1. AMANQUi, F. M. ; SERIQUE, K. J. ; LAMPING, F. ; AlBUQUERQUE, A. ; SANTOS, J. L. ; MOREIRA, D. A. . Implementing an Architecture for Semantic Search Systems for Retrieving Information in Biodiversity Repositories. In: Anais do 28ž Simpósio Brasileiro de Banco de Dados, 2013, Recife RS: Sociedade Brasileira de Computação, v. 23. p. 121-126.

2. AMANQUI, F. M. ; SERIQUE, K. J. ; LAMPING, F. ; AlBUQUERQUE, A. ; SANTOS, J. L. ; MOREIRA, D. A. Semantic Search Architecture for Retrieving Information in Biodiversity Repositories. In: Proceedings of the 6th Seminar on Ontology Research in Brazil, 2013. CEUR Workshop Proceedings, v. 1041. p. 83-93.

3. AMANQUI, F. M. ; MOREIRA, D. A. Web Semántica: Web Inteligente. Revista CompuScientia, Perú, 2013, v. 3. p. 15-18.

4. CARDOSO S. ; SERIQUE, K. J. ; AMANQUi, F. M. ; SANTOS, J. L. ; MOREIRA, D. A. A Gazetteer for Biodiversity Data as a Linked Open Data Solution. In: Web2Touch 2014 - Modelling the Collaborative Web Knowledge, Italy 2014 (Artigo Aceito).

5. AMANQUi, F. M. ; SERIQUE, K. J. ; DOMINGO S. ; AlBuqUERQUE, A. ; SANTOS, J. L. ; MOREIRA, D. A. Improving Biodiversity Data Retrieval through Semantic Search and Ontologies. In: The 2014 IEEE/WIC/ACM International Conference on Web Intelligence, Poland 2014 (Artigo Submetido).

\subsection{Dificuldades e Limitações}

O presente trabalho apresentou algumas dificuldades e limitações durante seu projeto e implementação:

- A primeira dificuldade encontrada foi durante a especificação do trabalho, pois na ocasião em que a revisão bibliográfica foi feita, notou-se uma falta de técnicas e modelos particularmente projetados para busca semântica de dados sobre biodiversidade.

- Um fator limitante encontrado diz respeito a pouca disponibilidade de tempo dos especialistas em biodiversidade para realizar os testes. 
- Outro fator limitante é o julgamento de relevância das fontes de informação recuperadas. Esse julgamento é essencial para avaliar o desempenho da arquitetura e depende de modo explícito do usuário.

\subsection{Trabalhos Futuros}

Como trabalhos futuros decorrentes desta dissertação destacam-se:

- Melhorias na inclusão de novos termos na ontologia OntoBio para inter-relacionar os indivíduos com outras ontologias, o que ajudaria no processo de integração e busca de informação.

- A integração de dados sobre biodiversidade dentro da Web Semântica não é uma tarefa fácil, principalmente devido à complexidade e a dispersão do conteúdo. Mantendo em vista as limitações acima, poderia-se analisar a incorporação de informações de outras áreas correlatas, como agricultura, biologia, medicina, climatologia, entre outros, às triplas RDF armazenadas na triplestore para, desta maneira, integrar essas informações ambientais para ajudar na descoberta de novas correlações entre os dados.

- Um trabalho futuro poderia explorar e estender a arquitetura de busca semântica com a utilização de dados geo-referenciados, permitindo assim realizar buscas semânticas utilizando a localização geográfica de cada espécie. A busca semântica geoespacial, intermediada pelo usuário, conseguiria tornar a busca por informação referente a locais de coleta de espécies mais precisa, no que diz respeito à precisão e cobertura de dados.

- A avaliação da proposta considerou as medidas de precisão, cobertura e F1. Outras formas de avaliar as busca semânticas poderiam também ser previstas, como considerar o tempo de resposta da busca por recursos na ontologia e o número de fontes de informação recuperadas. 


\section{References}

Albuquerque, A., 2011. Desenvolvimento de uma Ontologia de Domínio para Modelagem de Biodiversidade. Dissertação de Mestrado. Universidade Federal do Amazonas.

Amanqui, F. M., Serique, K. J., Lamping, F., Albuquerque, A., Moreira, D. A., Karina, F., Amanqui, M., Campos dos Santos, J. L., 2013. Architecture for Semantic Search Systems for Retrieving Information in Biodiversity Repositories. Anais do 28Âž Simpósio Brasileiro de Banco de Dados, 121-126.

URL http://sbbd2013.cin.ufpe.br/Proceedings/application/01.html

Amerland, D., 2013. Google Semantic Search: Search Engine Optimization (SEO) Techniques That Gets Your Company More Traffic, Increases Brand Impact and Amplifies Your Online Presence. Que Biz-Tech Series. Pearson Education, Limited.

URL http://books.google.com.br/books?id=0GAmlwEACAAJ

Antoniou, G., Harmelen, F. v., 2008. A Semantic Web Primer, 2Nd Edition (Cooperative Information Systems), 2nd Edition. The MIT Press.

Baader, F., Calvanese, D., McGuinness, D. L., Nardi, D., Patel-Schneider, P. F. (Eds.), 2003. The Description Logic Handbook: Theory, Implementation, and Applications. Cambridge University Press, New York, NY, USA.

Baeza-Yates, R., Ribeiro-Neto, B., Feb. 2011. Modern Information Retrieval: The Concepts and Technology behind Search (2nd Edition) (ACM Press Books), 2nd Edition. Addison-Wesley Professional.

URL http://www.amazon.com/exec/obidos/redirect?tag=citeulike07-20 \ \&path=ASIN $/ 0321416910$

Bailey, J., Bry, F., Furche, T., Schaffert, S., 2005. Web and semantic web query languages: A survey. In: Proceedings of the First International Conference on 
Reasoning Web. Springer-Verlag, Berlin, Heidelberg, pp. 35-133.

URL http://dx.doi.org/10.1007/11526988_3

Batistella, M., Alves, D., Artaxo, P., Bustamante, M., Keller, M., Luizão, F., Marengo, J. A., Martinelli, L., Nobre, C. A., Alves, M. D. S., Andreae, M. O., Asner, G. P., Avissar, R., Becker, K., Bustamante, M. M. C., Cohen, J., Maria, A. F., Dias, S., Silva, P. L., Figueiredo, R., Galarraga-sanchez, R. H., Kruijt, B., Krusche, A. V., Llerena, C. A., Lloyd, J., Luizão, F. J., Melack, J., Moutinho, R. D. S., Nobre, A. D., Novo, E. M. L. M., Piedade, M. T. F., 2007. Plano Científico LBA2 âĂŞ PROGRAMA DE PESQUISAS SOBRE INTERAÇÕES BIOSFERAATMOSFERA NA AMAZÔNI.

Berkley, C., Bowers, S., Jones, M., Madin, J., Schildhauer, M., Mar. 2009. Improving data discovery for metadata repositories through semantic search. pp. $1152-1159$.

Berners-Lee, T., Hendler, J., Lassila, O., May 2001. The semantic web. Scientific American 284 (5), 34-43.

URL http://www.sciam.com/article.cfm?articleID=00048144-10D2-1C7084A9809EC588EF21

Bizer, C., et al., 2010. Linked data - the story so far.

Boley, H., Tabet, S., Wagner, G., 2001. Design rationale of ruleml: A markup language for semantic web rules. pp. 381-401.

Canhos, V., 2003. Informática para biodiversidade: padrões, protocolos e ferramentas. Ciência e Cultura 39.

URL http://cienciaecultura.bvs.br/scielo.php?script=sci \_arttext $\backslash$ \&pid=S0009-67252003000200025

Carroll, J. J., Dickinson, I., Dollin, C., Seaborne, A., Wilkinson, K., Reynolds, D., Reynolds, D., 2003. Jena: Implementing the semantic web recommendations. pp. 74-83.

Consortium, O. G., 2012. Geosparql - a geographic query language for rdf data. http://www .opengeospatial .org/standards/geosparql/, accessed: 2013-1129.

Coral, C., Francisco, R., Mario, P., 2006. Ontologies for Software Engineering and Software Technology. Springer-Verlag, Berlin, Heidelberg. 
De S. Fedel, G., Medeiros, C. B., dos Santos, J. A., 2012. Sinimbu- multimodal queries to support biodiversity studies. In: Proceedings of the 12th international conference on Computational Science and Its Applications - Volume Part I. ICCSA12. Springer-Verlag, Berlin, Heidelberg, pp. 620-634.

Devedzic, V., Apr. 2004. Education and the semantic web. Int. J. Artif. Intell. Ed. 14 (2), 165-191.

URL http://dl.acm.org/citation.cfm?id=1434858.1434860

dos Santos, J. L. C., 2003. A biodiversity information system in an open data/metadatabase architecture. Ph.D. thesis, Enschede.

URL http://doc.utwente.nl/41436/

Dos Santos, V., Baiao, F., Tanaka, A., Aug. 2011. An architecture to support information sources discovery through semantic search. pp. $276-282$.

Eiter, T., Ianni, G., Krennwallner, T., Polleres, A., 2008. Reasoning web. SpringerVerlag, Berlin, Heidelberg, Ch. Rules and Ontologies for the Semantic Web, pp. $1-53$.

URL http://dx.doi.org/10.1007/978-3-540-85658-0_1

Feigenbaum, L., Herman, I., Hongsermeier, T., Neumann, E., Stephens, S., December 2007. The semantic web in action. Scientific American 297, 90-97. URL http://thefigtrees.net/lee/sw/sciam/semantic-web-in-action

Gacek, C., Gacek, C., Clark, B., Boehm, B., Abd-Allah, A., Abd-allah, A., Clark, B., Clark, B., Boehm, B., Boehm, B., 1995. On the definition of software system architecture.

GBIF, 2001. The global biodiversity information facility. Accessed: 2013-07-30. URL http://www.gbif .org/

Gennari, J. H., Musen, M. A., Fergerson, R. W., Grosso, W. E., Crubzy, M., Eriksson, H., Noy, N. F., Tu, S. W., 2002. The evolution of protégé: An environment for knowledge-based systems development. International Journal of HumanComputer Studies 58, 89-123.

Gomez-Perez, A., Corcho, O., 2002. Ontology languages for the semantic web. Intelligent Systems, IEEE 17 (1), 54-60.

Grau, B. C., Horrocks, I., Motik, B., Parsia, B., Patel-Schneider, P., Sattler, U., 2008. Owl 2: The next step for owl. 
Gruber, T. R., 1993. A translation approach to portable ontology specifications. Knowledge Acquisition 5, 199-220.

URL http://citeseerx.ist.psu.edu/viewdoc/summary?doi=10.1.1.101. 7493

Gruber, T. R., Dec. 1995. Toward principles for the design of ontologies used for knowledge sharing. Int. J. Hum.-Comput. Stud. 43 (5-6), 907-928.

URL http://dx.doi.org/10.1006/ijhc.1995.1081

Hassanzadeh, O., Lim, L., Kementsietsidis, A., Wang, M., 2009. A framework for semantic link discovery over relational data. In: In CIKM 2009.

Jones, C., 2000. Software assessments, benchmarks, and best practices. AddisonWesley Longman Publishing Co., Inc., Boston, MA, USA.

Jr., L. C. G., Medeiros, C. B., 2007. Ecologically-aware queries for biodiversity research. INPE, pp. 73-84.

URL http://dblp.uni-trier.de/db/conf/geoinfo/geoinfo2007.html

Kauppinen, T., de Espindola, G. M., 2011. Linked Open Science - communicating, sharing and evaluating data, methods and results for executable papers. Proceedings of the International Conference on Computational Science (ICCS 2011), Procedia Computer Science 4 (0), 726-731.

KLYNE, G.and CARROL, J., 2004. Resource Description Framework (RDF): Concepts and Abstract Syntax.

URL http: //www.w3.org/TR/2004/REC-rdf-concepts-20040210/

Latiri, C. C., Haddad, H., Hamrouni, T., 2012. Towards an effective automatic query expansion process using an association rule mining approach. J. Intell. Inf. Syst. 39 (1), 209-247.

URL http://dblp.uni-trier.de/db/journals/jiis/jiis39.html

Lewis, D., Software, O., 2008. Linked data deployment.

Li, W., Yang, C., Jul. 2008. A semantic search engine for spatial web portals. Vol. 2. pp. II-1278-II-1281.

Magnusson, W., 2013. Biodiversidade e Monitoramento Ambiental Integrado. PPBio INPA.

URL http: //books.google.com.br/books?id=y4WKGXiAFEOC 
Mangold, C., Sep. 2007. A survey and classification of semantic search approaches. Int. J. Metadata Semant. Ontologies 2 (1), 23-34.

URL http://dx.doi.org/10.1504/I JMSO.2007.015073

Mariano R, M., Calvanese, D., 2012. Quest, an OWL 2 QL Reasoner for OntologyBased Data Access. KRDB Research Centre for Knowledge and Data, Free University of Bozen-Bolzano, Bolzano, Italy.

Martins, S. D. S., Sanderson, J. G., e Silva-Júnior, J. D. S., Nov. 2006. Monitoring mammals in the Caxiuanã National Forest, Brazil âĂŞ First results from the Tropical Ecology, Assessment and Monitoring (TEAM) program. Biodiversity and Conservation 16 (4), 857-870.

URL http://link.springer.com/10.1007/s10531-006-9094-x

Mironov, V., Seethappan, N., Blondé, W., Antezana, E., Lindi, B., Kuiper, M., 2010. Benchmarking triple stores with biological data. CoRR abs/1012.1632.

Mizoguchi, R., 2003. Tutorial on Ontological Engineering: Part 2: Ontology Development. Tools and Languages. NEW GENERATION COMPUTING-TOKYO$22(1), 61-96$.

Moritz, T., Krishnan, S., Roberts, D., Ingwersen, P., Agosti, D., Penev, L., Cockerill, M., Chavan, V., 2011. Towards mainstreaming of biodiversity data publishing: recommendations of the gbif data publishing framework task group. BMC Bioinformatics 12 (S-15), S1.

URL http://dblp.uni-trier.de/db/journals/bmcbi/bmcbi12S.html

Peixoto, A., Barbosa, M., 2009. Coleções botânicas: objetos e dados para a ciência. ... da Astronomia e Ciências ..., 315-326.

URL http://www.mast.br/projetovalorizacao/textos/ livroculturamaterialepatrim $\ \%$ C3 $\ \%$ B4niodeC $\backslash \& \mathrm{~T} / 19 \mathrm{COLE} \backslash \% \mathrm{C} 3 \backslash \% 87 \backslash$ C3 $\backslash$

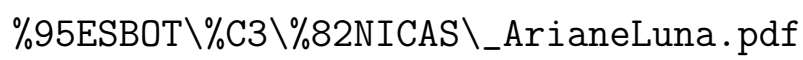

Popescu, A., Grefenstette, G., Moëllic, P. A., 2008. Gazetiki: Automatic creation of a geographical gazetteer. In: Proceedings of the 8th ACM/IEEE-CS Joint Conference on Digital Libraries. JCDL '08. ACM, New York, NY, USA, pp. 8593.

URL http://doi .acm.org/10.1145/1378889.1378906

Salton, G. (Ed.), 1971. The SMART Retrieval System - Experiments in Automatic Document Processing. Prentice Hall, Englewood, Cliffs, New Jersey. 
Santos, V. D., Baiao, F. A., Tanaka, A., 2011. An architecture to support information sources discovery through semantic search. In: Information Reuse and Integration.

Schreiber, G., Dean, M., February 2004. OWL web ontology language reference. http://www.w3.org/TR/2004/REC-owl-ref-20040210/.

SinBiota, 2013. Environmental information system of biota/fapesp program. sinbiota 2.1 prototype. http://sinbiota.biota.org.br/about/, accessed: 2013-07-30.

Smith, M., Welty, C., McGuinness, D., 2004. OWL web ontology guide.

Souza, R. R., Alvarenga, L., 04 2004. Web semantics and its contributions to information science. Ciência da Informação 33, 132 - 141.

SpeciesLink, 2013. speciesLink: Sistema de Informação Distribuído para Coleções Biológicas.

URL http://splink.cria.org.br/

Staab, S., Maedche, A., Handschuh, S., 2001. An annotation framework for the semantic web.

URL http://citeseer.ist.psu.edu/staab01annotation.html

Suter, R., Huser, H., 2013. An introduction to semantic search in microsoft sql server 2012.

Uschold, M., Gruninger, M., Dec. 2004. Ontologies and semantics for seamless connectivity. SIGMOD Rec. 33 (4), 58-64.

URL http://doi .acm.org/10.1145/1041410.1041420

Wainer, J., 2007. Métodos de pesquisa quantitativa e qualitativa para a ciência da computação. In: Atualizações em informática. pp. 221-262.

Xiong, J., Huang, W., Jin, C., Dec. 2009. An ontology-based semantic search approach for geosciences. Vol. 3. pp. $87-90$.

Zhao, C., Wang, J., Hu, W., Yu, X., Wang, X., Oct. 2010. An ontology-based semantic search model study. pp. $182-185$.

Ziegler, P., Dittrich, K., 2007. Data integration - problems, approaches, and perspectives. 


\section{Apêndice A}

\section{Lista de Axiomas de Mapeamento.}

[SourceDeclaration] Definição de Recursos

sourceUri OntoBioDB

connectionUrl jdbc:postgresql://localhost/OntoBioDB

driverClass org.postgresql.Driver

[MappingDeclaration] Definição de Mapeamentos

@ collection [I

1. mappingId Colletion-Genus

target : Genus-\{genus\} a :Genus .

source select distinct genus from collection

2. mappingId Genus-Species

target :Genus-\{genus\} :subkindOfEspGen :Specie-\{species\} .

source select genus, species from collection

3. mappingId Collection-Family

target :family-\{family\} a :Family .

source select family from collection

4. mappingId Family-Genus

target :Family-\{family\} :subkindOfGenFam :Genus-\{genus\} .

source select family, genus from collection

5. mappingId ClassifiedAsColetaTipoColeta

target :Collect-\{catalognumber\} :isClassifiedAsColetaTipoColeta :method-

\{method\} .

source select catalognumber, method from collection

6. mappingId mediationColetaLocalColeta err

target :Collect-\{catalognumber\} :mediationColetaLocalColeta :Local-

\{localityname\} .

source select catalognumber, localityname from collection

7. mappingId mediationColetaRespColeta

target :Collect-\{catalognumber\} :mediationColetaRespColeta :DetermineName\{determinelastname $\}$.

source select catalognumber, determinelastname from collection

8. mappingId spatiallyConteinedInLocalidadeMun 
target :Country-\{Country\} :spatiallyConteinedInLocalidadeMun :LocalityName-

\{localityname\} .

source select localityname, Country from collection

9. mappingId spatiallyConteinedInEstPais err

target :State-\{state\} :spatiallyConteinedInEstPais :Country-\{Country\} .

source select state, Country from collection

10. mappingId InstitutionalAffiliation

target :Collect-\{CatalogNumber\} :mediationInstituicaoVinculo :ResearchInstitution-

\{InstitutionImp $\}$.

source select CatalogNumber, InstitutionImp from collection

11. mappingId ResearchInstitution

target :ResearchInstitution-\{institutionimp $\}$ a :InstitutionalAffiliation .

source select distinct institutionimp from collection

12. mappingId kingdom-phylum

target :kingdom-\{kingdom\} :subkinofPhyKing :phylum-\{phylum\} .

source select kingdom, phylum from collection

13. mappingId kingdom-class

target :phylum-\{phylum\} :subkinofClassPhy :class-\{class\} .

source select phylum, class from collection

14. mappingId class - order

target :class-\{class\} :subkinofOrdClass :order-\{order\} .

source select class, order 1 as order from collection

15. mappingId order - familiy

target :order-\{order\} :subkinofFamOrd :family-\{family\} .

source select order1 as order, family from collection

16. mappingId geographicSpace latitude

target :GeographicSpace-\{county\} :latitude :Latitude-\{latitude\} .

source select county, latitude from collection

17. mappingId geographicSpace longitude

target :GeographicSpace-\{county\} :longitude :Longitude-\{longitude\} .

source select county, longitude from collection

18. mappingId GeographicSpace locality

target :Localityname-

\{localityname\} :localizationEspaGeoCoordGeo :GeographicSpace-\{county\} .

source select localityname, county from collection

19. mappingId spatiallyConteinedInMunEst( $(0)$

target :Country-\{country\} :spatiallyConteinedInMunEst :State-\{state\} .

source select country, state from collection ]] 


\section{Apêndice B}

Coleção de Referência sobre

Biodiversidade 


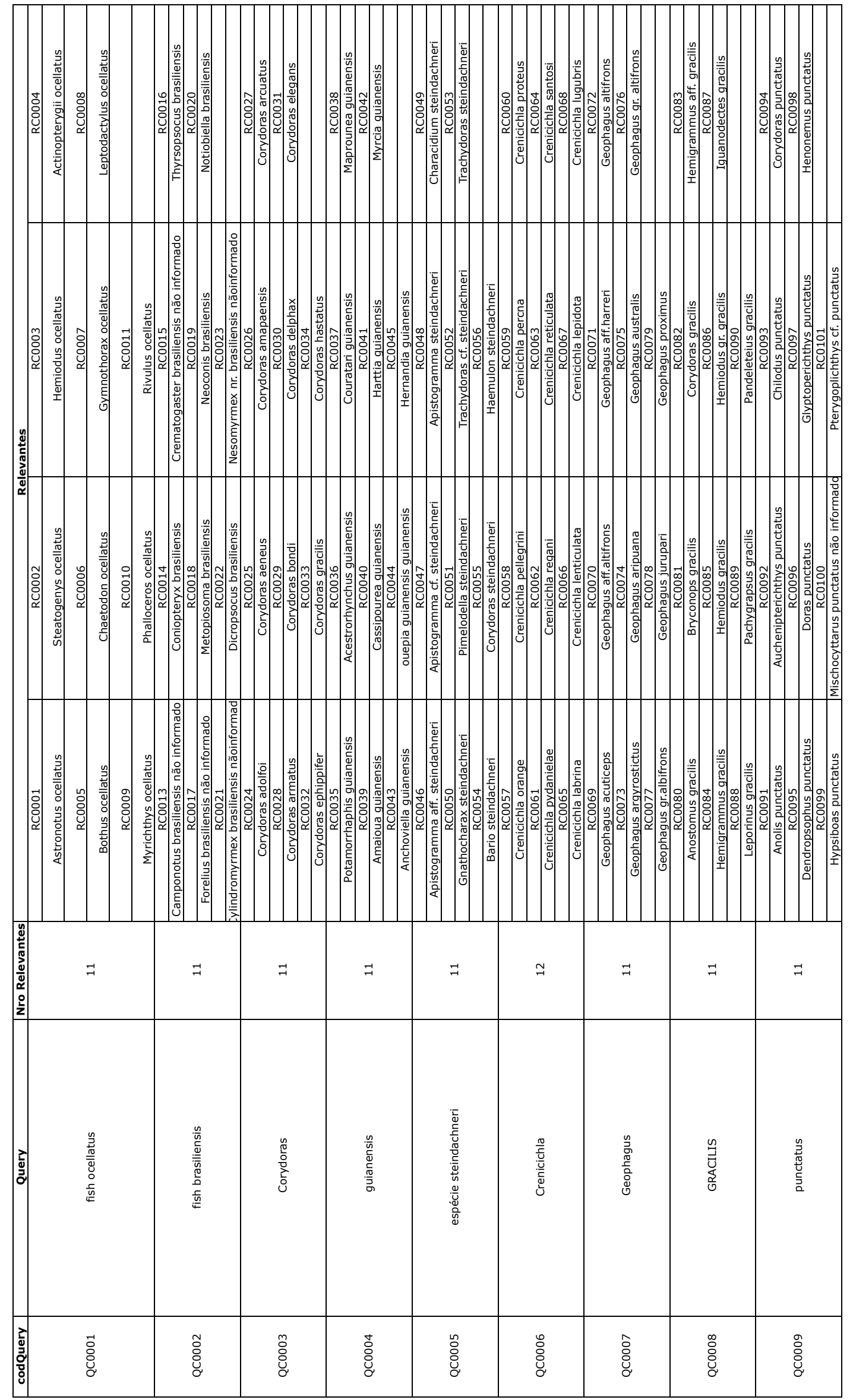




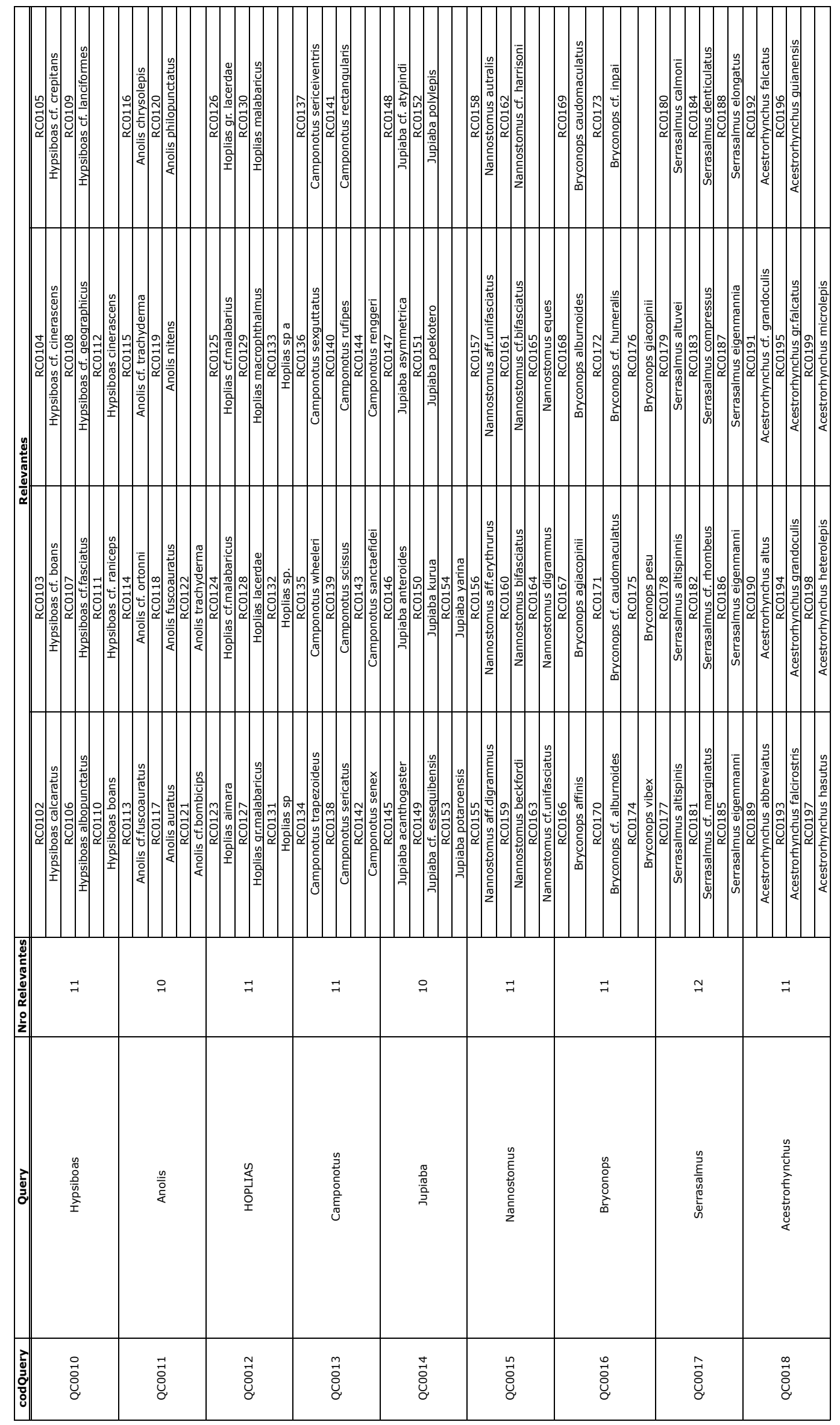




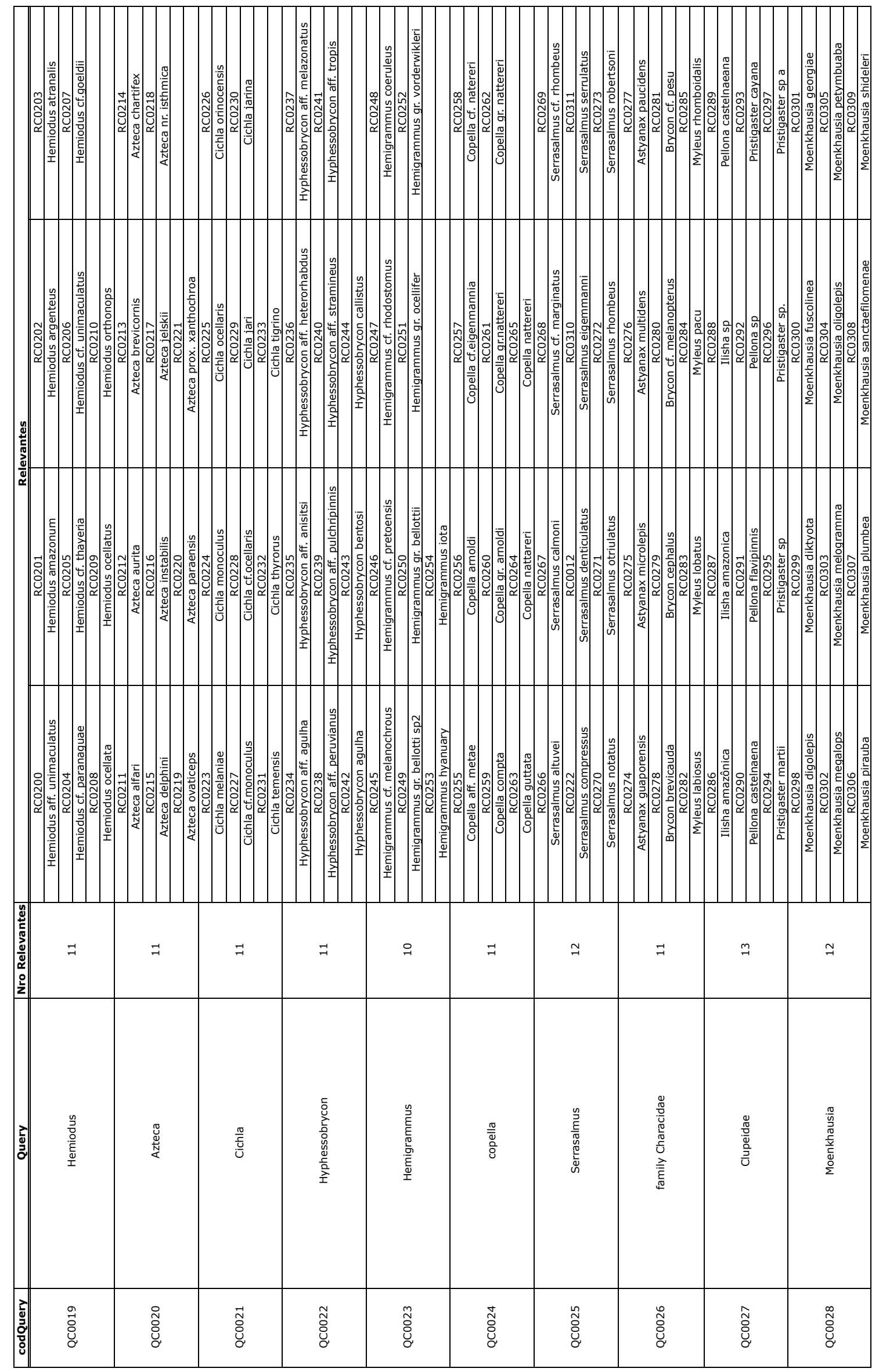

